\title{
Die Lymphorgane der weiblichen Genitalien und ihre Veränderungen bei malignen Erkrankungen des Uterus.
}

\author{
Von \\ Dr. Paul Kroemer, \\ Assistent an der Grossherroglichen Franenklinik zu Giessen. \\ Mit Tafel I-VI.
}

Die Lehre vom Lymphapparat der weiblichen Genitalien hat in der letzten Zeit für uns ein erhöhtes Interesse gewonnen, weil gerade auf diesem Gebiet wissenschaftliche und practische Fragen einander decken, beziehungsweise ergänzen und begründen. Wir brauchen genaue Untersuchungen vom Standpunkt des Anatomen, des Patholog-Anatomen und des Klinikers, um unsere Erfahrungen am gesunden und kranken Lymphapparat richtig einschätzen und verwerthen zu können für unser therapeutisches Handeln. Mögen nun biochemische Processe, die man theoretisch auf chemische Formeln zurückführen kann, den Stoffwechsel der Organe reguliren, oder mag wirklich die von R. Heidenhain so zäh vertheidigte vitale Energie der Körperzellen die Hauptrolle spielen, immer bleibt die Lymphe ein wichtiger Träger oder Vermittler chemischer Spannkräfte im Körperhaushalt - und es ist sicher das Lymphgefässsystem nicht nur ein Seitenreservoir für das überfüllte Blutgefässnetz. Behält so die Frage nach dem Beginn der feinen Lymphspalten und der Lymphbildung ein brennendes Interesse, so werden wir auch für unsere mechanischen und therapeutischen Vorstellungen als Grundlage die groben anatomischen Kenntnisse brauchen, selbst wenn wir nicht die Thure-Brand'schen Heilbestrebungen als Universalmittel verfechten. Eine septische Lymphangoitis der Gebärmutterwand, eine eitrige Lymphthrombose im breiten Ligament werden wir nicht mehr durch intrauterine Eingriffe $z u$ heilen trachten. Wir können bei infectiösen Beckenprocessen geleitet durch anatomische Vorstellungen den Wegen der Infections- 
keime folgen, ja - wenn wir die entscheidende Diagnose, ob der Lymph- oder der Blutweg befallen ist, getroffen haben - das Fortschreiten der Mikroorganismen womöglich vorher berechnen und verhindern.

Die malignen Tumoren: "Carcinom und Sarkom" verhalten sich in gewisser Hinsicht wie eine langsam verlaufende Infection. Auch sie folgen in ihrem Vorschreiten den präformirten Gewebsbahnen. Auch sie befallen die Lymphdrüsen und in früherer oder späterer Zeit entfernte Körperorgane. Da der Krebs vorwiegend auf dem Lymphwege seine Verbreitung findet - dieser Satz bleibt doch von dauernder Giltigkeit - so wird eine erfolgreiche Therapie immer und immer wieder damit rechnen müssen, dass nicht nur der locale Process, sondern auch die verschleppten Keime zu entfernen sind.

Auch hier wieder soll uns die anatomische Untersuchung auf dem Sectionstisch Aufklärung bringen über die Verbreitungsart des Krebses, die Section soll uns aber auch lehren, wie weit wir operatir unsere therapeutischen Bestrebungen ausdehnen können. Der Grundgedanke der modernen Heilbestrebungen, bei Carcinoma uteri den Tumor mit dem zugehörigen Lymphapparat des befallenen Organes zu entfernen, bleibt - um mit W. A. Freund zu reden per rationem et analogiam, das Tdealverfahren, solange wir ein Heilserum für den Krebs nicht besitzen.

Es liegt demnach klar auf der Hand, dass der Gynaekologe auf dem Lymphgebiet der ihn speciell interessirenden Regionen genauen Bescheid wissen will.-Vielleicht interessirt es auch manchen, über die

\section{historische Entwicklung unserer Kemntnisse über die Lymphbahnen} etwas zu hören.

Die Erkenintniss, dass ausser den. Blutgefässen besondere Chylus- und Lymphgefässe existiren, kam den Medicinern erst

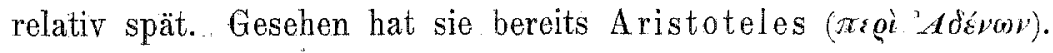
Mascagni referirt darüber: "Aristoteles lib. tertio dicit: „Fibrae intra nervum et venam suam habent naturam et nonnullae humorem saniem appellatum continent, tendunt a nervis ad venas ac inde ad nervos".".

Herasistratus beschreibt bei Frühgeburten milchgefüllte Arterien, deren "abnormen Inhalt" er sich durch die Unreife der Frucht erklärt. „Herophilus sah solche Milchgänge in Drüsenkörper münden, während doch sonst alle Adern der Leberpforte, zustrebten." 
Caspar Asellius hat zuerst mit Bewusstsein den getrennten Chylustransport in den Darmlymphgängen erkannt und gelehrt.

Wessling (Veslingius) entdeckte den Brustmilchgang. Wenigstens lese ich bei Mascagni eine Stelle aus den Epistol. post.: "Videtur Veslingius aliquam portionem vidisse ductus thoracici ab Eustachio jam descripti, quod etiam Hallerus et alii anatomici suspicati sunt."

Die eigentlichen lymphatischen, nicht den Chylus führenden Gefässe des Körpers wurden erst um die Mitte 17. Jahrhunderts in der. Leiche entdeckt und in ihrer Eunction am lebenden Thier erkannt: - 1651 von dem Schweden Olaus Rudbek, 1652 von dem bekannten Dänen Thomas Bartholinus und endlich in demselben Jahre 1652 von dem Engländer Jolivius ${ }^{1}$ ) (Georges Jolyff).

Von nun an werden in der Literatur ausser den Chylusgängen (Vasa lactea) auch Vasa "aquosa", "serosa", "lymphatica" erwähnt. Die 3 zuletzt erwähnten Autoren beschreiben bereits Beckenlymphbahnen bei Thieren und nehmen solche auch für den Menschen an, Bartholinus unter Entwicklung merkwürdiger theoretischer Gründe: („Das Kind brauche die Saugadern der Gebärmutter zur Ernährung; denn es habe das Saugen schon im Mutterleibe gelernt.")

Rudbek zeichnet bereits einen Uterus bicornis, von dessen Hörnern die Lymphbahnen seitlich im Bogen zur Cysterna chyli verlaufen.

Antonius Nuck beschreibt die Lymphbahnen des Uterus bei der Kuh; er lässt sie ebenfalls ohne Sonderung. von Corpus- und Collumbahnen, aber unter Annahme der Zwischenstation der Vasa iliaca in die Cysterna chyli einmünden. Die Vasa lymphat. uteri humani nimmt er per analogiam an, hat sie aber nicht darstellen können. Dagegen zeichnet er ganz gut die Ovarialbahnen, die er auch in die Cysterne einmünden lässt.

Es muss zu damaliger Zeit in der 2. Hälfte des 18. Jahrhunderts das anatomische Studium der Lymphbahnen gewissermassen als terra incognita ein beliebtes Arbeitsfeld abgegeben haben. Haller erwähnt, dass Johannes Mery zuerst die Saugadern „in utero humano" zu Gesicht bekam, ferner dass Morgagni und J. B. Winslow bei Frauen, die im Wochenbett gestorben waren,

1) Mascagni berichtet darüber: "Jolivius nihil scriptum reliquit, sed Angli nonnulli gloriam inventionis lymphaticorum vasorum ei tribuunt." 
im ganzen Genitalapparat Lymphgefässe nachwiesen. Also hier bereits war der Nachweis von Lymphbahnen durch Putrefaction bekannt.

Ich übergehe die Theiluntersuchungen und die an Thieren angestellten, vergleichenden Untersuchungen, an denen zu damaliger Zeit wohl jeder bedeutende Anatom betheiligt war. Mascagni berichtet von Ruisch, welcher z. B. die Klappen in den Lymphbahnen darstellte, ferner von Georges Duvernoi, ron Alexander Monroe, Richard Hale, Friedrich Meckel; - Johann Gottlob Haase ausserdem erwähnt wiederum Hewson, Cruikshank, Sheldon, und einen Anatomen Werner cum socio laborum Fellero.

Cruikshank wurde durch seinen Lehrer Hunter zu dem uns interessirenden Studium angeregt, nach dessen Tode er das Resultat der gemeinsamen Arbeit herausgab. Cruikshank übte bereits die Quecksilberinjection von grösseren Stämmen aus; ausserdem benutzte er am nicht schwangeren Uterus eine Art Fäulnissmaceration. Er spritzte die Arterien aus und legte den Uterus auf einige Tage in den Macerirtrog. "Es trat dann angeblich die Luft in die Sangadern und stellte sie deutlich dar. Cruikshank hat bereits richtige Vorstellungen. Doch bleiben seine Angaben, abgesehen von den uns nicht mehr geläufigen Bezeichnungen, zuweilen unklar und lassen einen weiten Spielraum zu. Er setzt die Vaginalbahnen in Beziehung zum Plexus hypogastricus und die Uterinbahnen lässt er in den Plexus iliacus internus an der Darmbeinblutader und -Schlagader münden. Eir kennt offenbar schon die Verbindung des Collum uteri zu den hypogastrischen und sacralen Drïsen und beschreibt Drüsenknötchen im Parametrium.

Johannes Gottlob Haase hat interessanter Weise in dem Bestreben, den von unten nach oben aufsteigenden Lymphstrom experimentell zu beweisen, durch Quecksilberinjection vom Schenkel aus die gesammten Becken-Lymph-Plexus und die Lumbalstämme bis zur Cysterna chyli and zum Ductus thoracicus anfüllen können. Er steht offenbar bereits unter dem Einfluss Mascagni'scher Erfahrungen, den er auch erwähnt; doch scheint er (1786) das grosse Werk des Italieners noch nicht zu kennen, obwohl die zu letzterem gehörigen Tafeln schon fertig lagen und bereits an die Academieen von Paris und Wien gegangen waren. Haase und sein Prosector Fischer haben die Neigung zu generalisiren. Die drei der Arbeit beigehefteten Tafeln sind nicht absolut überzeugend und für die 
Verhältnisse der weiblichen Genitalien unbrauchbar. Doch giebt er an, die von der Vagina, der Blase und dem Rectum kommenden Lymphbahnen gesehen zu haben: "Copiosissima occurrunt vasa; horum ea, quae a resica urinaria et intestino Recto eorumque imprimis lateribus et in femina a vagina uteri originem habent, magna ex parte in plexum obturatorium, ischiadicum et iliacum internum inseri etiam mea docuerunt experimenta."

Die Bahnen des Uterus bespricht er nicht gesondert, sondern er referirt nur ihren Verlauf durch die breiten Ligamente zu dem spermatischen Strang, mit welehem sie zum Ductus thoracicus gelangen sollen.

Wichtiger ist seine Eintheilung der Beckenplexus, welche er nach Herausnahme der Eingeweide studirt hat; er unterseheidet

1. den Plexus obturatorius (um die gleichnamigen Gefässe und den zugehörigen Nerven gelegen),

2. den Plexus ischiadicus (am Foramen ischiadicum magnum),

3. den Plexus iliacus externus zwischen den Vasa iliaca externa und dem Musculus psoas,

4. den Plexus iliacus internus zwischen Art. iliaca ext. und Art. hypogastrica,

5. den Plexus hypogastricus an der Gabelung der Bauchaorta und Vena cava.

Bei weitem die bedeutendste Arbeit über die Lymphorgane des ganzen Körpers jst in jener Zeit (1787) von dem Italiener Mascagni in seinem bekannten Atlas niedergelegt worden, und es gilt für dieses Meisterwerk auch heute noch, was er von seinen Vorgängern Rudbeck und Bartholin sagt: „Post id tempus pauca addita sunt ad explanationem et integram historiam horum vasorum usque ad praesentem nostram actatem. "Mascagni hat neben der Injection der Blutgefässe (mit Wachs) die Lymphbahnen mit Quecksilber angefüllt. Er benutzte einen Glas-Tubus, dessen Ende in eine feine rechtwinklig abgebogene Capillare ausläuft. Er kannte die Eigenthümlichkeit der serösen Häute, z. B. des Peritoneums, sich unmittelbar post mortem durch eine in's Abdomen gebrachte heisse Farblösung selbst zu injiciren. M. hat auch bereits seine Injectionsbefunde an den einzelnen Körpertheilen zum Theil durch die Betrachtung unter dem Mikroskop („Dollondi vel Cufiani mikroskopii lentibus secunda vel tertia ${ }^{\text {() }) ~ c o n t r o l l i r t ~ u n d ~ e r w e i t e r t . ~}$

Die Tafel XIV stellt die Lymphverhältnisse der weiblichen Genitalien in noch heute mustergültiger Weișe dar. 
Tab. XIV, so schreibt M. auf pag. 92:

"Historiam vasorum lymphaticorum ad glandulas aortae et cavac in abdomine accumbentes concurrentium prosequitur, cum, sublato peritonaei sacco, et visceribus in eodem contentis, splene excepto, et jecinoris portione, ostendat lymphatica in cuiusdam mulieris utero observata ac injecta duodecim circiter post partum diebus emortuae."

Seiner allgemeinen, zusammenfassenden Schilderung entnehme ich pag. 44:

"In foemina vaginae, ac inferioris uteri partis lymphatica numcrosissimis et amplis ramis ex superficie interna et externa originem sumunt, tum etiam ex earunden partium substantia, ideoque diversos formant ordines. In truncos conveniunt, qui dividuntur rursus, ac cum mox dictis in plexibus et glandulis pelvis congregantur.

Ea, quae ex parte uteri superiori, ex ligamentis latis, ex ovariis, tubaque Fallopiana nascuntur, similiter ampla, ac numerosissima se exhibent. Trunci, qui a ramorum unione formantur, plexum sub ovariis gignunt, ex quo duo, aut tres trunci derivant, qui in fasce spermatico excepti cum vasis sanguineis rursum teruntur, cumque in renum vicinia pervenerint, in plurimos ramos dispertiti se immittunt in glandulas aortae antrorsum, ac extrorsum nee non venae cavae antrorsum aceumbentes, ac inter easdem sitas; postquam glandulas ipsis alisque lymphaticis abdominalibus proprias trajecerint, inde tortuoso cursu descendunt primum dein retrorquentur, et glandulas petunt, quo lymphatica inguinalia et abdominalium magna pars concurrunt, ut cum is retro aortam in ductum thoracicum terminentur.

Nonnulla tamen dictum plexum sub ovario situm practereunt, ac truneis propriis se orsim cum fasce spermatico ad dictas glandulas producuntur.

Ex ateri extema superficie vasa quaedam lymphatica transeunt in ligamenta rotunda, quae prout injectionibus expertus sum, vasis sanguineis ctm lymphaticis implicatis conflantur; hinc vero alia ad glandulas inguinales, alia ad glandulas sub Poupartii ligamento sitas porriguntur."

Mascagni trennt Collum- und Corpusbahnen, deren parauterinen Verbindungsast, die grosse Seitenanastomose, er selten schön zur Darstellung bringt; er hat auch die praesacralen Drüsen und die Bahnen im Ligam. rotundum injicirt. Erstaunlich genau sind 
die kleinsten Drüsen auf der Beckenschaufel (auf dem Musculus iliacus int.) und an der Art. circumflexa ilium dargestellt.

War so die anatomische Untersuchung bis zu einem gewissen Grade erschöpft ${ }^{1}$ ), so blieb doch noch die Frage, inwieweit die Erfahrungen der pathologischen Anatomen sich mit jenen der normalen Anatomie deckten. Ejne Reihe namhafter Pathologen hat sich mit diesen Nachprüfungen beschäftigt, so Soemmering ( De morbis vasorum absorbentium") und Andral (Grundriss der pathologischen Anatomie, 1832, II. Theil), welch' letzterer 600 Leichen auf krankhafte Veränderungen der Lymphbahnen untersucht hat.

Ergiebiger für unsere Region waren wiederum die klassischen Untersuchungen Cruveilhi er's, welcher die dureh puerperale Infection natürlich injicirten Lymphbahnen der weiblichen Genitalien prägnant zur Darstellung bringt.

Nach Cruveilhier verlaufen die Collumbahnen

1. zu den Glandulae hypogastricae (in der Gabel zwisehen den Vasa iliaca externa und den Vasa hypogastrica gelegen),

2. zu den Glandulae sacrales (beiderseits am Sacro-lliacalgelenk gèlegen):

Die Corpusbahnen und die des oberen Collumbereichs veraufen mit den Lymphbahnen der Ovarien und Tuben zu den Lumbaldrüsen.

Cruveilhier beschreibt als gewöhnlichen Befund bei krankhaften Processen des Uterus die geschwollene Glandula obturatoria am gleichnamigen Foramen, zu welcher er eine Anzahl uteriner Lymphstränge ziehen sah.

Teichmann's grosse Arbeit beschäftigt sich mehr mit dem Ursprung und dem Verlauf der Chylusbahnen, des Ductus thoracicus ete. Die Lymphverhältnisse der Genitalorgane fanden in den letzten Jahrzehnten des vorigen Jahrhunderts erhöhte Beachtung. Zunächst suchte man durch histologische Untersuchungen namentlich der Ovarien und des Uterus der Lösung der allgemeinen Frage nach dem Ursprung der feinsten Lympheapillaren nahezukommen, so His, Sehwarz, Lucas Championnière, Fridolin; Lindgren, Leopold, Fioupe, Miercejewski, die beiden Hoggan's, Wallich.

Während His, Waldeyer und Schwarz sich mit den Lymph-

1) Den von Winkler erwähnten Zeitgenossen Mascagni's Namens Assalini habe ich nicht eruiren können. 
bahnen des Ovariums beschäftigten, studirten Miercejewski und Wallich das subseröse Lymphgefässnetz des Uterus. Fridolin beschreibt die Erweiterung der Uterus-Lymphbahnen in derSchwangerschaft, und Lucas Championnière und Fioupe erörtern bei der Besprechung des Puerperalfiebers den andtomischen Verlauf der Bahnen, welche die Infection befällt. Lucas Championnière beschreibt dabei oine Lymphdrüse, welche er im Parametrium an der Grenze zwischen Corpus und Collum fand. Fioupe und später Sappey stellten diesen Befund als unwahrscheinlich in Abrede, konnten ihn jedenfalls nicht bestätigen.

(Lindgren und Leopold sollen später noch Würdigung finden.)

Zwei Franzosen, Sappey und Poirier, haben in neuerer Zeit systematiseh die Jymphbahnen der weiblichen Genitalien mit dem verbesserten Quecksilber-Injectionsverfahren nachuntersucht.

Sappey unterscheidet die Parenchymbahnen der Tunica mucosa und der Yuscularis von den abführenden, mit Klappen versehenen Stämmen; er bespricht gesondert die einzelnen Bezirke und kommt zu folgendem Resultat:

"Die Lymphe der äusseren Genitalien ergiesst sich in die Gland. inguinales superficiales, d. $h$. die Drüsen an der Einmündungsstelle der Vena saphena magna in die Schenkelvene (innere Gruppe). Ebendahin entsendet der untere Scheidenabsehnitt seine Lymphstämme. ${ }^{*}$

Die Bahnen, welche von den zwei oberen Scheidendritteln sich sammeIn, enden nach $S$. in einer kleinen Drüse am Ansatz der Vagina aussen am Collum uteri (Glandula uterovaginalis).

Die unteren Collumbahnen biegen im Parametrium sofort nach hinten um und ziehen im Ligam. sacrouterinum zu den Gland. sacrales an der hinteren Beckenwand seitlich vom Rectum.

Die oberen Collumbahnen und die Corpuslymphstämme ziehen im breiten Ligament nach auswärts zu den Drüsen an der Gabelung der Vasa iliaca communia. Nur 1 bis 2 Bahnen des Corpus uteri ziehen mit dem Plexus ovarieus zu den Lumbaldrüsen.

Die Glandula obturat. kennt S. nicht. Trotzdem er das Vorhandensein der Gland. uterovaginalis vertheidigt, will er dieselbe mit den parametranen Drüsen von Lucas Championnière nicht identificirt wissen. - Als nicht constant schildert er die Beziehung des Collum uteri zu einer Drüse am 5. Lendenwirbel und in anderen Fällen zu den Drüsen, welche auswärts von der Vena iliaca externa nahe am inneren Leistenring liegen. 
Sappey's Schüler, Poirier, hat die Scheiden-Uterusbahnen mit grossem Fleiss studirt und in schönen Abbildungen dargestellt. Er hat Schleimhaut-, Muskel- und Serosabahnen besonders injiciren können, weiss aber, dass sie alle miteinander communiciren und in dieselben ausführenden Stämme sich ergiessen. Im Gegensatż zu Leopold und Fridolin, welche die ganze Mucosa corporis gewissermassen für einen flächenhaften Lymphsinus ansahen, schildert Poirier das reichverzweigte, regelmässige Lympheapillarnetz in der Mucosa uteri et vaginae. Die abführenden Bahnen der Scheide verlaufen im unteren Abschnitt zu den Gland. inguinales, im mittleren Abschnitt zu 1 bis 2 Drüsen zwischen Rectum und Arteria hypogastrica im Winkel zwischen Art. uterina, pudenda communis und umbilicalis (Gland. rectovaginales); die abführenden Bahnen des oberen Scheidendrittels endlich verlaufen mit den Collumbahnen zu den Drüsen des Plexus iliacus zwischen Art. iliaca ext. und Art. iliaca int. Die aus dem Collum austretenden Lymphbahnen sammeln sich an der Austrittsstelle der Vena uterina in 3 bis 4 dicke Stämme, welche mit zahlreichen, nach aussen sich öffnenden Klappen versehen sind und im Parametrium hinter dem Ureter liegend an der Basis des breiten Ligaments nach aussen zum Theilungswinkel der Art. iliaca communis ziehen, um hier in 2 oder 3 Drüsen zu enden. P. localisirt genau die Lage der einzelnen Drüsen, bespricht ihre Verbindung mit den Drüsen des grossen Beckenplexus und erwähnt auch eine an der Art. obturatoria gelegene Drüse, die in anastomotischer Verbindung mit dem Uterus stehe. Doch konnte er eine Lagebeziehung dieser Drüse zum Foramen obturatorium, wie Cruveilhier will, nicht feststellen. Die parametrane, von Iucas Championnière beschriebene Drüse hält er für eine Knäuelbildung der hier sehr zahlreichen Lymphbahnen.

Die Bahnen des Corpus uteri beschreibt er ähnlich wie Sappey als zwei starke Stämme, welche mit dem Plexus ovaricus zu den Lumbaldrüsen ziehen und in Höhe des 5. Lendenwirbels mit den Vasa lymphat. ovarii anastomosiren. Poirier giebt klare und übersichtliche Darstellungen seiner Injectionsresultate. Als wichtigen Befund hebe ich noch hervor, dass $\mathrm{P}$. die grosse Anastomose zwischen Corpus- und Collumbahnen als typisch bezeichnet und dass er feine Corpusbahnen im Ligam. rotundum zu den Gland. inguinales verlaufen sah. - Seine Beschreibung der 
Ovarialbahnen deckt sich mit derjenigen Sap pey's und der Darstellung von Bruhns; sie soll bei djesem noch näher erörtert werden.

Damit schliessen die classischen Untersuchungen über die Lymphbahnen, soweit sie systematisch im grossen Stil an einem umfassenden Material angestellt worden sind. Es dürfte wohl auch in der heutigen Zeit schwer fallen, ein solches Material den Injectionsversuchen zu opfern, wie es theilweise den alten Forschern zu Gebote stand. Bis zu einem gewissen Grade ist dies auch nicht nothwendig. Es genügt ja für Nachforschungen die Feststellung, dass die Resultate regelmässig in der Hauptsache mit denen der Vorgänger übereinstimmen.

Während nun im Anfang des vorigen Jahrhunderts die Bedeutung der groben Lymphbahnverhältnisse offenbar allgemein etwas überschätzt wurde, trat in den letztẹn Jahrzehnten gerade das Gegentheil ein. Man findet selbst heute noch in den gebräuchlichen Lehrbüchern der Anatomie, Physiologie, sowie unserer Specialwissenschaft die einschlägigen Capitel etwas stiefmütterlich behandelt. - Es ist nicht der kleinste Vorzug des ron Chrobak und v. Rosthorn herausgegebenen Werkes: „Die Erkrankungen der weiblichen Geschlechtsorgane. I. Th. Wien 1900", dass es in compendiöser Form die Resultate eines Sappey, Poirier, Mascagni in Wort und Bild wiedergiebt. Die in verkleinertem. Maassstabe reprodueirten Abbildungen der genannten Forscher sind in der That unübertroffen und gewähren auch demjenigen, welcher die theueren Atlanten nicht zur Verfügung hat, ein vollkommenes Verständniss der fraglichen Verhältnisse.

Die Abbildungen Craveilhier's finden sich reproducirt in E. Martin's "Handatlas der Gynäkologie und Geburtshilfe", Berlin 1878, Tafel 56 und Tafel 57.

Während nan die Anatomie und Physiologie mit der Untersuchung nach dem Ursprung von Lymphbahnen und -Drüsen und der Lymphströmung sich beschäftigte, haben neverdings 2 Momente die Untersuchungen über die ableitenden Iymphbahnen wieder angeregt: „Die Aenderang der Injectionstechnik und das klinische Interesse. " Das alte Verfahren, mit Quecksilber die Lymphbahnen auszufüllen, ist sehr schwer zu erlernen, und es lag nahe, statt des schwerfälligen Stoffes eine leicht flüssige Injectionsmasse zu suchen. In der That hat seit Teichmann fast jeder Anatom sein eigenes Injectionsverfahren und -Instrumentarium, wie man aus dem betreffenden Abschnitt äber Injectionstechnik in der Encyklopädie der mikro- 
skopischen Technik von P. Ebrlich etc. ersehen kann. Lösungen der verschiedensten Forbstoffe in Wasser, Leim, Celloidin, Terpentin, Wachs, endlich Fettlösungen mit Nachhärtung in Osmiumsäure werden verwendet. Trzasker-Chrzonszczewsky in Kiew empfiehlt seine Methode der physiologischen Injection von Blatund Lymphgefässen, wobei gewöhnlich Cochenille-Carminlösungen ins Blut oder in die Körperhöhlen bezw. -Gewebe eines lebenden Thieres gebracht werden. Er studirt dann am getödteten Thier den Verlauf der selbstinjicirten Bahnen. Die Blutgefässe können postletal mit Contrastfarben injicirt werden. Das Verfahren giebt nach Maassgabe der von dem Autor beigegebenen Abbildungen farbenprächtige Resultate und beweist wohl die Thatsache der Diffusion, ohne über das Vorhandensein oder Nichtyorhandensein der Saftspalten Aufschluss zu geben. Man dachte schliesslich daran, durch Injection von pyogenen Bacterien eine natürliche Eiteranfüllung der Lymphbahnen zu erzielen (Sappey's putréfaction). Es brauchen auch nicht die lebenden Bakterien zu sein. Die leukotaktischen Toxine verrichten denselben Zweck. Das beweisen A mann's Versuche der natürlichen Leukocyteninjection des Uterus. In höchst origineller Weise brachte Amann jr. leukocytenanlockende Substanzen in das Cavum uteri, während er die Wanderzellen durch chinesische Tusche (die er in die freie Bauchhöhle brachte) färbte. Er verband also die Erfahrungen von v. Recklinghausen über die Färbbarkeit der Wanderzellen in der Peritonealflüssigkeit (Kraus) mit den Lehren der Bakteriologie. Auf den Rath Buchner's nahm er als leukotaktische Substanz Aufschwemmungen von sterilisirten Bakterienculturen. Die schwarzgefärbten Leukocyten sammelten sich in der subserösen Muskelschicht und besonders im Schleimhautstroma. Dabei konnte $A$. eine directe Ausmündung der Schleimhautlymphbahnen im Collum durch eine Art Vacuolenbildung nach dem Cavum uteri hin beobachten.

Die gebräuchlichste aller modernen Methoden für die Darstellung der Lymphbahnen ist das von Gerota angegebene Injectionsverfabren leichtflüssiger Terpentin - Aether - Farblösungen mittelst der sogenannten Gerota-Spritze. Nicht die Art der Injection, d. h. nicht der interstitielle Einstich ist neu - diesen hat schon Mascagni geübt, - sondern die Lösung und die verwendete Spritze. Das Wesentliche an derselben ist das anzuschraubende Ansatzstück, in dessen konisch auslaufendes Ende eine feine, über der Flamme ausgezogene Glascapillare mittels Handschuhleders 
eingedichtet wird. Die Spritze kann durch jede handliche, etwa 10 bis $20 \mathrm{ccm}$ fassende Spritze ersetzt werden, und Polano schlägt vor, anstatt der theuren Gerota-Spritze eine Hahn'sche Augenspritze mit dem Ansatzstück nach Gerota zu versehen. (Spritze und Glascapillaren bezieht man bei Altmann-Berlin durch Vermittlung jedes Instrumentenmachers.) Die gebräuchlichsten von Gerota angegebenen Lösungen sind kurz folgende:

A. Blaue Injectionsflüssigkeit. $4 \mathrm{~g}$ Preussisch-Blau (Oelfarbe!) werden mit $6 \mathrm{~g}$ reinem Terpentinöl in einem Porzellanmörser sorgfältig verrieben, sodass keine Klümpchen mehr sichtbar sind. Unter allmäligem Zusatz von $30 \mathrm{~g}$ Aether sulfuric. wird die Lösung leicht fiussig gemacht und durch doppelte Leinwand oder feines Mikroskopirleder filtrirt. Die lösung hält sich in einer Flasche mit eingeschliffenem Glasstopfen tagelang, wird aber vor jedem neuen Gebrauch durch Leder in die Spritze eingesogen.

B. Rothe Injectionsflüssigkeit. $2 \mathrm{~g}$ feinsten Zinnobers (der sogenannte unter Wasser zerriebene Zinnober!) werden mit 20 Tropfen ungekochten Leinöls 15 Minuten lang sorgfältig verrieben. Nach Zusatz von $3 \mathrm{~g}$ Terpentinöl und $5 \mathrm{~g}$ Chloroform wird die Lösung in bekannter Weise filtrirt. Die Lösung soll womöglich für jede Injection frisch bereitet werden.

Das Gerota'sche Verfahren hat unleugbare Vorzüge. Es erfordert bei handlichem Apparat zwar Sorgfalt wie jede Injection, verspricht aber doch sicheren Erfolg selbst für den Anfänger. Es ist daher begreiflich, dass es zur Zeit geradezu modern geworden ist, mit dem Gerota'schen Verfahren die Lymphbahnen chirurgisch wichtiger Körperregionen darzustellen (Gerota, Bruhns, Stahr, Most).

Ton der uns interessirenden Beckenregion injicirte Gerota selbst die Lymphbahnen der Blase und des Rectums. Auch die schönen Untersuchungen von Bruhns über die Lymphbahnen der weiblichen Genitalien entstanden unter der Anleitung Gerota's. Bruhns stellte seine exacten Untersuchungen an 54 Leichen an. Seine Resultate sind so wichtig, dass wir ihn am besten selbst reden lassen.

Bruhns, Die Lymphgefässe der weiblichen Genitalien. Archiv für Anatomie und Physiologie, Anatomisehe Abtheilung, Jahrg. 1898 p. 75. Sehlussfolgerungen:

Bruhns schreibt: "Zum Schlusse möchte ich meine Resultate noch einmal kurz zusammenstellen: 
1. Die Lymphbahnen der grossen und kleinen Labien und die der Clitoris hängen unter einander zusammen. Ihre abführenden Stämme münden in der Regel in die innere und obere Gruppe der oberflächlichen Leistendrüsen. Zu diesen Drüsen scheinen auch die Lymphstämme von der Glandula Bartholini zu verlaufen. Zwischen dem grossen und kleinen Labium der einen Seite lassen sich Verbindungen durch Lymphbahnen mit den Leistendrüsen der anderen Seite nachweisen.

2. Die Lymphbahnen der Mucosa und der Muscularis vaginae hängen unter einander zusammen. Ihre abführenden Stämme pflegen zu den auf beiden. Seiten der Art. hypogastrica gelegenen Drüsen zu ziehen. Die Lymphbahnen des dem Hymen benachbarten Theiles der Vaginalwand stehen auch in Verbindung mit den Lymphwegen der Labien und hierdureh mit den Leistendrüsen. Endlich treten von der hinteren Scheidenwand Lymphstämme auf das Rectum und münden in die der Muscularis des Nastdarmes unmittelbar anliegenden Rectaldrüsen, welche bei Anschwellung in klinischen Fällen der Palpation per rectum leicht zugänglich sein müssen.

3. Im Uterus hängen sowohl im Collum wie im Corpus die Lymphbahnen der Schleimhaut wie der Muscularis zusammen Ferner anastomosiren die Lymphgefässe des Collum und des Corpus ateri unter einander.

Vom Collum uteri her führen Lymphstämme zu den Drüsen im Winkel zwischen Art. hypogastrica und Art. iliaca externa.

Die vom Corpus uteri sich sammelnden Lymphstämme sind in vier Gruppen zu scheiden: Die vom mittleren Theil des Corpus uteri ziehen ebenfalls zu den Drüsen im Winkel zwischen Art. hypogastrica und Art. iliaca externa, die vom Fundus verlaufen zum Theil nach dem Ovarium zu und von hier aus nach oben entlang der Art. spermatica interna zu den Lumbaldrüsen. Eine dritte Gruppe, sehr feine Stämmchen, breitet sich vom Fundus uteri in die Wand der Tuben aus; endlich nehmen noch andere Lymphstämme gleichfalls vom Fundus uteri her, im Lig. rotundum zu den Leistendrüsen ihren Weg.

4. Von der Tuba aus zieht die Lymphe nach dem Lymphplexus am Hilus des Ovariums und von hier aus nach oben zu den Lumbaldrüsen.

5. Aus dem Ovarium sammeln sich sechs bis acht und mehr dicke Lymphstämme, die sich in die zahlreichen Lumbaldrüsen ergiessen. 
6. Die sogenannten tiefen, unter der Fascia lata femoris liegenden Leistendrüsen, deren Vorhandensein von Auspitz ganz in Abrede gestellt wurde, kommen doch in der Zahl von zwei bis vier vor, allerdings sind sie nicht constant zu finden."

Die Bruhns'schen Resultate decken sich somit mit denen von Sappey und Poirier und stimmen mit denen Maseagni's fast absolut überein. Nur Sappey's Sacralbahnen des Collum uteri konnte Bruhns nicht injiciren. Diese Verbindung fand or tiefer von dem oberen Scheidendrittel aus.

Zur selben Zeit entstand im Breslauer anatomischen Institut unter Leitung des Anatomen Stahr, welcher bereits mit viel Erfolg das Gerota'sche Verfahren anwendete, die bekannte Arbeit ron Peiser als Beantwortung einer von Küstner gestellten Preisfrage der Universität. Klinisches Interesse stand im Vordergrund. Daher konnte Peiser sich beschränken. Streng genommen berichten seine Injectionsversuche nur von den Collumbahnen. Erfreulicher Weise ergaben auch Peiser's Resultate eine Bestätigung der früheren Untersuchungen. Sie sind nach seinen eigenen Worten eine Zusammenfassung der Angaben von Sappey und Poirier und stimmen am meisten mit den pathologischen Befunden ron Cruveilhier überein. Die Glandulae uterovaginales im Ligament bezw. Parametrium dagegen, sowie die ron Cruveilhier am Foramen obturatorium beschriebene Lymphdrüse konnte Peiser nicht finden, glaubt aber, dass die unterste Drüse $\left(\mathrm{H}_{1}\right)$ im kleinen hypogastrischen Gefässdreieck zu dem Nervus obturatorius in Lagebeziehung treten kann.

Die Peiser'schie Arbeit, rom klinischen Interesse angeregt, verfolgt klinische Interessen. Es galt ja nachzuweisen, ob eine Exstirpatio uteri mit Ligamenten und anhängendem Lymphapparat in continuo möglich wäre. Der Kampf gegen das Carcinom hat in seltener Weise anatomische und klinische Arbeit angeregt (Wertheim, Ries, Rumpf, Clark (Kelly) Halban und Tandler, Feitel u. A. m.). Dieselben Beweggründe, welche wohl zur Zeit in jeder Klinik gelten, haben auch unsere Anstalt veranlasst, neben der klinischen die anatomische Untersuchung in gleicher Weise zu pflegen. Beide sollen sich ergänzen - und so bin ich denn - angeregt durch meinen verehrten Chef - seit meiner ersten Veröffentlichung über unsere Carcinomerfahrungen den anatomischen Untersuchungen treu geblieben, zumal der Verlauf der 
Carcinomfrage eines jeden Klinikers Interesse dauernd wach erhalten muss.

Meine eigenen Untersuchungen (bezw. Injectionsexperimente) erstrecken sich auf 14 Kinderleichen (Neugeborene), 7 an intercurrenten Krankheiten gestorbene Personen (darunter 1 Kind von 7 Jahren) und 9 Carcinomleichen; 4 von den letzteren kamen nach der abdominalen Radicaloperation zur Section. Herrn Professor Pfannenstiel, sowie Herrn Geh. Medicinalrath Professor Dr. Bostroem danke ich an dieser Stelle für das mir überlassene Material.

Zur Injection kamen ausser den Kindern nur 2 Erwachsene im Ganzen also nur wenig Leichen im Vergleich zu den früheren Untersuchern. Ich stellte aber die Versuche deswegen bald ein, weil sie eine erstaunliche Uebereinstimmung mit Bruhns und den anderen ergaben.

Ausser den an der Leiche ausgeführten Injectionen habe ich eine Reihe operativ gewonnener Uteri, Tuben und Ovarien zu Specialuntersuchungen injicirt.: Es empfiehlt sich dies so einfache Verfahren zur Herstellung von klinischen Demonstrationspräparaten ausserordentlich. Namentlich geben injicirte Ovarien die schönsten Bilder auf Durehschnitten bei Lupenbetrachtung. Flache Rasirmesserschnitte werden in Xylol aufgehellt und bei schwacher Vergrösserung $(40-60)$ betrachtet. Man erhält dadurch am leichtesten eine Vorstellung über das räumliche Verhältniss der Lymphbahnen zum Gewebe. So kann man auch (in Xylol) die breiten Ligamente (nach der Injection) von Kinderleichen ausspannen und durchmustern, wobei die zahlreichen Klappen an den Ligamentbahnen mit zierlicher Zeichnung hervortreten. Schwierig ist die Injection der Mucosa uteri. Eine Schleimhaut im ganzen Bereich des Cavum uteri zu injiciren ist mir nie gelungen. Doch ist dies für mikroskopische Zwecke nicht nöthig. Am leichtesten stellt sich das subseröse Lymphnetz dar. Bei allen von mir injicirten Kinderleichen, welche ich nach den Angaben von Bruhns-Peiser durch Wegnahme der Symphyse und Eröffnung der Scheide vorbehandelte, konnte ich bei Einstich in die Portio den ganzen Uterus injiciren. 2 mal war die Theilung der Bahnen in beiden Uterushälften so ausgesprochen, dass beispielsweise bei Injection in die rechte Portiohälfte erst die rechte Portiohälfte und deren ableitende Bahnen sich füllten, ehe die Injectionsflüssigkeit auf der Höhe des Corpus 
uteri auf die linke Hälfte überging. Fig. 2 deutet diese Theilung der Bahnen im unteren Bereich der Gebärmutter durch die rapheartige Grenzscheide auf der Mitte der Hinterfläche des vorgezerrten Uterus an. In 2 Fällen füllten sich zwar die Lymphcapillaren des ganzen. Uterus, aber nur auf einer Seite die ableitenden Wege. Der Uterus wird im Moment der Injection länger und dicker und richtet sich etwas auf. - Die Injection der beiderseitigen Leistendrüsen von einem Vulvaeinstich aus gelingt fast immer. Ich verzichte darauf, die Protokolle der einzelnen Fälle zu geben, um nicht zu ermüden, zumal sie ja meist nur eine Bestätigung schon bekannter Thatsachen bringen, und will mir nur erlauben, bei der nun folgenden Schilderung abweichende oder ergänzende eigene Erfahrungen hervorzuheben.

Zur Injection benutze ich die von Polano neuerdings angegebene Injectionsflüssigkeit.

Polano (Beitr. zur Anatomie der Lymphbahnen im menschlichen Eierstock, Monatsschr. für Geburtsh. und Gynäk., Bd. XVII, H. 3, S. 289) schreibt: "Meine Farblösung wird folgendermaassen bereitet: Prenssisch-Blau (Oelfarbe) wird in einem Mörser mit Aether verrieben. Diese Lösung wird auf trockenen, d. h. wasserfreien, pulverisirten Campher gegossen. Es genügen einige Cubikcentimeter, um eine grössere Menge Campher zur sofortigen Lösung zu bringen. Dieses entstandene, äusserst dünnfiüssige Gemisch wird schnell durch ein doppeltes Fliesspapierfilter in eine fest verschliessbare Flasche gegossen. Vor dem Gebrauch setzt man einige Tropfen Chloroform auf $10 \mathrm{ccm}$ Farblösung, die eine Gerota'sche Injectionsspritze füllen, hinzu; - nach einigen Versuchen gelingt es leicht, die möglichst concentrierte Stammlösung durch jedesmalige Aetherchloroformverdünnung dem entsprechenden Zweeke anzupassen."

Diesen Ausführungen Polano's möchte ich noch hinzusetzen, dass man mit dem genannten Verfahren bei Kinderleichen die schönsten Resultate erhält. Bei Erwachsenen versagt zuweilen jede Injectionsart. Zur Injection verwende ich eine gewöhnliche, $20 \mathrm{ccm}$ fassende Spritze, welche man bequem mit einer Hand beherrschen kann. Statt der Findichtung der Glascapillare mit Handschuhleder verwende ich eine Art Stopfbüchsenverschluss, d. h. das Ansatzstück besteht aus 2 ineinander zu schraubenden Hälften mit correspondirender centraler Bohrung. Die lichte Weite der letzteren beträgt eine Kleinigkeit mehr als die Dicke der gebräuchlichen 
Glascapillaren. Nach dem Ausziehen der Spitze über der Flamme wird die Glascapillarröhre imit einem 2-3 mm langen dünnen Gummischlauch bezogen, welch' letzterer etwa $1 \mathrm{~cm}$ oberhalb des weiten Endes der Capillare zu sitzen kommt. Beim Einführen der Glascanüle in die centrale Bohrung der beiden Ansatzstücke sitzt der Gummimantel zwischen denselben und wird nun durch das Ineinanderschrauben der Metalltheile comprimirt, wodurch der enge Spaltraum zwischen Glasrohr und Metallhülse luftdicht abgeschlossen wird. Der Gummischlauch ist wohl in jedem Laboratorium als Aetherzuführungsschlauch an den gewöhnlichen Gefriermikrotomen vorhanden. Das Auswechseln vollzieht sich rasch und bedarf keiner grossen Kunstfertigkeit. Die Spritze wird nach jedem Gebrauch gereinigt und das Ansatzstück neu montirt, so dass beim neuen Gebrauch nur die Spritze auf Schlussfähigkeit zu prüfen ist. Der Spritzenstempel muss vorzüglich schliessen. Die Glascapillare biege ich gern bajonettförmig und ziehe die Spitze lang aus, so dass bei einer unvorhergesehenen Verstopfung trotz Abschneidens der verstopften Partie die Oeffnung genügend fein bleibt, um die Injection fortsetzen zu können. Die Flüssigkeit wird womöglich für jede Injection friseh bereitet. Für die Darstellung der ableitenden Bahnen wählt man gesättigte Farblösungen und injicirt mit nicht zu enger Canüle. Beim Einstich in das schon vorher peinlich gesäuberte Gebiet wird ein leiser Druck auf den Kolben ausgeübt, damit kein Gewebe oder Blut in die Capillare eindringt. Die linke Hand fixirt mit vorsichtiger Gewalt die Injectionsstelle um die Capillarspitze; während nun die rechte Hand ein wenig die Canüle zurückzieht, um der zu injicirenden Flüssigkeit Spielraum zu lassen, wird der Spritzenstempel ganz allmälig mit stetig wachsender Kraft herabgedrückt. Bei gelungener Injection bildet sich am Einstich zunächst eine diffuse Verfärbung, von welcher aus die Netze der Lymphbahnen mit grosser Schnelligkeit sichtbar werden. Die Flüssigkeit schiesst gewissermaassen hinein. Wenn statt der Netzzeichnung dendritische Verzweigungen sichtbar werden, so ist die Injection misslungen, weil die Blutbahnen erfüllt worden sind. Man thut daher gut, vorher die letzteren mit Wachs oder Gelatine auszuspritzen. Natïrlich wählt man dabei Contrastfärbung (vgl. Fig. 3).

Für mikroskopische Nachuntersuchungen ist das beschriebene Verfahren sehr zu empfehlen. Eine besondere Nachbehandlung der injicirten Stücke ist nicht nothwendig. Härtung und Einbettung erfolgt nach Belieben wie an anderen Objecten. Die Lymphbahnen 
erscheinen wie mit hellblauen Linien ausgezeichnet. Der Aether verdunstet und die Campherfarbmasse schlägt sich an der Wand nieder. Die Färbung bleibt auch bei Hämatoxylinfärbung der Schnitte different genug. Im Uebrigen kann man durch Nachbehandlung der in Hämatoxylin gefärbten Schnitte mit van Gieson'scher Lü̈sung jeden Grad der gewünsehten Contrastfärbung erzielen.

\section{Allgemeiner Ueberblick ïber die Lymphrerhältnisse der weiblichen Genitalien.}

Vor dem Eingehen auf die speciellen Verhältnisse der Beckenregion scheint mir ein allgemeiner Veberblick unerlässlich. Das Lymphgefässsystem der Genitalorgane des Weibes ist ausserordentlich reich entwickelt. Sohleimhaut, Muscularis und Serosaüberzug baben ihre eigenen Bahnen, die aber alle in jeder Schicht mit denen der anderen Schichten anastomosiren, so dass das Resultat einer Injection auf die ableitenden Bahnen von der Stelle des Einstiehs nicht beeinflusst wird. Diese überall in den Organen sich findenden Lymphlacunen bilden unter sich zierliche Netze, wie sie namentlich von Poirier mit seltener Regelmässigkeit für die Mlucosa uteri et vaginae dargestellt worden sind. Das System soll am reichsten gegliedert sein in der Vaginalschleimhaut. Von allen diesen Parenehymbahnen unterseheiden sich die abftihrenden Stämme scharf durch ihren Bau (sie besitzen eine Muscularis und Adventitia) und ibre Verlaufsart. Die ableitenden Stämme anastomosiren untor einander nicht; sie erscheinen im injicirten Ligament wie Perlenschnuren in Folge regelmässiger, seitlicher Aussackungen. Zwischen je zwei solcher Dilatationen ist das Gefäss gleichsam eingeschnürt, weil hier an der Innenwand jedesmal dünne Membranen wie Taschenfalten vorspringen: die sogenannten Klappen, welche alle in demselben Sinne nach dem Venensystem zu sich offnen, ihre concave Seite somit dem letzteren zuwenden. Man kann also diese Gefässe zwar prograd im Sinne des fortlaufenden Lyimphstromes injiciren, aber nicht retrograd, wenigstens nicht ohne übermässige Gewalt.

Alle die zablreichen ableitenden Bahnen werden an irgend einer Stelle unterbrochen von Lymphdrüsen, welche niemals allein, sondern zu zwei bis vier und mehr sich an Knotenpunkten des Blutgefässsystems finden. Dort, wo grosse Arterien sich gabeln und Venen zusammenströmen, werden beide blatführenden Systeme 
umstrickt von den Lymphgefässgeflechten mit den zugehörigen Drüsenknoten. Wir müssen uns nämlich von der Annahme frei machen, dass jede Drüse nur $1 \mathrm{~V}$ as afferens und 1 correspondirendes Vas efferens hat. Die ableitenden Bahnen communiciren zwar während ihres intercurrenten Verlaufes nicht mit einander; sobald sie aber die 1. Etappe des regionären Drüsengebietes erreicht haben, stehen sie wiederum unter dem. Gesetz weitgehendster Anastomose. Das Vas efferens einer Drüse gabelt sich in 2 oder 3 Aeste, von denen einer zur Nachbardrüse verlaufen kann. An Stelle eines Vas efferens treten 3 bis 4 heraus. Ein Vas afferens kann also mehrere Drüsen versorgen. Die Vasa efferentia der einen Drüse sind Vasa afferentia der anderen benachbarten desselben und des nächstliegenden Lymphgeflechtes, sodass Verbindungsäste hinauf- und hinuntersteigen und man beispielsweise ron einer Drüse im Centrum der Beckengeflechte alle benachbarten vor und hinter den grossen Gefässen injiciren kann. Schliesslich kann ein Vas efferens in seltenen Fällen vor dem Eintritt in die Drüse einen Verbindungsast zum zugehörigen Vas efferens senden (Umgehungsbahn). Die uns interessirenden Drüsengruppen ziehen sich von der Einmündungsstelle der Vena saphena magna (Regio subinguinalis) entlang den grossen Becken- und Bauchgefässen an der hinteren Bauchwand aufwärts bis zum Ursprung der Nierenarterien.

\section{Die Leistendrüsen}

liegen theils auf der Schenkelfascie (Lymphogland. inguinales superficiales ${ }^{1}$ ), theils unter derselben (T. gl. inguin. profundae) direct am Einmündungswinkel der Vena saphena magna in die Vena femoralis. Die Angaben Mascagni's über diese Drüsen sind ron Sappey und Bruhns nur bestätigt worden.

Die oberflächlichen Leistendrüsen, 7 bis 13 an der Zahl, liegen im Kreise herum um die Saphenamündung. Je weniger Einzeldrüsen sich finden, um so grösser ist jede von ihnen. Gerota berichtet über die Versuche, die betreffenden Drüsen in ein Schema zu ordnen. (Sappey, Auspitz, Quénu, Rauber,

1) Bezüglich der Nomenclatur folge ich dem Vorschlage von His, (Die. anatomische Nomenclatur. Arch. für Anat. u. Phys. Anat. Abth. 1895, Supplementband) und bezeichne alle echten Lymphdrüsen, soweit sie als Organa adenoidea und Gefässdrüsen anzusehen sind, als Lymphoglandulae = Lgl. im Gegensatz zu den parametranen noduli lymphatici. 
Poirier, Tillaux, Testut, Richet.) Ziehen wir mit Quénu eine gerade Linie, welche mit der Richtung der Vena saphena bzw. mit deren gedachter Verlängerung nach oben auf dem Schenkel identisch verläuft and setzen eine Senkrechte darauf, welche die erste Grade an der Saphenamündung schneidet, so wird dieses stebende Linienkrevz 4 Gruppen von Drüsen trennen, 2 obere und 2 untere, von denen wiederum je eine innere Gruppe von je einer äusseren getrennt ist. Am Schnittpunkt der Senkrechten findet man 1 grosse oder mehrere kleinere Drüsen als Mittelpunkt der ganzen Gruppe. Die obere äussere Gruppe liegt dabei beim stehenden Menschen am höchsten, nahe der Spina ant. sup. oss. ilei. Die beiden oberen Gruppen insgesammt sind nahezu parallel angeordet zu dem Ligam. Poupartii, bleiben aber unterhalb desselben. Poirier hat mehr 'den klinischen Verhältnissen Rechnung getragen, indem er eine innere obere Gruppe als Groupe génital, eine äussere obere Gruppe als Groupe féssier (Gesässgruppe) und eine untere als Schenkelgruppe (Groupe crural) unterschied. Aehnlich theilt Sappey diese Drüsen ein.

Nach dem übereinstimmenden Urtheil aller Beobachter bilden die oberen und inneren, zuweilen auch die unteren inneren der oberflächlichen Leistendrüsen die erste Etappe für die ableitenden Bahnen der äusseren Genitalien und die Analgegend (Vasa lymphatica haemorrhoid. inferiora). Die oben erwähnte Eintheilung nach Sappey, Poirier enthält zugleich die Angabe der regionären Gebiete, welche zu den unteren und äussere Drüsengruppen gehören.

Die tiefen Leistendrüsen (Lgl. inguin. profundae) 2 bis 3 selten mehr, liegen dicht unter der Schenkelfascie (Mascagni fand ihrer zuweilen bis 7) ron dem Einmündungswinkel der V. saph. mag. in die $V$. femoral. auf und an der letateren bis in die Region des Ligam. Poupartii. Injectionen von einer der mittleren Jgl. inguinales superf. werden die tiefen Leistendrüsen, welche von Auspitz geleugnet wurden, immer nachweisen lassen. Die tiefen Drüsen, welche also mit den oberfächlichen anastomosiren, nehmen die Lymphbahnen der tiefen vorderen Beinmuskeln auf und senden ihre Vasa efferentia zu 1 bis 3 Drüsen im inneren Schenkelring, deren grösste median von der Vena femoral. im Anulus cruralis int. constant zu finden ist und als Rosenmüller'sche Drüse bekannt ist. Die andern 2, wenn sie vorhanden sind, liegen auf der Art. und Ven. femoralis.

In dieser selben Region münden die feinen vom Corpus uteri 
ins Ligam. rotundum ziehenden Stämmchen, theils in die Lgl. inguin. prof., theils in die Drüsen dicht unter dem Poupart'schen Band. $\mathrm{Zu}$ der Rosenmüller'schen Drüsenetappe haben nicht alle Leistendrüsen Beziehung. Ein grosser Theil der aus den letzteren entspringenden $V$ asa efferentia zieht sich ohne Unterbrechung hinter den Vasa cruralia (zwischen diesen und dem Musculns psoas) nach aufwärts unter dem Ligamentum Poupartii hindurch in die Bauchhöble hinein, um hier zum Plexus iliacus externus zu werden. In diesen münden auf der Innenseite die Vasa efferentia aus den Drüsen im Schenkelring und weiter aufwärts die Anastomosen von den an der Seitenwand des kleinen Beckens liegenden Lymphdrüsen, welche dem Plexus hypogastricus seu iliacus internus angehören. Tafel XII, Fig. 1 und Fig. 2 in dem Atlas von Mascagni erläutern die Verhältnisse. Namentlich Fig. 1 zeigt, wie reich das Lymphgeflecht an der Hinterseite dor Gefässe zwischen Musculus psoas, Os ilei und der Blutgefässscheide ist. Von den im Schenkelring auf und neben den Gefässen liegenden Drüsen jst in pathologischen Fällen eine oder die andere zuweilen vom Abdomen aus zu tasten und wird z. B. bei der abdominalen Radicaloperation wegen Carc. uteri nicht selten entfernt (Amann, Kleinhaus) vergl, auch meinen Aufsatz in der Monatsschr. XVHI, 5.

Diese Drüsen leiten eben bereits über zu den LgI. iliacae externae, welche auf und an den gleichnamigen Blutgefässen liegen, eine Gruppe wie erwähnt nahe der vorderen Bauchwand 1 oder 2, selten mehr, eine andere weiter aufwärts nahe der Gabelungsstelle der Art, iliaca communis. Die nach aussen liegenden Drüsen liegen gewöhnlich zwischen Arterie und Musculus psoas, die nach innen gelegenen gehören dem kleinen Gefässdreieck an und schmiegen sich oft zwischen Arterie und Vene ein. Andere liegen an der Innen- und Hinterseite der Vene. Schliesslich können an Stelle der letzteren oder ausser diesen besondere Knoten in dem Raum zwischen den Vasa iliaca int. und externa verlagert sein, oder an der Vena iliaca communis von dieser abrücken nach dem Promontorium zu, so dass sie auf das Sacroiliacalgelenk zu liegen kommen und dann als Lgl. sacrales laterales imponiren. Eine ganz constante Lagebeziehung der Drüsen giebt es eben nicht. Die Drüsen am Poupart'schen Band gehen über in die I.ggl. iliacae externae, die letzteren in die Lgl. iliacae communes. An der Bifurcation der Vasa iliaca communia in ihre Theiläste treffen sich Plexus iliacus externus und Plexus iliacus internus seu hypogastr. An 
diesem Knotenpunkt also trifft man die meisten Drüsen; ebenso sicher aber kann man in der Nische zwischen dem Musc. psoas. und den Vasa iliaca comm. wie externa ober- und unterhalb der Communisgabelung grosse Knoten finden.

Aehnlich wie die Vasa iliaca externa werden auch die Vasa hypogastrica von einem Lymphgeflecht umsponnen, zu welchem, wie erwähnt, eine Reihe von Drüse gehören. Au der Aussenseite, besser gesagt an der Vorderseite der Gefässe u. z. oberflächlich im kleinen Gefässdreieck finden sich gewöhnlich 2 Lymphoglandulae, deren tiefer gelegene oft nahe dem Uterinaursprung liegt. An der Hinterseite der Vasa hypogastrica zwischen diesen und dem ausstrahlenden Bündel der Sacralnerven, welche hier den Stamm des Nerv. ischiadic. bilden, liegen 2 bis 3 Drüsen, in welche der Plexus lymphat. ischiadicus, d. h. die Lymphe aus der tiefen Schenkelund Gesässmusculatur einmündet. Diese Drüsen sind schwer zugänglich, da sie am Foramen ischiadicum magnum liegen. Wenn man nach dem üblichen Verfahren bei der Wertheim'schen Carcinomoperation den Ureter nach aussen zerrt, verdeckt man sich stets den Zugang zu diesen Drüsen und zu 1 bis 2 anderen, welche in der Theilungsstelle der Art. hypogastrica (nach Poirier in dem Winkel zwischen Art. umbilicalis, vaginalis und pudenda communis) liegen und als Rectovaginaldrüsen bezeichnet werden, weil sie die mittleren Scheidenbahnen und die Vasa lymph. haemorrhoidalia media (Quény, Bruhns) aufnehmen. Diese Drüsen, zuweilen auch die im hypogastrischen kleinen Gefässdreieck bilden zugleich die 2. Etappe für die ableitenden Stämme der Harnblase.

Endlich fand ich auch stets in der Tiefe des kleinen Gefässdreiecks die Drüse am Nervus obturatorius bei Kindern, wie bei Erwachsenen. An einem ron der Portio aus injicirtem Becken sah ioh bei dem Ausschälen der gesammten Beckenorgane die blaven Lymphstränge den Nerven mit den zugehörigen Blutgefüssen umstricken und bis in den Canalis obturatorius selbst hineinziehen. Ohne Präparation wäre mir dieser überraschende Befund vollständig entgangen. Wie Haase vom Schenkel aus die Injectionsmasse ins Becken trieb, so kann man sie bis zu einem gewissen Grade auch retrograd heraustreiben. Durch den Plexus lymph. obturator. tritt die Lymphe aus den grossen Sehenkeladductoren in den Plexus lymph. hypogastr. ein. Fig. 4, כ и. 6 erläutern die Lage der fraglichen Drüsen zu den Vasa iliaca. 
Nach hinten und medianwärts von der Einmündungsstelle der Vena hypogastrica in die Vena iliaca communis - somit bald zum Plexus lymph. iliacus internus (hypogastr.), bald zum Plexus lymph. iliac. comm. gehörig — finden sich die oben schon erwähnten Drüsen, welche auf der Seitenfläche des Kreuzbeins seitlich vom Rectum liegen und daher als Lgl. sacrales laterales bezeichnet werden (die medialen Sacraldrüsen, von Gerota als Lgl. mesorectales bezeichnet, liegen im Mesorectum).

Machen wir uns noch ein Mal klar, dass die Lymphbahngeflechte die grossen Blutgefässe umspinnen, dass die Drüsen an und neben ihnen, vor und hinter den Gefässen sich zeigen, so erscheint die Bezeichnung der alten Forscher logisch, welche Drüsen und zugehörige Lymphplexus nach den Blutgefässstämmen derselben Gegend benannten. In diesem Sinne ergiesst sich die Lymphe der unteren Extremitäten durch die Leistendrüsen in den Plexus iliacus ext. (jederseits), die des kleinen Beckens und seiner Organe in den Plexus iliacus internus seu hypogastricus. Die Plexus iliac. ext. und int. vereinigen sich zum gemeinsamen Plexus iliacus nnd gehen an der Aortengabelung über in den Plexus lumbalis inferior. Dieser letztere vereinigt seine Lymphe mit derjenigen aller darüber liegenden Drüsen bis zum Abgang der Nierenarterien, welche letztere den mächtigen Plexus lumbalis superior bilden. In jeder Etappe ziehen kurze Verbindungsbahnen von Drüse zu Drüse, es münden ferner tiefaufsteigende ableitende Bahnen aus, während andere Lymphstränge ohne Unterbrechung an der Etappe vorüber der nächst höheren zustreben. Aus dem Plexus lumbalis entwickeln sich die 2 mächtigen Trunci lumbales, welche sich mit den Trunci intestinales hinter der Aorta in die Cysterna chyli ergiessen (in Höhe des 2. Lumbalwirbels).

Von dieser Bezeichnung weicht die namentlich in klinischen Arbeiten gebräuchliche Nomenclatur ab. - Man hat sich die Frage mehr praktisch zurechtgelegt. Die grossen Beckengefässe schliessen im Ganzen 3 Dreiecke ein, von denen das grosse Gefässdreieck zwischen den Art. iliacae communes in der Aortengabel, das kleine zwischen Vasa iliac. ext. und Vasa hypogastr. jederseits in der Communisgabel liegt. Da man bei der operativen Ausräumung der Drüsen erst die Aussenseite der Gefässe, dann das kleine Gefässdreieck und endlich die Innenseite absucht, so scheint es einfacher, alle Drüsen ausserhalb der Gefässdreiecke als Gl. iliac. externae zu bezeichnen, die höher gelegenen nahe der Aorten- 
theilung rechnet man gewöhnlich bereits dem Pl. Iumb. inf. zu; die Drüsen in dem kleinen Gefässdreieck werden mit Cruveilhier als Gl. hypogastricae bezeichnet, die Drüsen im grossen Gefässdreieck endlich sind die Gland. sacrales laterales, welche eben den Drüsen an der Aussenseite - als die entsprechenden Drüsen an der Innenseite der grossen Gefässe (Vasa iliaca comm. et int.) correspondiren. Man muss sich nur vergegenwärtigen, dass die Art. hypogastrica dicht vor der Artic. sacroiliaca liegt und die von ihr entsendeten Art. sacrales laterales (Spinaläste) eigentlich direct nach dem Ursprung in die Foramina sacralia lat. tauchen, ferner dass die obere der seitlichen Sacraldrüsen nahe der Aortentheilung auf oder an dem Promontorium liegen und zur untersten G]. Iumbalis inf. werden kann, um die Angaben von Mascagni mit denen von Sappey, Bruhns und Peiser vereinbaren zu können. Alle Beobachter sahen dieselben Drüsen (vergl. das Schema von Bruhns mit der Zeichnung Peiser's und der Tafel XIV bei Mascagni). Nur über die Bezeichnung und die Abgangsstelle der zuleitenden Bahnen war oder ist man nicht einig.

Die Form und Grösse der einzelnen Lymphdrüsen kann sehr variabel sein. Sie schmiegen sich als spindelige Körper zwischen Arterie und Vene, sie umgeben als bohnenförmige, breite Masse von vorn oder hinten her die Rundung einer grosssen Vene, sio erscheinen kugelig wie Erbsen oder flach linsenförmig, zuweilen wie der: Kopf oines Pilzes vom Hilus her ausgehöhlt; allenthalben aber sieht man in der Nähe der grossen Gebilde kleine Nebendrüs'chen, manchmal im Hilus 2 ja 3 (bei den spindeligen Formen an der Spitze im Verlauf des Vas. affer. oder effer.), um welche Nebendrüsen sich die Lymphbahnen knäuelförmig herumwinden.

Die Zahl der Drüsen ist meist grösser als man erwartet. Der Plexus lumbalis (sup. et inf.) enthält zum mindesten 6-10 Drüsen, ich habe in pathologischen Fällen 16 und mehr grössere Knollen beobachtet. Was die Plexus iliaci betrifft, so finden sich an der Aussenseite der Vasia iliac. comm. gewöhnlich 2 Drüsen in der Psoasnische und 3 im Verlauf der Vasa iliac. ext, davon die letzte oder die 2 letzten nahe der vorderen Bauchwand. Im kleinen Gefässdreieck finden sich 3, seltener 4 oberflächliche Drüsenkörper, von denen einer gewöhnlich genau am Theilungswinkel der Art. iliac. comm., 2 mehr nach der Art. hypogastr. zu liegen. Dazu kommen $1-2$ Drüs'chen am Nervus obturator. und $2-3$ an der 
Wurzel des Nervus ischiadic. In der Ausstrahlung der Art. hypogastr. fand ich nie mehr als 2 Drüsen (Lgl. rectovaginales). Die zwischen den grossen Gefässen und dem Reetum gelegenen Drüsen (Lgl. sacrales laterales) finden sich $z u 2-3$ nahe boi einander liegend.

Es ist somit eine stattliche Anzahl von Drüsen (26-36), welche dem Psoas entlang an den grossen Gefässen bis hinauf zur Niere und im kleinen Becken an allen Austrittspforten und Gefässgabelungen gewissermaassen als Knotenpunkte eines complicirt gebauten Geflechtes stationirt sind. Dabei muss man noch in Erwägung ziehen, dass die kleinen Nebendrüsen, welche ich oben erwähnte, in pathologischen Fällen, wenn eine oder zwei benachbarte Drüsen functionsunfähig werden, hypertrophiren und zu grossen Drüsen anwachsen können, so dass man in der Regel bei Sectionen oder bei Operationen an einzelnen Stellen oder ganz allgemein eine auffällig grosse Zahl von Drüsen finden kann. Ob dies auf einer Neubildung von Drüsen, d. h. von adenoider Substanz aus indifferentem Fettgewebe, oder wie ich nach meinen Untersuchungen annehmen möchte, auf der Ausbildung schon vorhandenen Materiales beruht, wird schwer zu entscheiden sein. Jedenfalls beeinträchtigt die Entscheidung nicht das thatsächliche Bestehen der Ersatzkräfte. Die grosse Zahl der Drüsen, welche wie complicirte Sieborgane in den Lymphstrom eingeschaltet sind, ist ein Schutz bei der Ueberwältigung von eingedrungenen Infectionserregern. Die Bacterien werden von einer ganzen Drüsengruppe aufgefangen. Erliegt eine Drüse im Kampf, so treten neue Nachbarn für sie ein, und es bleiben zunächst noch Drüsen genug, um die normale Function im Körperhaushalt zu versehen. Freilich geht die Regenerationskraft nicht ad infinitum (auch dies spricht für schon vorhandene, in der Zahl begrenzte Reserveanlagen) - auch die Reserven werden endlich erschöpit, und es kann eine dauernde Lymphstauung einer Extremität beispielsweise nach einer acuten Vereiterung der regionären Drüsen $(\mathrm{Sack})$ eintreten, wie sie nach operativer Ausränmung z. B. der Achselhöhle für den Arm genugsam bekannt ist.

Diese allgemeinen Erörterungen mussten den speciellen Besprechungen voraufgehen, weil sie auf alle Etappen Bezug haben und nicht an jeder Stelle wiederholt werden sollen. Es wird ein Leichtes sein, die Ausmündungsstellen der ableitenden Stämme, welche aus den Beckenorganen sich sammeln, in das allgemeine Schema einzutragen. Die abführenden Stämme münden gewöhnlich 
an mehreren Knotenpunkten des oben geschilderten Drüsennetzes aus. Es bestehen da offenbar gewisse Variationen. Auch bleiben wohl alle Injectionsversuche unvollkommen, d. h. die Lymphverbindungen aller Organe sind reichlicher, als man es zuweilen nach dem Injectionsresultat vermuthet. Wenn einzelne Bahnen zuweilen nicht injicirt erscheinen, so bedeutet das zunächst noch nicht, dass sie ïberhaupt nicht vorhanden sind, sondern nur, dass die Technik noch nicht vollendet genug war. Das Mikroskop würde die Bahnen noch nachweisen. Darum erscheint mir die Forderung unerlässlich, unsere Injectionsresultate mit dem Mikroskop nachzuprüfen. Die speciellen Verhältnisse der einzelnen Regionen geben im Folgenden Anlass genug, dies im Einzelnen klarzulegen.

Die Lymphbahnen der vorderen Bauchwand.

Gerota hat neuerdings die Lympheanäle der Nabelgegend und der Unterbauchwand untersucht und die Ergebnisse der Mascagnischen Forschungen ergänzt. Wie überall, so schliessen auch hier die abführenden Lymphbahnen im Groben an den Verlauf der Blutgefässe an. Die Parenchymbahnen bilden äusserst feine Netze, welche wie überall an der Körpcroberfläche ein feines, intracutanes über einem weiteren subeutanen Lacunensystem bilden. Am Nabelschnuransatz erscheinen die Lacunen als ein dichteres Ringgeflecht. In der Nabelschnur selbst konnte ich keine präformirten Canäle nachweisen. Die zarte, durch Injection erzielte Färbung erwies sich stets im mikroskopischen Bild als diffuses Infiltrat, die einzelnen Lücken waren künstlich geschaffene, unregelmässige Rissspalten ohne Endothelauskleidung.

Aus den Parenchymnetzen der Bauchhaut entstehen feine Stämmchen, welche im tiefen, subcutanen Fettgewebe nach oben zum Nabelring, nach unten zur Arteria und Vena epigastr. superficialis hinstreben. Die letzteren, als Vasa lymph. hypogastrica bezeichnet, verlaufen bis zur Mündung selbständig und treten als unbedeutende, feine Röhren in die Lgl, inguinales superfic. (obere Gruppe) ein. Mascagni konnte nicht weniger als 12 hypogastrische Stämmchen injiciren, wie überhaupt die Zahl der in den Leistendrüsen endenden lymphbahnen eine sehr bedeutende ist. Die Tafel VIII in dem Atlas ron Mascagni zeigt z. B. ausser den Genitalbahnen und den 12 eben erwähnten hypogastrisehen Stämmen - 37 Lymphgefässe von der Vorder- und Innenfläche des Schenkels entstammend - 12 Bahnen, welche von der Ge- 
sässgegend in der Verlaufsrichtung der Vena circumflexa ilei superficialis herantreten - endlich 6 von der Aussenseite des Oberschenkels entspringende Bahnen.

Die am Nabelring sich sammelnden Stämmchen können zuweilen hier in einer kleinen Lymphdrüse münden, welehe Gerota $1 \mathrm{mal}$ am Nabelring, d. h. wohl auf der Fascie, 1 mal hinter dem Nabelring, also präperitoneal, fand. Von hier ans füllen sich bei Injectionen am Nabelring feine Lymphbahnen, welche entlang der Vena umbilicalis im Ligam. teres hepatis eine Strecke weit aufwärts zu verfolgen sind. Am Nabel stehen offenbar die Lymphbahnen aller Wandschichten mit einander in Verbindung. Die Anastomosen verlaufen in gleicher Weise wie die Para umbilicalvenen (Braune, Sappey), welche die Venen im Jigamentum teres hepatis mit der Vena epigastrica inferior und den Hautvenen verbinden. Erfahrungen aus der pathologischen Anatomie lehren uns, dass bier bei carcinomatöser Infiltration des Peritoneums Metastasen auf dem Lymphwege sowohl ins Ligamentum teres hepat. als nach der Oberfläche hin sich entwiekeln können. Auch wir sahen bei Autopsieen und Probelaparotomieen solche Nabelmetastasen bei Carc. corporis uteri wie bei inoperablen Ovarialkrebsen. - Die tiefen intramusculären Lymphbahnen der vorderen Bauchwand ziehen zur Art. (Vena) epigastr. inferior, an welchen sie entlang nach abwärts verlaufen, um am Hauptstamm der Arterie in 2 oder 3 kleine Drüsen zu münden. Die Vasa efferentia dieser Drüsen und die selbständigen Stämmchen streben am lateralen Rectusrand nach abwärts und ziehen am medianen Rand des inneren Leistenringes, den Funiculus spermaticus (Ligamentum rotundum) kreuzend, zu den tiefen Leistendrüsen dicht am Ligam. Poupartii oder etwas höher zu den an der Vena iliaca ext. liegenden Drüsen.

\section{Die Lymphbahnen der Harnblase.}

Sappey hatte keine befriedigenden Resultate bei seinen Blaseninjectionen. Daher erklärt es sich wohl, dass noch neuerdings seine Annahme, die Blasenschleimhaut entbehre der Lymphbahnen, referirt wird (S. Polano, S. 493). Die beiden Hoggans und Cruikshank haben die Blasenbahnen gesehen, ebenso Albarran, welchen Gerota erwähnt, und endlich hat Gerota selbst sie neuerdings nachgewiesen.

Gerota fand sogar ein sehr reiches Lymphnetz mit engen Maschen in der Mucosa resic. urin,, von dem aus kleine, selbst- 
ständige Stämmchen die Muscularis durchbrechen, um mit den Muscularisbahnen zu den regionären Drüsen zu ziehen. Am Trigonum communiciren die Mucosa-Lymphbahnen mit denen der Urethra, und wahrscheinlich ziehen auch in die Ureterenwand, an der Harnleitermündung, Communicationswege hinein.

Die Lymphgänge der Muscularis vesicae urin. laufen in eigenthümlichen querliegenden Schlingen, welehe die Arterien mehrmals kreuzen, und unterscheiden sich dadurch auch auf den ersten Blick von dem serös-subserösen Peritonealnetz, welches regelmässige dünngezeichnete Netze bildet und manchmal bei flachen Einstichen in das Corpus uteri injicirt wird.

Die abführenden Lymphstämme der Blasenvorderwand verlaufen getrennt von denen der Hinterwand; beide Arten sind kurz und arm an Klappen. Die Bahnen der Hinterwand enden, an der Art. umbilicalis (vesicalis superior) sich sammelnd, in mehreren kleinen Drüsen (Lgl, vesicales laterales), welche sich ziemlich regelmässig (nach Gerota 7 mal in 10 Fällen) an der Art. umbilicalis finden. Die Stämmchen der Blasen-Torderwand wenden sich zum Plexus venosus vesicalis ant. und münden hier am Blasenhals dicht an der Symphysenhinterwand in kleinen Lymphdrüsen, welche Gerota als Lgl. vesicales anteriores bezeichnet. - Die Vasa efferentia dieser Drüsen laufen um den Blasenhals herum, vereinigen sich seitlich mit den Vasa efferentia der Lgl. vesic. lateral. und ziehen als abführende Blasenbahnen II. Ordnung mit den Artt. vesicales zu der Theilungsstelle der Art. hypogastrica. Sie münden in einer Drüse dicht am Ursprung der Art. uterina (Glandula uretorouterina), oder sie überschreiten die Art. hypogastr. und das ganze kleine Gefässdreieck und finden erst in den Drüsen auf den Vasa iliaca ext. ihre Unterbrechung.

Die weibliche Uretllura bildet kein selbstständiges System. Thre Lymphbahnen communiciren am Blasenhals mit denen der Blase. Injectionen in die äussere Urethralgegend haben das gleiche Resultat wie alle vulvären Einstiche.

Der Ureter soll nach Sappey gleichfalls frei von Lymphbahnen sein. In der That konnte ich eine parenchymatöse Injection seiner Wand nicht zu Stande bringen. Einstiche in eine der hypogastrischen Drüsen liessen (bei Erwachsenen) nur solche Bahnen hervortreten, welche vor oder hinter dem Ureter verliefen oder ihn kreuzten; aus allen war er glatt auszulösen. Bei Injection in die Ureterwand drang die Injections- 
masse in die Drüsen an der Iliaca communis-Gabelung. Die mikroskopische Untersuchung der Ureterenwand ergab jedoch ein wenig befriedigendes Resultat, insofern die Farbmasse zerstörend, aber nicht injicirend gewirkt hatte. Die feste äussere Kapselschicht war abgehoben, und nur wenig endothellose Spalten (Kunstproduet) in der Muscularis ureteris selbst waren blau injicirt, so dass sich mir die Annahme einer freien Lymphströmung in endothelfreien Saftspalten aufdrängte. In dem conisch sich verdickenden Blasenende des Ureters und in dem intramuralen Verlauf der Mündung muss wohl das Lymphnetz der Blase Anastomosen in die Ureterenwand entsenden. Die carcinomatöse Infiltration des Ureters bei Gebärmutterkrebs findet sich hier an dieser Stelle und beginnt vom Blasenansatz aus. Dagegen kann man den in seinem freien Verlauf (im Parametrium) rom Carcinom umwachsenen Ureter rein ausschälen; solange er noch beweglich sich verschieben lässt, ist er carcinomfrei.

Die ableitenden Bahnen des Ureters sah Stahr nach 'seiner Mittheilung in dem Atlas von Bardeleben im unteren Bereich zu den Drüsen an der seitlichen Beckenwand, im oberen za den Lumbaldrüsen verlaufen. Auch ich konnte jüngst bei zwei Kindern die entsprechenden Befunde erheben. Während seines Verlaufes an der seitlichen Beckenwand entsendet der Ureter kleine Stämmchen, welche sich auswärts wendend zu den hypogastrischen oder äusseren iliacalen Drüsen begeben. Im Bereich des oberen Drittels gehen Stämmchen medianwärts ab, welche zur Aorta streben (Gland. lumbal. sup.); oben wie unten ziehen die Lymphcanäle z. Th. eine Strecke weit auf dem Ureter entlang, unten sogar bis zur Blasenwand.

Die Lymphbahnen der weiblichen Genitalien.

Auch hier müssen wir die feinen klappenlosen Parenchymbahnen und die klappenführenden, ableitenden Stämme auseinanderhalten. Die ersteren stehen untereinander in weitgehendster Communication. Sie bilden ein feinmaschiges Netz von seltener Regelmässigkeit, wie dies am schönsten von Poirier für Scheide und Uterus dargestellt worden ist. Die Injection der Schleimhaut giebt feinere Netze als der intramusculäre Einstich. Doch bleibt dies ohne praktische Bedeutung, da die Schleimhautbahnen mit den tiefer gelegenen Muskelgängen in directem Zusammenhange stehen, und bei oberflächlicher wie bei tiefer Injection dieselben ableitenden Stämme sich füllen. 
Infolge der jüngsten Arbeiten auf diesem Gebiet (Peiser, Bruhns) ist die Nomenclatur nach Cruveilhier und Sappey in der gynäkologischen Fachliteratur so beliebt geworden, dass auch ich dieselbe für die Bezeichnung der regionären Drüsengruppen anwenden möchte. Wir verstehen unter der Bezeichnung L L. hypogastricae alle Drüsen, welche im kleinen Gefässdreieck zwischen den Vasa iliaca ext. und den Vasa hypogastrica liegen, -.. die Drüsen answärts rom kleinen Gefässdreieck an und auf den Vasa iliaca exi. werden als Lgl. iliacae ext., - die Drüsen einwärts vom kleinen Gefässdreieck zwischen Vena hypogastr. und Vena iliaca communis einerseits und dem Reetum andererseits werden als $\mathrm{Lgl}$. sacrales laterales bezeichnet, Drüsen an und auf den Vasa iliaca communia werden als Lgl. iliacae communes benannt, bei hohem Sitz sehon als Lgl. lumbales inferiores den Drüsen an der Theilungsstelle der Aorta und Vena cava zugerechnet; - die darüber sitzenden Lymphdrüsen an der Aorta und Vena cava aufwärts bis zum Abgang der Nierenarterien endlich werden wie allgemein als Lgl. lumbales superiores den unteren gegenübergestellt.

Die Vulva und zwar grosse wie kleine Labien mit der Clitorisgegend, Urethralmündung, dem Hymen und unteren Scheidendrittel entleeren ihre Lymphe in etwa 5 bis 8 grössere Stämme, welche von der Vulva an nach auswärts zur oberen inneren Gruppe der Lgl. inguinales superfic. (Sappey) verlaufen. Die mittleren Babmen verlaufen horizontal, die oberen im Bogen mit nach oben convexer Krümmung, die unteren analog den oberen aber mit entgegengesetzt gekrümmten Bogen. An den Commissuren vorn und hinten findet Gefässaustausch zwischen rechts und links statt, so dass man von einem Einstiohi aus sowohl direct - durch die ableitenden Bahnen - wie anch indirect auf dem Umwege über das Parenchymnetz die beiderseitigen Leistendrüsen füllen kann. Einstiche in die Bartholin'sche Drüse - selbst tiefe - gaben Bruhns die gleiehen eben geschilderten Resultate. - Nach Fille steht diese Region auch in Beziehnng zu dem Rectovaginalplerus. - Nach Rille's Zusammenstellung. nehmen auch französische Autoren (Hugiex, Martin und Léger, Tarnier) an, dass die Lymphbahnen der Gland. Bartholini zu Drüsen im Becken an der Seite zwischen Rectum und Vagina verlaufen, während ein anderer französischer Autor Bounet dies verneint. 
Ich selbst sah bei tiefer Injection in dieser Gegend an der Leiche eines frühgeborenen Kindes zunächst nur die Bahnen oberflächlich zu den Inguinaldrüsen ausstrahlen, offenbar über den Umweg der Scheidenschleimhaut. Nach Wegnahme der seitlichen Beckenwand und Blosslegung der Beckenorgane sah ich zu meiner Ueberraschung 2 divergirende, starke Lymphstränge im tiefen, paravaginalen Gewebe nach aufwärts in die Tiefe des Beckens ziehen, deren einer blasenwärts in den Lgl. vesicales ant., deren anderer rectalwärts in den Drüsen zwischen den Endästen der Art. hypogastrica endete. Beide umfassten nach oben divergirend die Vagina. - Damit würde die klinische Beobachtung übereinstimmen, dass bei Bartholinitis relativ sehr selten die Inguinaldrüsen anschwellen, häufiger die seitlichen Rectovaginaldrüsen, welche man in entzündlichem Zustande als schmerzhafte Knoten vom seitlichen Fornix vaginae aus tasten kann.

Der mittlere Bezirk der Vagina entleert nach Poirier seine Lymphe in eine oder zwei Drüsen, welche zwischen Vagina und Rectum im Winkel zwischen Art. vaginalis, umbilicalis und pudenda communis liegen. Bruhns fand als typisch die Verbindung mit einer oder zwei Drüsen, welche zwischen dem Rectum und der Art. hypogastr. liegen, zuweilen aber auch mit den Drüsen im kleinen Gefässdreieck. Wahrseheinlich bestehen beide Verbindungen.

Je weiter man mit den Einstichen aufwärts geht, um so leichter injiciren sich im mittleren und oberen Bezirke der Scheide zweierlei Bahnen: - bei seitlichem Einstich Verbindungen zu den unteren Drüsen im kleinen Gefässdreieck, vor allem zur tiefsten, an der Abgangsstelle der Art. uterina liegenden Drüse - und beim Einstich im hinteren Scheidengewölbe die Sacralbahnen zu den Lgl. sacrales laterales. Ausserdem konnte Bruhns vom Fornix post. aus eine Reihe kleiner Drüsen injiciren, welche seitlich rom Rectum am Beckenboden lagen; er fand ferner feine Communicationsbahnen zu Drüs'chen, welche auf der Fascia recti, seltener zu solchen, welche unter derselben liegen, also bereits dem Anorectalgebiet angehören. Dieser Zusammenhang beider Lymphgefässsysteme, welcher klinisch durch seine Wechselwirkungen ganz wahrscheinlich gemacht oder bestätigt wird, wird auch von Moran hervorgehoben.

Für den Uterus steht als Hauptverbindung die Beziehung des Collum zu den Lgl. hypogastricae, sowie die des Corpus zu den Lumbaldrüsen fest (s. Fig. 1 u. 2). Vom Collum uteri zunächst 
ziehen 2 bis 3 starke Stämme (im Verein mit den oberen Scheidenund unteren Körperlymphbahnen) mit der Art. uterina den Ureter kreuzend jederseits durch das Parametrium, treten hier, wie ich vorweggreifend bemerken möchte, mit einer Anzahl (2-5) kleiner Drüs'chen (noduli lymphat. parametranes) in Beziehung und erreichen mit der Art. uterina die seitliche Beckenwand, um sich hier nach aufwärts und hinten wendend in die Lgl. hypogastr. des kleinen Gefässdreiecks zu ergiessen. --. Die einzelnen mit zierlichen Klappen ausgezeichneten Gefässe gehen vor und hinter dem Ureter weg; sie können ihn auch an der ganzen seitlichen Beckenwand von yorn und hinten einrahmen oder kreuzen. Doch bleibt bei Injectionen vom Uterus her die Wand des Creters selbst frei (vergl, oben S. 80).

Die zweite Verbindung des Gebärmutterhalses durch das Lig. sacrouterinum zu den Lgl. sacrales laterales - von Sappey beschrieben - ist von Bruhns nicht bestätigt worden. Sie besteht aber und wurde anch von Peiser als typisch festgestellt. Ich selbst konnte sie durch Injection und mikroskopische Untersuchung nachweisen. Diese Etappe ist bei neugeborenen Kindern wohl entwickelt und zwar leicht zu finden, wenn man von der Corpushinterfäche an der oberen Cervixgrenze einsticht und in der Richtung gegen die Cervix mit starkem Druck injicirt. Es erscheinen dann in den Bogenfalten des Sacrouterinbandes, 2 bis 3 in den Faltenabsätzen mit immer grösser werdenden Bogen verlaufende Bahnen, deren tiefste den kleinsten Bogen beschreibt und hart am Rectumrande verschwindet; die höheren sind länger und streben zur Vena iliac. communis-Innen- bezw. Hinterfläche. Nimmt man das Mesorectum und die Art. haemorrhoidalis sup. hinweg oder zerrt es mit dem Rectum (Flexura sigmoidea) medianwärts, so treten die seitlichen Sacraldrüsen im grossen Gefässdreieck wohl injicirt hervor.

Von der Mitte des Gebärmutterkörpers aus ziehen zwei oder mehr mittelstarke Aeste dicht über und mit den seitlichen Collumbahnen zu den oberen hypogastrisehen Drüsen in der Gabel der Art, iliaca communis.

Von beiden Uterushörnern strahlen feine Lymphstränge in die Ligam. rotunda aus, mit welchen sie durch den Leistencanal ziehen, um in den tiefen Inguinaldrüsen zu münden. Die Hauptstämme des Corpus jedoch (2 bis 3) verlaufen höher oben von den Spitzen der Uterushörner aus in der Höhe des Ovarialansatzes und zwar 
vor oder unter dem Hilus ovarii durch das breite Ligament, tauchen an dessen Seitenrand ins Ligam. ovariopelvic., um hier im Verein mit den Tuben- und Ovarialbahnen aufwärts zu den Lumbaldrüsen zu ziehen. Eine Communication zwischen den ableitenden Corpusund den Ovarialbahnen scheint nur ausnahmsweise vorzukommen. Sie wurde von Poirier dargestellt, von Bruhns aber nicht bestätigt.

Der uterine Theil der Tube steht in Lymphaustausch mit dem Uteruskörper. Die feinen Bahnen der Pars isthmica und ampullaris (s. Fig. 3) sammeln sich in wenige (meist 2) Stämmchen, welche am unteren Tubenrande im Ligamentum entlangziehen und im Plexus ovaricus mit den ableitenden Lymphsträngen des Ovariums sich vereinen.

Die Pars abdominalis tubae mit dem Fimbrienkranz bildet ein selbständiges ableitendes Gefäss. Verbindungszweige laufen in der Fimbria ovarica von Tube zu Ovarium und im Ligam. ovarii medianum vom Cornu uteri zum Ovarium bezw. umgekehrt. Aus dem Hilus ovarii treten nach Bruhns und Polano 6-9 ziemlich gleichmässig mittelstarke Lymphcanäle, welche durchs Mesovarium zum Ligamentum latum ausstrahlen und hier unter Betheiligung an der Bildung des Plexus sousovarique sofort nach aussen hinten und oben abbiegen in das Ligam. ovariopelvicum; hier ziehen sie, mehr den inneren Rand einnehmend, mit Corpus- und Tubenbahnen zu den Lumbaldrüsen. Bei dem Verlauf durchs breite Iigament machen die Corpusbahnen den vorderen, also grösseren Bogen, die Ovarialbahnen den hinteren, kleineren Bogen; die ersteren betrachtet man besser von der Vorderseite des breiten Bandes, die letzteren von dessen Hinterseite. Vgl. Fig. 1 und Fig. 2. Im weiteren Verlauf sammeln sich die Ovarialbahnen mehr um die spermaticalen Blutgefässe und zeigen in Folge dessen die Tendenz, höher auszamünden (Lgl. lumbales superiores) als die Corpusbahnen, welche zu den unteren und oberen Lumbaldrüsen in Beziehung treten.

An der Bildung des Plexus sousovarique, welcher am Ovarialansatz im breiten Ligament als Durchtrittsknotennetz für obere Corpus-Tuben-O farialstämme stationirt ist, nehmen auch abirrende Zweige aller 3 Organe Theil. Die eigentlichen ableitenden Stämme aber treten von vornherein unverzweigt ein und bleiben meist isolirt.

Betrachtet man nach gelungener Injection das Ligam. latum gegen das Licht, so zeichnen sich eine Menge zierlicher Gefässe ab, am oberen Rand unterhalb der Tube alle die Gefässe, welche dem 
Ligam. ovariopelvicum zustreben. Ihr Bündel, Anfangs am Uterushorn schmal, wird nach aussen zo immer mehr verstärkt durch die Stämme der Tube und der Ovarien. Vom Plexus sousovarique erblickt man zierliche Netze in der Mesosalpinx und im Ligam. lat. unterhalb des Ovarialansatzes. Endlich imponirt an der Seitenkante der Gebärmutter nach aussen von den Blutgefässen vom inneren Muttermund bis zum oberen Corpusdrittel aufsteigend: die grosse Seitenanastomose zwischen Cervix- und Corpnslymphbahnen, welche zuweilen ein grösseres Lumen besitzt als die ableitenden Stämme. Auch Mascagni zeichnet sie Taf. XIV und ebenso Poirier. Klinisch ist sie wiederholt bestätigt worden ( $\vee$. Franqué), und ist ihr typisches Vorkommen ebenso sicher als das der Sacraldrüsen.

Während nun im Allgemeinen die abführenden Stämme nicht miteinander in Verbindung stehen, communiciren die regionären Drüsen selbst in weitestgehendem Maasse untereinander und zwar auf- und absteigend, sowie nach den Seiten hin mit allen Nachbardrüsen. Von den uns interessirenden Stationen empfangen z. B. die Lgl. hypogastr. die Bahnen von dem oberen Scheidenabschnitt, rom Collum und unteren Corpustheil, und dieselben Drüsen communiciren weiterhin mit den Lgl. iliacae externae und lumbales inferiores, mit den Lgl. sacrales laterales und endlich retrograd mit den Drüsen in der Tiefe des Beckenzellgewebes in der HypogastricaEndausstrahlung (Lgl. rectovaginales), am Plexus nervor. sacral. (Lgl. ischiadic.) und endlich mit der Lgl. obturatoria (Cruveilhier), welche in der Tiefe am Nervos obturator. liegt und nicht zu den oberflächlichen hypogastrischen Drüsen gehört.

Alle Bahnen, welche zu den Gland. hypogastricae verlaufen (Fornix vaginae, Collum, unteres Corpus uteri) können z. Th. wenigstens direct nach aussen ziehen und in die Drüsen an den Vasa jliac. extern. und commun. einstrahlen. - Gewöhnlich sind die letzteren aber bereits II. Etappe.

Die intermediären, kleinen Drüsen im Parametrium - von einigen Untersuchern [Lucas Championnière, Henle," Sappey] hervorgehoben, von anderen (Peiser) bestritten - sind abgesehen von ihrer Kleinheit für die Injection schwer nachzuweisen, weil sie bei Kindern wie bei Erwachsenen dem Lumen der Lymphgefässe [die meisten, jedoch nicht alle] mehr seitlich angelagert sind, während die grossen Drïsen an der Beckenwand richtige Stromunterbrecher darstellen. Bruhns fand zwischen der Art. hypogastr. und der Uterusseitenkante nicht weniger als 5 bis 10 kleine Drüsen 
und zwar sowohl nach der Blase als nach dem Rectum zu. Der Grund für die Differenzen der Bcobachter liegt in dem Fehlen der mikroskopischen Nachuntersuchung, für welche Polano's Verfahren überaus günstig ist.

Als Hauptergebniss meiner anatomischen Untersuchungen an Leichen von Kindern und Erwachsenen, sowie an dem operativ gewonnenen Krebsmaterial referire ich: "Die Zahl der Lymphverbindungen und der regionären Drüsen des Uterus ist grösser als man bisher annahm." Auf die Communicationsbahnen zum Rectum mit and ohne Umweg über das Scheidengewölbe hat Bruhns (Moran) aufmerksam gemacht. Ebenso besteht eine Lymphanastomose nach vorn zur Blase hin. Yergl. Fig. 1, welche ausser dem feinen Netz der Serosabahnen noch einen tiefen Lymphstamm an der hinteren Blasenwand mit charakteristischer Schleifenbildung injicirt zeigt (bei Einstich in die Portio!). - Die hinteren Collumbahnen im Sacrouterinband sind constant; denn sie finden sich bereits beim Kinde vollständig angelegt mit der zugehörigen Drüsenetappe.

Ebenso regelmässig sind die intermediären Lymphknoten im Parametrium bei Kindern wie bei Erwachsenen. - - Man ist stets überrascht, in den Parametrien Lymphknoten, Nervenstämme und sympathisehe Ganglien in Begleitung der Vasa uterina zu finden. Wenn bisher von einer Inconstanz der Drüsenbefunde die Rede war, so möchte ich gerade für eire Constantheit der Drüsenkeime eintreten. Die Drüsen sind rorhanden. Man fühlt und sieht sie nur schwer. - Die von Bruhns an der Ureter-Uterinakreuzung beschriebene Drüse konnten wir bei Carcinomoperationen $3 \mathrm{Mal}$ als besonders kräftige hypogastrische Drüse bestätigen. Diese Drüse - bei Carcinom des Uterus am ehesten gefährdet - leitet von den intercurrenten parametranen Knötchen (welche meist nur als Noduli lymphatici zu bezeichnen sind) über zu der I. Etappe der regionären Lymphdrüsen, den L. hypogastricae, welche 3 bis 4 an der Zahl im vorderen kleinen Gefässdreieck liegen. Die unterste kann eben bei tiefem Sitz zur Gland. uretero-uterina werden. Injectionsversuche von einer dieser vorderen hypogastr. Drüsen aus erweisen ihre weitgehenden, oben bereits geschilderten prograden und retrograden Verbindungen. Eine Betrachtung der von ihrer Unterlage abgelösten grossen Gefässstämme (vergl. Figur 4-6) lehrt, dass die sogenannten hypogastrischen Drüsen nur ein Theil der in diesem Gefässconflux liegenden Lymphknoten ist. Re vera werden 
die Vasa iliaca extern., commun. und intern. von den Drüsen und deren Communicationsbahnen allseitig von vorn wie von hinten umsponnen. - Eine anatomische Auslösung der Lymphorgane dieser Region in continuo ist - davon kann sich jeder an injicirten Leichen überzeugen, - ohne Abhebung der Gefässstämme und ohne Abpräpariren der Gefässscheide unmöglich. Unabhängig von den oberflächlichen hypogastrischen Drüsen fand ich in allen untersuchten Leichen die tiefen Beckendrüsen am N. obturator., ischiadic. und in der Ausstrahlung der Art. hypogastrica: - ferner die Drüsen an den Vasa iliaca ext., namentlich die Gruppe nahe an der vorderen Bauchwand, constant auch die grossen Drüsengruppen an den Vasa iliaca comm., Aorta und vena cava. Die Darstellung der Gefässdurchschnitte (Fig. 6) erläutert am klarsten ohne viele Worte die Lagebeziehung der Drüsen, welche häufig an der Hinterseite der Arterien sitzen und die Vene zwischen sich fassen.

Die Drüsen auf der Vena iliaca externa, nahe dem inneren Schenkelring, anastomosiren retrograd mit den Drüsen im inneren Schenkelring (Rosenmüller) und den tiefen Inguinaldrüsen. Sie können also von der Vulva her durch die oberflächlichen Inguinaldrüsen, ferner vom Gebärmutterkörper her durch die im Ligament. rotundum zu den tiefen Inguinaldrüsen verlaufenden Corpusbahnen - in beiden Fällen also prograd über die Inguinaldrüsenetappe injicirt werden. Dieselben Lgl. iliacae ext. können auch retrograd bei Umkehr der Stromrichtung von dem Lgl. hypogastr. aus Keime aufnehmen."

Als atypische Drüsenbefunde erwähne ich noch die von Gellhorn an der Art. circumflexa jlium bei einer Section gefundenen Knoten. Mascagni's Taf. XIV zeigt ausser den Drüsen an der Art. circumflexa ilium sup. noch ähnliche Noduli auf dem Musculus iliacus. Auch bei meinen Injectionen konnte ich derartige Seitenäste an den Hauptbahnen auf der Beckenschaufel und am unteren Nierenpol darstellen.

Die von Staude auf dem Giessener Gynäkologen-Congress nur summarisch mitgetheilten atypischen Drüsengruppen des Beckenbodens" werden wohl unter eine der oben skizzirten Gruppen fallen.

Im Allgemeinen kann man somit überall da Lymphdrüsen erwarten; wo Blutgefässe verlaufen. Die Grösse und die Zahl der Lymphdrüsen wird sich nach dem Volumen des Gefässstammes richten, d. h. die Wurzel eines bestimmten Gefässgebietes ist zu- 
gleich der Hauptverdichtungsknoten in dem weit ausgedehnten, complicirt gebauten Lymphsystem. Er wird in unserer hypogastrischen Region, wo die Saugadern des Schenkels, des Gesässes und des Beckens zusammenströmen, besonders mächtig sein. Der Verlauf der Lymphbahnen freilich kann sich - das muss zugegeben werden - von dem der regionären Blutgefässe emancipiren.

Die Lymphgefässe des Anus und des Rectums.

Um die Lymphorgane des Beckens ersehöpfend zu behandeln, folgt eine kurze Wiedergabe der von Gerota neuerdings unter Zusammenfassung der früheren Erfahrungen (Mascagni, Sappey, Richet, Quény, Quain Testut) festgestellten Thatsachen. Die Lymphgefässe des cutanen Theils am Anus bilden ein so dichtes Netz, dass bei Quecksilberinjectionen, welche Gerota Anfangs nach Sappey's Beispiel noch anwendete, die Umgebung des Anus den Anblick einer einzigen spiegelnden Quecksilberschicht darbietet. Wenig Einstiche füllen den ganzen Analring und sehr leicht auch die Mucosa ani (was ich für die Polano'sche Injectionsmasse nur bestätigen kann) wegen der zahlreichen Anastomosen. Aehnlich wie die Venengeflechte dieser Region bilden auch die Lymphnetze varicöse, ampulläre Aussackungen. Unter der Haut verbinden sich die in die Tiefe sich fortsetzenden Lakunen zu einem zweiten Netz im subcutanen Gewebe. Aus beiden entwickeln sich jederseits 3 bis 6 abführende Stämme, welche im tiefen Fettgewebe an der Innenfläche des Oberschenkels bald in unmittelbarer Nachbarschaft der Genitalregion, bald mehr unterhalb nach der Vorderfläche des Schenkels ziehen und hier im Scarpa'schen Dreieck in den Lgl. inguinales superfic. münden, und zwar enden sie in der unteren inneren Guppe dieser Drüsen, während die Vulvabahnen in der oberen Gruppe (Sappey) ihre I. Unterbrechung finden. Doch ist dieser Unterschied nicht durchgreifend. Jedenfalls entspricht die klinische Maassregel, bei geschwollenen Leistendrüsen nicht nur die Genitalgegend, sondern auch Anus und Rectum zu untersuchen, den anatomischen Thatsachen, dass genitale und anale Lymphbahnen zuweilen nach denselben oberflächlichen Leistendrüsen verlaufen können, und zwar sowohl nach der oberen, wie nach der unteren, inneren Gruppe. Diese äusseren Analbahnen nennt Gerota nach der von Quény eingeführten Bezcichnung: "Vasa lymphat. haemorrhoidalia inferiora."

Die Pars mucosa ani, obwohl leicht von der Analhaut aus zu 
ixjiciren, sendet die aus den Parenchymnetzen hervorgehenden Hauptgefässe submucös eine Strecke weit nach aufwärts, worauf sie die Muscularis recti durchbrechen, an der Seitenwand der Ampulla recti nach aufwärts ziehen und meist nach kurzem Verlauf in kleinen Drüsen enden, welch' letztere in den Theilungswinkeln der Art. haemorrhoidalis superior und ihrer Aeste liegen. Da die Lymphbahnnetze der Mucosa recti, welche namentlich an den Columnae Morgagni zierliche Bilder liefern, in ihren Sammelstämmen dasselbe Verhalten zeigen, so findet man nach Gerota an der Seitenfläche des Rectums vom $O s$ coccygis bis aufwärts zur seitlichen Umschlagsfalte des Peritoneums zahlreiche kurze aufsteigende Lymphstämmohen mit den zugehörigen kleinen Lymphdrüsen in den Winkeln der Arterienverzweigungen, und zwar begleiten stets zwei Lymphgefässe 1 Arterie und 2 Venen. Die Durchbruchsstelle durch die Muscularis ist für alle 3 Gefässarten die gleiche. Gerota zieht daher das Facit: „Die Jiymphbahnen der Anal- und Rectalschleimhaut finden ihre I. Drüsenetappe in den zablreichen Anorectaldrüsen, welche an der Seitenwand des Rectums im periproctitischen Fettgewebe eingebettet sind." Die Lymphstämmchen selbst nennt er mit Quény Vasa lymphat. haemorrhoidal. superiora. Dic Lymphbahnen der Muscularis recti et ani konnte Gerota nur beim Hunde injiciren. Nach Analogie der thierischen Befunde nimmt or an, dass auch beim Monschen die musculären Lymphbahnen den gleichen abtührenden Weg wählen, wie die mit ihnen communicirenden Schleimhautlacunen.

Die an der Kreuzbein-Vorderfläche (im Verlauf der Art. sacralis media hinter dem Rectum und höher oben im Mesorectum) liegenden Drüsen (vergl. Taf. XIV bei Mascagnit), die sogenannten Lgl. mesorectales, bilden somit erst die II. Etappe für die rectalen Lymphbahnen. Luschka, Cruveilhier, Tillaux, Testut, Débierre, Beaunis and Bouchard, Hoffmann kennen die Anorectaldrüsen nicht und halten die medialen Sacraldrüsen (Lgl. mesorectales) für die I. Etappe. Die Anorectaldrüsen liegen z. Th. zwischen Fascia propria recti und der Museularis, z. Th. in der Hülle selbst, die Lglandul. mesorectales (bei Induration gut fühlbar) liegen dicht auf dem Os saerum zwischen diesem und der Fascia recti. Endlich konnte Gerota (ähnlich wie Quény und dessen Präparator Manson) 2 mal unter 20 Fällen von der Mucosa ani aus mehrere kurze Stämmehen injiciren, welche in dem einen Falle zwischen Musculus levator ani und der Beckenfascie aufwärts 
strebend in einer Drüse am Foramen ischiadicum maius endeten, in dem anderen Falle mit der Art. haemorrhoidalis media verlaufend an deren Ursprung ihre Drüsenetappe fanden. Quény und Gerota bezeichnen diese schwer zu injicirenden Bahnen als Vasa lymphat. haemorrhoid. media. Damit würde auch hier Mascagni's allgemeine Angabe, dass die Lymphbahnen der Pars analis recti in den tiefen Beckendrüsen ihre erste Unterbrechung finden, für einen Theil der Fälle wenigstens zu Recht bestehen.

\section{Mikroskopische Untersuchungen über den feineren Ban der Lymph- bahnen des Uterus und seiner Anhänge.}

Während die Blutgefässe ein in sich geschlossenes Röhrensystem bilden, stellt das Lymphgefässsystem gewissermaassen einen seitlichen Anhang desselben dar. Aus blind endigenden, mit Endothel ausgekleideten Räumen entstehend, wächst es allmählig zu venenähnlichen Stämmen (mit Intima, Media und Adventitia) an, welche sich sammeln und in das Venensystem ausmünden. Wie die Lymphbahnen die Blutgefässe umstricken, so haben andererseits auch die grösseren Lymphstämme ihre arteriellen und venösen Capillaren, wie dies bereits Mascagni experimentell durch Contrastinjectionen erwiesen hat. Im Allgemeinen aber sind Blutgefässe und Lymphlacunen im Körper räumlich getrennt. Die aus den Blutgefässen in die Gewebe übertretende Flüssigkeit: „das Ernährungsplasma" muss also auf dem Wege vom Blutgefäss zum Lymphcanal entweder diffundirend die trennende Gewebsschicht durchsetzen oder in feinen endothellosen Saftspalten die einzelnen Zellorganismen umspülen. Ueber das Verhältniss der feinen Lymphcapillaren zu den fraglichen Saftspalten, ja über die Existenz dieser letzteren ist viel geschrieben und gestritten worden. - A priori sollte man eine Diffusion durch eine Endothelmembran für gleich wahrscheinlich halten, mag sie nun einem Blut- oder einem Lymphgefäss angehören, $d . h$. den Vorgang der Diffusion durch geschlossene Gefässwände, den man für die Blutgefässe annimmt, auch für die Lymphbahnen als die Regel annehmen. Der Sachverhalt liegt aber bei den Lymphbahnen insofern anders, als man hier mit dem Vorkommen von danernden Stomata rechnen muss. Zum mindesten sind dieselben für die serösen Hänte durch v. Recklinghausen's klassische Arbeit über die Fettresorption sichergestellt. Indessen sind die Ansichten über die sonstigen Körperregionen noch sehrr getheilt, so dass z. B. Bonnet-Greifswald, wie uns Polano mit- 
theilt, die Frage folgendermaassen charakterisiren konnte: „Entweder bilden die Lymphgefässe (-Capillaren) ein in sich geschlossenes System gegen die Saftlücken oder -Spalten im Bindegewebe und nehmen die Lymphe durch Diffusion auf, oder sie sind dauernd offen, oder sie öffnen sich vorübergehend durch Dehiscenz zur Aufnahme der Lymphe, z. B. die Stomata am Zwerchfell. Möglicher Weise kommen alle 3 Anordnungen neben einander vor.

Aehnliche Streitfragen schweben bezüglich der Entwicklung der Lymphgefässe. Entgegen Gulland und Saxer, welche die Lymphbahnen auf eine Erweiterung von Mesenchymspalten mit Auskleidung flacher Zellindividuen zurückfübren, wobei schliesslich jede Bindegewebszelle zum Endothelindividuum werden könnte, lässt Ranvier die Lymphgefässe als Anfangs solide, später hohle Epithelsprossen aus dem Venensystem hervorgehen.

Gulland und Saxer sahen bei Schaf- und Rindsembryonen die ersten subcutanen Lymphgefässe als primitive Mesodermspalten, welche zwar von Endothel ausgekleidet waren, aber noch keine zusammenhängenden, Gefässe bildeten. Ranvier dagegen konnte bei Schweineembronen unter $9 \mathrm{~cm}$ Länge die Lymphgefässe überhaupt nicht injiciren. Dagegen glaubte er bei älteren Embryonen am Mesenterium ein distal fortschreitendes Wachsthum der Lymphgefässe durch erst solide; später hohle Sprossen beobachtet zu haben. Ranvier nimmt daher an, dass die Lymphgefässe vom Venen. system aus in ähnlicher Weise distal fortwachsen wie eine Drüse mit verzweigtem Gangsystem von einer Schleimhautröhre ans. Damit würden die Lymphbahneu ron den Saftspalten prineipiell verschieden sein und ihr Endothel ebenso different von den Bindegewebszellen, wie das der Blutgefässe, welches man ja als Epithelabkömmlung anzusehen neverdings immer mehr geneigt wird. Ranvier's Annahmen sind im Uebrigen noch keineswegs allgemein erwiesen.

Noch eine kuræe Bemerkung über die sogenannten perivasculären Lymphräume, wie sie inbesondere durch His im Centralnervensystem nachgewiesen worden sind. Polano hat neuerdings das Interesse an dieser Frage wieder angeregt, und so ist wohl ein Hinweis auf die modernen Anschaungen der Anatomen berechtigt. Ich bognüge mich mit der Feststellung, welche ich A. Kölliker's Handbuch der Gewebclehre 1902. III. Bd. S. 689 und S. 690 entnehme, dass diese perivasculären Räume - als "Blutplasma" führende Spalten - nicht mit den perivasculär angeordneten "Lymph- 
gefässen " anderer Körperregionen zu vergleichen sind; die letzteren umstricken seitlich anliegend die Blutgefässe, indem die kleineren Lymphröhren sich nm die grösseren Blutgefässe spiralig herumwinden, aber die Blutgefässe haben keine Lymphscheide in dem Sinne, dass das Blutgefäss in einem grösseren Lymphgefäss stecken sollte. Eine wahre Einscheidung von Blutgefässen durch Lymphräume kommt nach Ebner (Kölliker) nur im Mesenterium des Frosches vor.

Die histologischen Untersuchungen scheinen eher dafür zu sprechen, dass gerade beim Menschen das Lymphgefässsystem allseitig gegen die sogenannten Saftspalten abgeschlossen ist. Von eigentlichen Poren oder Stomata im Sinne von v. Recklinghausen ist beim Menschen weder am Peritoneum des Zwerchfells noch sonst an einer serösen Haut etwas nachgewiesen worden. ${ }^{1}$ ) Ueberall, wo Lymphgefässe des Zwerchfells Aussackungen nach der Peritonealoberfläche hin treiben, liegt über der Seitenöffnung zum Mindesten noch eine Schicht von Epithel- bezw. Endothelzellen. Wenn allerdings die sogenannte interepitheliale Kittsubstanz im Sinne Flemmings (Anatom. Hefte Bd. 6 p. 1) als von Flüssigkeit erfüllte Lücken anzusehen sind, so gäbe dies eine plausible Erklärung für die Thatsache der Säfteströmung und Zellwanderung aus einer serösen Höhle in die andere und in die Substanz der in der Höhle liegenden Organe hinein.

Die Experimente scheinen dies auch für unsere Region $z u$ bestätigen. - Kraus und $\Delta$ mann benutzten die von v. Recklinghausen eingeführte Vethode, die Lymphzellen der Peritonealflüssigkeit durch Tuscheinjection ins Abdomen zu kennzeichnen. Kraus fand die geschwärzten Wanderzellen subepithelial im Eierstocksgewebe. Amann lockte sie durch intrauterin einverleibte, leukotactische Emulsionen durch die Serosa in die Gebärmutterwand bis in die Muscosa, ja bis ins Cavum uteri.

Ebenso wie am Peritoneum des Zwerchfells bei den Injectionen Farbflüssigkeit ohne Zerstörung des Gewebes an die freie Oberfläche tritt, so konnte wohl jeder Untersucher an der Serosa uteri ein ähnliches Verhalten beobachten, und wie ich vorwegnehmen möchte, an der Mucosa uteri verhält es sich ähnlich. Es scheint somit, dass die Lymphbahnen an den Körperoberflächen je nach Bedingungen bald geschlossen, bald an gewissen Stellen durchgängig sein können

1) Vergl. Köllikers Handbuch d. Gewebelehre. 6. Aufl. III. Bd. S. 688. Areliviv f. Gynäkoiogie. Bd. 73. H. 1. 
- oder kurz gesagt, dass sie ein Porensystem mit guter Schliessregulirung besitzen. $O b$ der Befund von besonders gearteten Zellgruppen im Oberflächenverband (S. Kölliker l. c.) schon eine Art von Schliesszellenapparat garantirt, wie er in der Pflanzen-Epidermis vorkommt, wird sich schwer erweisen lassen. Man kann eben die v. Recklinghausen'schen Versuche über Fettresorption am Kaninchenzwerchfell nicht am lebenden Menschen anstellen.

Für das Vorhandensein von Lymphporen spricht immerhin die Selbstinjection des menschlichen Peritoneums. Schon den alten Anatomen (Mascagni) war diese Eigenschaft bekannt. Bringt man in die geschlossene Bauehhöhle eines Menschen 12 bis 36 Stunden nach dem Tode eine Farblösung (Aufschwemmung von Tusche, Ocker, Zimnober in heissem Wasser) so zeigen sich nach einigen Stunden Lymphnetze mit den Farbpartikelehen angefüllt auf dem Zwerchfell, auf der Leberoberfiäche (zuweilen auch, wie ich mich überzeugen konnte, im Douglas am breiten Ligament und an der Beckenhinterwand).

Anch Kölliker sah an herausgeschnittenen Zwerchfellstückchen des Kaninchens die Selbstinjection, und letztere findet nach seiner Erfahrung noch statt unter widrigen Druckverhältnissen. Ist nicht das Entstehen und Aufsaugen grosser Exsudate, welches in relativ kurzer Zeit vor sich gehen kann, ein weiterer Wahrscheinlichkeitsbeweis für die Annahme eines facultativen Porensystems. Zum mindesten wird der Vorgang dadurch mechanisch verständlich.

Alle diese zumeist am Peritoneum angestellten Versuche und Beobachtungen scheinen dem Lymphgefässsystem des Bauchfells, obwohl es mit den Isymphräumen aller Bauchgefässe breit communicirt, eine gewisse charakteristische Eigenthümlichkeit, eine Art Selbständigkeit zu sichern. Die Erfahrungen der pathologischen Anatomen decken sich damit. Wir wissen, dass der Krebs, mag er rom Magendarmtractus, oder vom Uteruskörper, oder vom Ovarium ausgehen, sobald er in breiterem Umfange die Serosa erreicht hat, einen eigenthümlichen Verbreitungsmodus annehmen kann, den wir mit allgemeiner Bauchfellcareinose bezeichnen: Auch der Kliniker ist geneigt, das Bauchfell als Organ za betrachten. Der Chirurg reehnet mit seiner Leistungsfähigkeit bei jedem operativen, intraabdominalen Eingriff. Ihm ist manche postoperative Exsudation eine rettende Secretion, z. B. bei der Bauchfelltuberculose. Diese Secretion "des heilenden Serum" und die Resorption, auf welche Kraft wir ja oft bauen, werden anatomisch für mich 
wenigstens' durch den eigenartigen Bau des Lymphgefässsystems in eclatanter Weise erläutert.

Auch im Bereich der Beckenorgane hat die Serosa ihre eigenen Lymphbahnen (vergl. den Abschnitt über die Lymphbahnen der Blase! Fig. 1).

Injectionsversuche zur Anstellung histologischer Untersuchungen sind am Uterus systematisch nur von Leopold gemacht worden. Die von letzterem citirte Arbeit Lindgren's liegt mir im Original nicht vor. Das, was in den Referaten über Lindgren's Schilderung der Collum-Lymphbahnen gesagt wird, kann von mir nicht bestätigt werden.

Leopold untersuchte eine grosse Anzahl Uteri von Thieren (Schaf und Schwein) und menschliche Uteri der verschiedensten Jahresklassen. Die präformirten Jymphspalten der Serosa sind auf seinen Bildern stellenweise sehr schön dargestellt.

Die mikroskopischen Bilder injicirter Schnitte stammen zum grössten Theil von thierischem Material mit Ausnahme von Fig. 8 (Schnitt aus der Muscularis uteri mit Injection der Lymphund Blutgefässe), welche eine gute Anschauung von der Gefässvertheilung in dem Myometrium gewährt.

Leopold's Anschauung, dass die Mucosa uteri ein flächenhaft ausgebreiteter Lymphsinus sei, in welchem nur Blutgefässe und Epithelschläuche eingebettet seien, bedarf einer Ergänzung.

Die Lehre rom adenoiden Bau des Stroma mucosae uteri, dessen Maschen einen äusserst variablen Gehalt an Wanderzellen aufweisen können, ist so fest in unserer Vorstellung geworden; dass ich darüber kein Wort zu verlieren brauche. Aber wir müssen Leopold's sinnreichen Gedanken ergänzen: "Die Mucosa uteri hat wie jede Lymphdrüse ein wohl entwickeltes System präformirter Lymphbahnen, welches an Reichhaltigkeit dem des Myometriums gleichkommt. Die übereinstimmenden Resultate von Sappey, Poirier and neverdings von Bruhns haben dies zur Genüge erwiesen. Meine eigenen Befunde mit dem Aether-Campher-Farbverfahren sollen in Wort und Bild die neuere Anschauung illustriren. Um die Schleimhautbahnen durch Injection zu füllen, muss man sehr flache Einstiche machen und mit ganz gleichmässigem Druck injiciren. Trotzdem gelingt es sehr selten, grössere Schleimhautflächen gleichmässig gut zu füllen. - Bald entsteht bei zu starkem Druck ein diffuses Extravasat, bald läuft die Injectionsmasse in die tiefen Bahnen und spritzt eher an den Schnittwunden 
des Uterus und der Ligamenta im Strahl heraus, als dass sie in die Schleimhaut dränge. Ich habe eine Zeit lang jeden exstirpirten Uterus in allen Schichten injicirt, bis ich endlich die gewünschten Bilder in genügender Klarheit erhielt. Auch hier empfiehlt es sich, die Blutgefässe mit Contrastfarben (mit Carminleim oder -Gelatine) zu injiciren. Doch genügt auch die einfache Injection der Lymphbahnen, um letztere von den leeren Bluträumen zu unterscheiden. Wenn man übrigens die Schnitte mit Pikrocarmin-Pikrinsäure färbt und etwa 10 Minuten lang in wässeriger Eosin-Lösung mit OrangeG-Zusatz nachbehandelt, erscheinen dje Blutpfooppfe in den braunrothen Gefässen leuchtend roth, jedenfalls different von den blau injicirten Lymphcanälen. Hämatoxylin-Tinction mit van Gieson Nachfärbung empfiehlt sich nur bei sehr gesättigter Injeetionsfarbe, weil doch die Leuchtkraft des Preussisch-Blau durch das Bämatoxylin beeinträehtigt wird.

Für das Studium und die Auswahl der mikroskopisch zu untersuchenden Stellen empfiehlt es sich, in jedem Falle eine genaue Lupenbetrachtung der Präparate vorzunehmen. Ferner untersuche ich regelmässig dünne Scheiben (Rasirmesserschnitte) nach Aufhellung in Xylol mit schwachen Objecten und erhalte gerade hierbei die schönsten Bilder, weil die Bahnen verschiedener übereinander liegender Schichten zugleich sichtbar werden, und somit das Bild zugleich körperliche Anschauung von den Raumverhältnissen gewährt. - Was nun zunächst bei oberflächlicher Lupenbetrachtung der injicirten Mucosa auffält, ist die Differenz in der Weite der Corpus- und der Cervixlymphbahnen: im Corpus fand ich engmaschige Netze von breiten Lacunen, welche namentlich an den Knotenpunkten sich erweitern, in der Cervix dünne, am unaufgehellten Gewebe oft schwer sichtbare Canäle, deren Anordnung auch nicht so regelmässig ist, wie die in der Körperschleimhaut. Die Hauptsammelstämme lanfen in den Mittelpfeilern der Plicae palmatae, und za diesen strömen die feinen Netze aus den dazwischen liegenden, vertieften Nischen. Die ron Poirier dargestellte, gleichmässige Netzformation, welche nach seinen schönen Abbildungen auch in der Cervix ohne Rücksicht auf die Architektonik der Plicae palmatae sich zeigt, scheint wohl nur bei Quecksilberinjection zu resultiren. Die Injection führt fast immer zu einer Ueberdehnung, wahrseheinlich bei dem sohwer flüssigen Quecksilber (Poirier) mehr als bei den Aether-Campher-Lösungen.

Fig. 10 giebt die Lymphverhältnisse in der Cervical- 
schleimhant und der inneren Muskelschicht wieder. Die Lymphcapillaren - überall mit Endothel ausgekleidet - dringen bis an die Oberfläche und umspinnen die Drüsen mit zarten, sehr engen Lacunen, die za einem Netz von oft bizarren Formen zusammenfliessen. An der Oberfläche wie an den Drüsen liegen diese feinen Lymphspalten dicht unter der Epithellage bezw. unter deren Grenzlamelle gegen das Stroma hin. Im Allgemeinen ist man erstaunt über die Engigkeit der Capillaren. Sie umgeben in ihren Anfangsnetzen die Drüsen und die oberflächlichen Gefässe (vergl. Fig. 10) und breiten sich dann in der Grenzschicht zwischen Mucosa und Muscularis interna in mehr längs, d.h. parallel zur Oberfläche verlaufenden Bahnen aus. Letztere (t. S. Lb. Fig. 10) sind bereits etwas an Umfang gewachsen und ergiessen sich in ziemlich starke, perforirende Canäle (p. im Lb. Fig. 10), welche die Muscularis durchbrechen und zu den grösseren Blutgefässen in der äusseren Muskelschicht hinstreben. Fig. 10 erläutert auch das Verhältniss der Lymphcapillaren zu derı kleineren Gefässen, welches überall im Genital-System von der Vagina angefangen bis zum Ovarium und zur Tube - sei es in der Schleimhaut oder in der Muskelschicht - constant bleibt. Die Blutgefässe werden von den Lymphbahnen umsponnen, aber nicht eingescheidet. Auf dem Querschnitt kann sich das spiralig sich windende Lymphgefäss als sichelförmiges Lumen um das Blutgefäss herumlegen, aber eine Wandpartie des Blutgefässes bleibt stets in continuo mit dem Gewebe der Unterlage.

Die perforirenden Lymphgänge (p. im Lb. Fig. 10) streben im äusseren Drittel der Cervixwand entsprechend der Verlaufsrichtung der Uterinatheiläste schräg nach aufwärts zur Anheftungsstelle des Peritoneums, d. h. zur Austrittsstelle der Venae uterinae. Die Venen können je von 2 und mehr Lymphstämmen begleitet werden. -

Seitlich oberhalb des Scheidenansatzes an der Cervix mischen sich mit diesen cervicalen Bahnen ähnliche, welche von der angrenzenden Scheide im subvaginalen Gewebe stets in Begleitung der Venen heraufsteigen: "Die Lymphstrasse im subvaginalen Gewebe steht in breiter Communication mit dem Abflusssystem der Cervix. Das bekannte Bild Poirier's (die Lymphgefässe des Collum uteri) giebt eine gute Vorstellung von dem Reichthum der ausmündenden Lymphbahnen, welche sich an der Wurzel des breiten Ligaments in jene 5 oder mehr definitiven Stämme ergiessen, über deren Verlauf bereits oben zur Genüge berichtet worden ist. 
Im Ganzen und Grossen bestimmt die Architektonik der Musculatur den Verlauf der Lymphgefässe. Schon im Collum uteri zeigen die Lymphcapillaren das Bestreben gewissermaassen in jeder Etage nach allen Seiten Anastomosen zu bilden. Nur lassen sich nicht alle gleichmässig gut injiciren, offenbar wegen der Engigkeit der Röhren.

Um so schöner lässt sich diese Eigensehaft der Parenchymbahnen im Corpus uteri nachweisen (verg]. Fig. 7-11). In allen Schichten kann man auf Sagittal- wie Horizontal- oder Frontalschnitten das Lymphbahnsystem mit einem Netz vergleichen, in welchem freilich die Lacunen einer bestimmten Richtung als die weitesten und somit als die Hauptbahnen imponiren, d. h. die Lymphe hat in jeder Region ihre bestimmte Stromrichtung, aber Sicherheitsventile bestehen nach allen Seiten hin.

Die Betrachtung der durch die Zeichnungen wiedergegebenen Bilder illustrirt ganz besonders den Vorzug der dicken Vebersichtsschnitte bei Xylolaufhellung gegenüber den dünnen Paraffin- oder Celloidinschnitten, welch' letztere zum Studium der Endothelverhältnisse unerlässlich sind. Die in Xylol aufgehellten Schnitte aus der Mittelschicht des Myometriums (Fig. 7) geben ohne die Nothwendigkeit weiterer Erklärungen die beste Vorstellung von der regelmässig netzlörmigen Verbindung der intermusculären Lymphgefässe, welche zum grossen Theil unabhängig von den Blutgefässen verlaufen. Dabei bleibt freilich der Satz bestehen, dass die Blutgefässe (Venen) stets von Lymphbahnen begleitet sind.

Je grösser das Oaliber des Blutgefässes, um so mehr nehmen auch die Lymphbahnen das Aussehen von dünnen Venen an, d. h. die grösseren Venen werden eben von 2 oder mehr Sammelröhren begleitet. Ausserdem bekommt man zuweilen an oder sogar in der Venenwand feine Jymphcapillaren, zu Gesicht; endlich erinnere ich noch an die zahlreichen Bilder in der Nähe kleinerer und mittlerer Blutgefässe, welche als perivasculäre Sicheln seit v. Recklinghausen's Untersuchungen (Seelig) allgemein bekannt sind.

Mit den gröberen Lymphsträngen, we]che das oben geschilderte Netz zwisehen dem Geflecht der innig miteinander verwebten Muskelbalken bilden, stehen feine und feinste Lymphcapillaren in Verbindung, welche in die Muskelfelder, oder besser gesagt -Bündel eindringen und die kleinen Solitärfaseikel umstricken. Dieselben - theoretisch von manchen Beobachtern nach Analogie der Blut- 
capillaren angenommen, - - konnte ich $1 \mathrm{Mal}$ in der an die Mucosa corporis angrenzenden Schicht darstellen. Fig. 11 (nach einem Gefrierschnitt gezeichnet) zeigt mehrere Bildebenen übereinander, sodass man an zahlreichen Stellen die Capillaren als wirklich präformirte Röhren verfolgen kann. Der gefärbte Campher hat sich nur an den Wänden niedergeschlagen und wie eine Endothelbeize auch die Endothelien gezeichnet. Der Querschnitt dieser Röhren ist stets kreisrund und lässt an der Peripherie Kernzeichnung erkennen. In Folge der von der Mucosaseite her unter starkem Druck erfolgten Injection sind die Lymphbahnen der Schleimhaut und der submucösen Grenzschicht stark dilatirt (wohl zumeist Kunstproduct). Immerhin sind an allen von mir beobachteten Schnitten in der submucösen Grenzschicht wie in den äusseren, subserösen Muskellamellen die Parenchymbahnen stets weiter, als die Lacunen der übrigen Wandbestandtheile. In beiden Regionen können Krebse, wie wir sehen werden, zuweilen auffallend rasch vordringen. Wiederum dictirt der specifische Bau des Organs die Verlaufsrichtung der Parenchym-Lymphbahnen. In der lockeren, submucösen Schicht sowie im subserösen Gebiet steigen Lymphstrassen auf- und abwärts, sie verbinden sich gegenseitig durch Queranastomosen nach rechts und links, nach vorn und hinten. Die Verlaufsrichtung bleibt immer parallel der Oberfläche - sei es der Innenfläche - sej es der Aussenfläche des Organs. Die zwischen diesen beiden geräumigen Systemen sich ausbreitenden Muskelbahnen stellen dagegen perforirende Gänge dar, welche sich, radiär von innen nach aussen strebend, durch das Gewirr der Muskelbündel hindurchwinden und gewissermaassen senkrecht in die längsverlaufenden oberflächlichen Lacunen einmünden.

Ebenso müssen die aus der Mucosa corporis sich sammelnden Bahnen senkrecht $z u$ den Längsbahnen der submucösen Grenzschicht verlaufen, da ihnen in dem adenoiden Schleimbautstroma nur von den Uterindrüsen die Verlaufsrichtung zudiktirt wird. An der Oberfläche des Cavum uteri beginnen diese feinsten, ausserordentlich zahlreichen Canäle als feines Gewirr, dessen Maschen sehr eng sind; die senkrecht zur Schleimhautoberfläche in die Tiefe ziehenden Röhren werden um so geräumiger, je mehr sie sich der submucösen Schicht nähern. Im Uebrigen ist die Zahl der Anastomosen in der Schleimhaut erstaunlich gross; man kann auch hier im Allgemeinen nur sagen, dass die Lympheapillaren die Uterindrüsen wie die Gefässe umspinnen, ohne letztere einzuscheiden. Fig. 9a 
und b zeigt im Sagittal- wie im Frontalschnitt den Reichthum der Schleimhautlymphnetze. Fig. 9a lässt zugleich erkennen, dass die Bahnen sich an der Oberfläche dicht unter dem Epithel, oder vielleicht in demselben frei öffnen. Hier tritt mit Leichtigkeit Injectionsmasse aus, hier wird andererseits ebenso leicht Inbalt des Cavum uteri eingesogen werden können. Fig. 8 a demonstrirt ferner den Zusammenhang der Muskelbahnen des Uterus mit dem feinen Serosa-Lymphnetz. Die Serosa besitzt also wie überall so auch auf dem Uterus ihre eigenen Lymphcapillaren, welche an zahlreichen Stellen an der abdominalen Oberfläche frei enden. Welche Wichtigkeit dieser Umstand für das Verständniss manches puerperalen Infectionsverlaufes hat, liegt wohl klar auf der Hand.

Die bereits von Leopold geschilderten ampullären Räume, welche in den Verlauf der Serosalymphbahnen unmittelbar unter der Oberfläche in regelmässigem Abstand von einander eingeschaltet sind, fand ich in allen dünnen Schnitten.

Noch einige Bemerkungen zu der sogenannten Gefässschicht, welche ron Seelig an der Grenze, zwischen dem mittleren and äusseren Drittel des Myomotriums angenommen wird. Eine constante Gefässschicht fand ich zunächst nur an der Seitenkante des Lterus entsprechend dem Ansatz des breiten Ligamentes und auch hier vorwiegend an oder in der äusseren Muskelschicht, nioht aber ausschliesslich innerhalb der letzteren. Namentlich in der Cervix ist dieses Verhalten constant und ron Waldeyer (Das Becken, Fig. 80 b) in schöner Weise zur Darstellung gebracht. Siehe auch meine Fig. 22, welche nach einem Horizontalschnitt durch den Uterus etwas über der Höhe des inneren Muttermundes angefertigt ist.

Die parenchymatösen Lymphbahnen der Tube.

Die Lymphbahnen der Tube wurden bisher sehr stiefmütterlich behandelt. Die Tube ist in der That ausserordentlich schwer zu injiciren. Wie die Blutextravasate bei Stieltorsion oder Gefässarrosion bei Tubargravidität, so sucht die Injectionsmasse in dem subserösen und submucösen Stratum sich zerstörend ihren Weg, ohne in die engen Capillaren einzudringen; trotz zahlreicher Versuche erhält man immer und immer wieder dasselbe Bild, nämlich auf Querschnitten zwei dicke Ringe von Injectionsmasse, welche nach innen den Schleimhautcylinder, nach aussen die Serosa von der Muscularis abheben. Die Sohichten liegen also von 
aussen nach innen betrachtet, wie folgt: 1. Serosa, 2. Farbextravasat, 3. Muscularis, 4. Farbextravasat, 5. Mucosa! Dennoch gelang es mir, die Tuba Fallopii an Kinderleichen 48 Stunden post mortem von einem Portioeinstich aus zu injiciren (vergl. Fig. 3). Bei Erwachsenen führte der flache Einstich von der Mucosa der Tubenampulle aus zum Ziel. Eine Betrachtung des Querschnitts Fig. 12 (Lupenzeichnung) lehrt, dass die Lymphbahnen als relativ weite Lakunen im Innern der Tubenfalten beginnen. Sie umgeben auf Querschnitten sichelförmig die Blutgefässe und können bei Lymphstaung (z. B. bei Tubargravidität) die letzteren soweit umfliessen, dass die Blutgefässe halbinselförmig (auf Querschnitten) in das Lumen der Lymphgefässe hineinragen bezw. vom Innern der Lymphräume aus betrachtet in der Wand derselben als randständige Leisten sich geltend machen. An Flachschnitten, welche die Basis der grossen Tubenfalten truffen, sieht man ziemlich regelmässig die Sammelröhren dieser centralen Faltenbahnen (s. Fig. 13) eine Strecke weit längs verlaufend mit den Blutgefässen alterniren, sodass man oft 3 bis $4 \mathrm{mal}$ hintereinander Arterie - Vene Lymphgefäss abzählen kann. Im Gegensatz zu diesen ziemlich weiten Röhren sind die Muskelbahnen eng und lassen schwer den Endothelnachweis führen. Gerade hier tritt mit Vorliebe die Injectionsmasse aus den präformirten Bahnen zerstörend heraus. Natürlich finden sich auch in der Muscularis und zwar am antimesometralen, wie ganz besonders am mesometralen Rand der Tube stärkere, an kleine Venen erinnernde Lymphbahnen. Das aus dem vereinigten Schleimhaut- und Muskulaturlymphnetz hervorgehende, oberflächliche System in der Subserosa und Serosa ist wiederum sehr reich und zierlich gegliedert und gleicht im kleinen der betreffenden Schicht des Uterus (Vergl. Fig. 1 bis 3). Wenn man unter der Lupe die Serosa der injicirten Tube an einer Stelle einschneidet und abzieht, so bleibt ein Theil der Bahnen an der Serosa, ein anderer Theil auf der Muscularis haften, and man sieht beim weiteren Ablösen der Serosa kleine Stämmchen, welche sich in die Muscularis perforirend hineinsenken, zwischen Serosa und Muscularis sich anspannen, sowohl an der Vorder- wie an der Hinterfläche der Tube. Die subserösen Lymphnetze beider Flächen reichen sich über die freie Tubenkante die Hand - sie gehen in einander über. Nach der Mesosalpinx zu vereinigen sich die zahlreichen kleinen Bahnen der Pars isthmica und ampullaris in 2, seltener in 3 mit Klappen versehene, abführende Stämmchen, welche mit dem Plexus oraricus 
zu den Lgl. lumbales superiores ziehen. Der Tubenmund mit seinem Fimbrienkranz entsendet ein eigenes Gefäss. Polano fand auf der Fimbria ovarica tubae bei Einstichen vom Ovarium aus eine Schleifenbahn. - Ich selbst sah auch bei Tubeninjectionen Communicationsstränge an dieser Fimbria entlang ziehen.

Die Pars keratina tubae führt ihre Lymphe zum Uterushorn $a b$, von dem aus sie auch gewöhnlich sich mit injiciren lässt.

\section{Die Parenchymbahnen des Orarium}

sind in letzter Zeit von Polano ausführlich geschildert worden, und kamn ich mich dementsprechend kurz fassen. Ich selbst habe nur wenig Ovarien injicirt und kann fast in allen Purkten die Erfahrungen Polano's, z. Th, auch die von Sappey bestätigen. (Bruhns berührt nur die ableitenden Stämme des Eierstocks.)

In der Albuginea fand ich feinste Lymphspalten nur an Stellen, von welchen in Folge von früherer Follikelberstung das feste Gefüge der äusseren, weissen Sehicht auseinandergefasert war. - Bei Ovarialcysten, welche vom Innern aus entstehend die parenchymatöse Schicht zu einer papierdünnen Hülle ausgezerrt hatten, sah ich am Ovarialpol zuweilen zierliche Oberflächennetze; wahrscheinlich schimmerten hier die tieferen Lymphgänge durch die verdünnte Albuginea durch. In der Zona parenchymatosa liegt der eigentliche Ursprung der feinsten Lymphspalten. Wie überall in den weiblichen Genitalorganen so konnte auch im Ovarium von keinem der neueren Untersucher ein System endothelloser Saftspalten nachgewiesen werden. Nach den übereinstimmenden Erfahrungen Aller sind bereits die teinsten Lymphcapillaren mit Endothel ausgekleidete, präformirte Röhren, welche aber erst am wachsenden Follikel für die Injection nachweisbar werden. An jedem injieirten Ovarium erkennt man unter der farblosen, weissglänzenden Albuginea die Zone der Primärfollikel, in welche nur wenig Bahnen sich hineinerstrecken. Die Primärfollikel scheinen noch keine Lympheapillaren zu besitzen.

In der tieferen parenchymatösen Schicht, in welcher sich die wachsenden Follikel finden, umspinnen die Lymphbahnen die Parenchymbestandtheile mit feinen Netzen, welche schon Sappey in klassischer Weise beschreibt. In der That gewährt die Lupenbetrachtung injicirter Follikel von ihrer Innenfläche aus die zierlichsten Bilder reich verzweigter Netze. Ich selbst konnte an dünnen Schnitten die feinsten Ausläufer dieser Netze bis in die 
Tunica interna einiger Follikel verfolgen. 3-4 Systeme von anastomosirenden Lymphgängen liegen nach aussen von der Tunica interna und externa in immer. weiteren Kreisbogen übereinander. Die Maschen werden nach aussen hin weitläufiger, und an der Grenze der Zona parenchymatosa gegen die Zona vascularis gehen daraus zahlreiche lacunäre Lymphbahnen hervor, welche nun entsprechend dem allgemeinen Gefässverlauf radiär zum Hilus ovarii streben.

In ähnlicher Weise wie die wachsenden Follikel werden auch die Graaf'schen Follikel, die Corpora lutea und deren Endproducte, die Corpora fibrosa (albicantia) von den Lymphcapillaren umsponnen, welche sogar in den bindegewebigen Kern der Corpora lutea und fibrosa vordringen. Nur das Stigma des sprungreifen Follikels verliert nach His, Waldeyer, Polano seine sämmtlichen Blut- und Lymphgefässe. Der Follikel hebt gewissermaassen an der Kuppe seine nackte Tunica int. aus dem Gefässgebiet heraus über die Oberfläche.

In der Zona vasculosa bekommen die Lymphbahnen mit dem Wachsen ihres Lumens ausser der Endothelauskleidung eine festere bindegewebige Wand und etwa im letzten Drittel ihres intraovariellen Verlaufes eine Muscularis nach Art zarter Venen. Die ersten Klappen finden sich schon im Hilus selbst, meist erst ausserhalb des Ovariums, im Mesovarium.

Von dem Reichthum des Eierstocks an Lymphbahnen macht man sich eine Vorstellung, wenn man auf fortlaufenden Querschnitten durch das injicirte Organ in jeder Schnittfläche zahlreiche blaue Spalten und Canäle verfolgt.

Die Lymphräume bleiben gerade in der Markschicht des Ovariums relativ selbstständig ohne Anlehnung an die kräftigeren Blutgefässe, und nur spärliche, dünne, sichelförmige Lumina winden sich durch die dichten Blutgefässknäuel. Erst kurz vor dem Hilus, wo alle Gefässe - ob Blut, ob Lymphe führend - zusammendrängen, sieht man die Lymphbahnen gewöhnlich den Venen an einer Seite flankirend anliegen. Es macht den Eindruck, als ob einige dieser injicirten Lacunen spiralig um die Venen herumlaufen.

So leicht die Injection von Kinderovarien aus die ableitenden Bahnen füllt, so schwer ist es andererseits, an solchen Kinderovarien trotz Injection die Entstehung der Lymphräume zu studiren. Jedenfalls sind auch hier präformirte Räume nachweisbar. In der Zone der Eiballen bilden dieselben ein mehr. radiär verlaufendes 
System gleichmässig enger Röhren, welehe sich durch die Parenchymbestandtheile winden und schlängeln, um in der Tiefe an der Grenze gegen die gefässreiche Markschicht in Beziehung zu relativ weiten, ampullären Sammelräumen zu treten, ans welchen dann die ableitenden Stämme hervorgehen. Von letzteren erwähnten wir bereits, dass sie (nach Bruhns) 6 bis 9 an der Zahl ans dem Hilus ovarii treten und im freien Rande des Ligam. ovariopelvicum mit den Vasa spermatica zu den L. gl. lumbales superiores ziehen. Die von Poirier gefundene Anastomose zwischen Ovarialund Corpusbahnen am $\nabla$. Lumbalwirbel konnte auch ich nicht nachweisen. Die von Polano vom Ovarium aus injicirten Lymphcanäle in der Fimbria ovarica und im ligamentum ovarii medianum konnte ich ron der Tube bezw. vom Uterus her, also in umgekehrter Richtung, darstellen, so dass ihr Bestand wohl gesichert ist. Auch hier stehen die Parenchymbahnen unter dem Gesetz weitgehender Anastomosen.

Die vorzüglichen Abbildungen Polano's machen es unnöthig, meine eigenen Präparate abzubilden, da ich Wiederholungen vermeiden möchte. (Die abführenden Stämme siehe auf Fig. 2!)

\section{Die ableitenden Bahnen und die zugehörigen Lymphdrïsen.}

Während die parenchymatösen Bahnen also miteinander zahlreiche Anastomosen bilden, bleiben die abführenden Stämme aller Regionen bis zur 1. Etappe der zugehörigen Lymphdrüsen unverzweigt. Das charakteristische Aussehen der abfübrenden Stämme, welches man treffond mit "Rosenkranzform" bezeichnet hat, ist verursacht durch die zahireichen Klappen, welche nach Art der Venenklappen in regelmässigen Zwischenräumen das Lumen der Canäle unterbrechen und das Kaliber von aussen her eingeschnürt erscheinen lassen. Die Klappen öfnen sich nach dem Venensystem zu. Zwischen je zwei aufeinander folgenden Klappen buchtet sich das Lymphgefäss seitlich aus. Diese Aussackungen lassen sich eben mit den Perlen eines Rosenkranzes vergleichen. Bringt man nach gelungener Injection eines Uterus das herausgeschnittene breite Ligament aufgehellt in Xylol unter eine Lupe, so zeigen sich die Wandverhältnisse der im Ligament verlaufenden Stämme. Die Zeichnung der Lymphgefässcontouren durch die Aetherkampferfarbe ist so zierlich, dass der beste Zeichner kaum im Stande ist, sie wiederzugeben. In den mikroskopischen Schnitten gleichen die ableitenden Bahmen den kleinen Venen. Nur haben sie viel zahl- 
reichere Klappen und eine schwächere Tunica media, die oft den Eindruck macht, als wäre sie zerrissen und gewissermassen liederlich angeordnet. Der Grund dafür liegt in einer Eigenthümlichkeit, welche Flemming aufgeklärt hat. Statt einer geschlossenen Media können zahlreiche Jymphstämme nur ein Geflecht verzweigter, glatter Muskelfasern aufweisen, zwischen welchen in der Aufsicht leere Lücken ausgespart bleiben. Flemming konnte aus der Media soleher Lymphgefässe verzweigte glatte Muskelfasern mit 2 oder mehr Zipfeln jsoliren.

In einiger Entfernung vom seitlichen Rande des Uterus zeigen sich zuweilen im aufgehellten Ligam. latum kleine gelblichbraune Knötchen, welche mit der blanen Injectionsmasse mehr oder weniger wie gesprenkelt sind; man findet sie im Verlauf der Vasa uterina an der Vereinigungsstelle von breitem Ligament und Parametrium. Es sind dies die in letzter Zeit vieigenannten parametranen Lymphdrüsen, die ich als Noduli lymphatici parametranes bezeichnen möehte. Die Verschiedenheit im Bau dieser Lymphknoten, welche von Mohnkorn- bis zu Haselnussgrösse schwanken, erhellt aus Fig. 17 und 18. In Fig. 17 enthält das Parametrium, soweit es am Uterus geblieben ist, jederseits nur eine Drüse, welche aber mikroskopisch bereits dem Aussehen einer richtigen Lymphoglandula nahekommt. Beiderseits waren fast auf allen untersuchten Schnitten 3 bis 5 Randfollikel neben zahlreichen Marksträngen zu erkennen. In Fig. 18 erscheinen im Verlauf der Art. uterina ausser den zwei zugehörigen Venen, von denen die vordere durch einen Thrombus verschlossen ist, und einem sympathischen Ganglion $\mathrm{g}$ mit Nerv 3 kleine Noduli lymphatici von einfachstem Bau. Es sind adenoide Gewebsherde ohne besondere Differenzirung, welche wie Pilze ins Lumen der Lymphbahnen ragen, obne dasselbe zu unterbrechen. Eine Besonderheit zeigt nur das äusserste der drei Knötehen, indem bei diesem das zugehörige Lymphgefäss an einer Wandseite auch von aussen her mit adenoider Substanz bekleidet wird. Das Vas afferens spaltet sich gewissermassen, um das Lymphknötchen zu umfassen; dabei löst sich aber die vordere Wand auch nach aussen vom Lymphsinus in einen adenoiden Mantelsaum auf. Der Lymphknoten erinnert zwar noch sehr an die einfachen Noduli lymph. z. B. des Darmes oder der Respirationsschleimhaut, leitet aber durch Grösse und Andeutung besonderer Randfollikel zu den wahren Lymphdrüsen über. Die nächste Stufe der Entwicklung würde dann durch die Drüsen in Fig. 17 markirt. 
Vielleicht lohnt es sich, hier Einiges über die Entwickelung der Lymphdrüsen einzuflechten. Schon früher, gelegentlich meiner Dermoidstudien, war mir der charakteristische Unterschied in dem Verhalten der Noduli lymph. zu den fertigen Lymphoglandulac aufgefallen. Die ersteren liegen dem Lumen der Lymphgefässe seitlich an, die letzteren unterbrechen wie ein Sieb die Lymphbahn. Die einen sind für den Lymphstrom so gut wie keine Hindernisse, da er sie nur an der Oberfläche benetzt, während die wahren Lymphdrüsen als richtige Stromunterbrecher die Lymphe filtriren, indem sie den Strom durch eine Art Wundergeflecht leiten. Gulland und Saxer, welche die Entstehung der Lymphdrüsen bei Thierembryonen verfolgten, geben an, dass die primären Lymphspalten von dem zur Lymphdrüse werdenden, adenoiden Knoten genau so eingestülpt werden, wie die Harncanälchen durch einen embryonalen Nierenknäuel. Oeffnet sich die Gelässwand an der dem Knoten anliegenden Partie, so ragt der adenoide Keim wie ein Pilz ins Lumen des Lymphgefässes, und wir haben das einfache Verhältniss der Noduli lymphatici yor uns. Dass sich diese Noduli ohne selbstständigen Sinus nicht nur im Parametrium der Neugeborenen finden, sondern auch in dem der Erwachsenen erhalten bleiben, ist nichts Wunderbares, zumal doch der Körper an zahlreichen Schleimhantstellen dieselben Primärfollikel zeigt. Vjelleicht geben solehe Knötchen, die man auch in der Nähe der grossen Lymphdrüsen findet, die Erklärung für die Regeneration von Lymphdrüsen nach entzündlicher Verödung der Nachbardrüsen ab. Drüsenneubildung bedentet dann nur ein Auswachsen sehon vorhandener Anlagen.

Das Verhältniss des Primäriollikels zum Lymphgefäss bleibt ziemlich lange bestehen. Erst spät wachsen im embryonalen Leben in dem primitiven Randsinus, d. i. der Spaltraum zwischen Follikelsubstanz und freier Gefässwand, adenoide Bälkchen und Stränge von der Follikeloberfläche zur Gefässwand hinüber: „Der Sinus wird gegliedert". Der dem Sinus abgekehrte Pol lässt die Blutgefässe aus- und eintreten. Lassen wir in unserer Phantasie den Lymphknoten wachsen und sich mit immer nea entstehendem Gewebe in den Sinus vorbuchten, so werden wir endlich auf das Schema Fig. 19 kommen, welehes die vatürlichen Verhältnisse einer kleinen Beckenlymphdrüse wiedergiebt. Die aufgeblätterte, gedehnte Gefässwand der ersten Anlage ist nun zur Drüsenkapsel geworden, welche die schon ansehnliche Drüse bis zum Hilus umfasst. Am convexen Pol mündet das Vas afferens - nun ein kleines Gefüss 
im Verhältniss zu dem inzwischen mächtig gedehṇten Randsinus. Aus dem concaven Drüsenhilus des bohnenförmigen adenoiden Körpers tritt das Vas efferens heraus zugleich mit der Vene; an derselben Stelle strebt die Hauptarterie hinein, um sich im adenoiden Gewebe zu verzweigen (im Schema No. 19 nicht ausgezeichnet!). Auch die Kapsel mit den Trabekeln hat ihre Blutgefässe, welche aber vom convexen Pol mit dem Vas afferens herantreten. Es sind die Vasa nutricia der zur Drüsenkapsel gedehnten Gefässwand. Die von der Kapsel ausstrahlenden Stütztrabekel sind beim Menschen gewöhnlich sehr zart; sie theilen das eigentliche adenoide Parenchymgewebe in Randknötchen (Randfollikel) und bizarr gewundene centrale Balken, die sogenannten Markstränge. Denkt man sich nun zwischen adenoidem Parenchymgewebe und den Trabekelsepten überall einen lymphgefüllten Spaltraum $=$ den Sinus in "seinen Ausläufern", so erhellt daraus, dass in jedem Theil der Drüse stets die adenoide Substanz rom Lymphsinus umflossen ist, welch letzterer wieder von den Trabekeln bezw. der Kapsel begrenzt. wird.

Das Parenchymgewebe zeichnet sich durch ein sehr feines Reticulum aus, in dessen Maschen zahlreiche Lymphzellen der verschiedensten Werthigkeit lagern. Von der Oberfläche der Follikelund Markstänge spannen sich durch den Sinus za den Trabekeln und zur Kapse] reticuläre Fasern mit groben Maschenräumen, in welchen bald viel, bald wenig Wanderzellen lagern. Da der Sinus der erweiterte Raum eines Lymphgefässes ist, so leuchtet ohne Weiteres ein, dass seine Wände überall auf dem Reticulum und den Parenchymgrenzflächen mit Endothel bekleidet sind. Ebenso versteht man aus der Entstehungsgeschichte, dass die Drüsenkapsel eigene, ernährende Blutgefässe und glatte Muskelfasern enthält. Auch Nervenfasern habe ich in der Kapsel verlaufen sehen. Im Uebrigen treten die Blutgefässe (und Nervenfasern) für das adenoide Gewebe dort ein, wo der ganze Drüsencomplex primär entstand, also am Hilus, und sie verbreiten sich in zierlichen Bäumchen and Netzen im Innern der Markstränge und Randfollikel.

So lange eine Lymphdrüse functionsfähig ist, erscheinen in den Randfollikeln die sogenannten Flemming'schen Keimcentren; d. h. hellere Bezirke mit zahlreichen, in Mitose befindlichen grossen Zellen. Daneben finden sich Phagocyten, Wanderzellen und Degenerationsproducte, die sogenannten tingiblen Körper Flenming's. Die Keimcentren bleiben. für gewöhnlich auf die Randfollikel beschränkt; sie sind eine Functionserscheinung und sind der Ausdruck 
für die Leukocytenvermehrung, welche in der wahren Lymphoglandula das Drüsensecret darstellt. Es kann hier nicht meine Aufgabe sein, die Lehre von den Lymphdrüsen und -Bahnen im Allgemeinen zu erschöpfen. Ich muss mich auf das Nothwendige beschränken, verweise aber auf die Angaben in Kölliker's Mikroskopischer Anatomie, II, 2, S. 539, auf die Arbeiten von His (Zeitschr. für wissenschaftl. Zoologie, XI-XV), H. Frey, Untersuchungen über die Lymphdrüsen, Leipzig 1861, Flemming, 1. c., und Kölliker's Handbuch der Gewebelehre (s. oben).

\section{Welche Veränderungen treten im Lymphsystem des Uterus auf bei der Entstehung und dem Fortschreiten eines malignen Tumors in utero?}

Zur historischen Entwickelung dieser Frage sei nur kurz daran erinnert, dass Seelig an dem Institut von v. Recklinghausen. als der Erste nach Abel und Landan exact das Fortschreiten von Careinommassen in den Lymphbahnen unserer Region festgestellt hat. Seine Beobachtungen bezogen sich im Wesentlichen auf vorgeschrittene Collumkrebse und sind neuerdings von v. Franqué und Puppel zwar in ihren Sehlussfolgerungen angegriffen, anatomisch jedoch bestätigt worden. Seelig's Befunde hat wohl jeder Beobachter gemacht, und so findet man auch in allen neueren Arbeiten über das Uteruscarcinom Angaben über Carcinomthromben in den Lymphbahnen. Mackenrodt's, Russel's, Cullen's Befunde von carcinomatösen Lymphthromben in den Ligamenten, Veit's sprungweise Infiltration der Lymphbahnen im Ligam. latum machten aul die Betheiligung der ableitenden Bahnen beim Krebs der Gebärmutter von neuem aufmerksam, nachdem schon vorher Wagner, Cruveilbier, Blan und Dybowski, sowie Williams, Dittrich und manch Anderer sich mit dem Schicksal der regionären Drüsen bei Carcinoma uteri beschäftigt hatten. Seither hat das Interesse an der Frage der Heilbarkeit des Gebärmutterkrebses die Kliniken fort und fort zu anatomisch-histologischen Studien angeregt. Zwar stellte Winter fest, dass die Recidive nach Krebsoperationen sich za 3/4 local einstellen und nur in Ausnahmefällen die Drüsen allein betreffen; indessen haben aber Ries, Rumpf, Clark, Kelly - von der Ansicht ausgehend, dass die regionären 
Drüsen frühzeitig befallen würden - wie bekannt das modernste Verfahren: die radicale Entfernung der krebsigen Gebärmutter im Zusammenhange mit den regionären Drüsen, angestrebt. Peiser's Untersuchungen und Schlussfolgerungen mussten die Operateure in dieser Richtung bestärken. Wertheim und zahlreiche moderne Operateure in Europa und Amerika haben den Gedanken aufgegriffen und ausgebaut, so dass bereits jetzt die Fachliteratur aller Sprachen von einschlägigen Arbeiten erfüllt ist und kaum ein Congress von Fachgenossen vorübergeht, ohne eine Debatte über die Krebsfrage zu zeitigen.

Für unsere im Wesentlichen anatomische Fragestellung kann ich die vorwiegend operativ-klinischen Fragen zum grössten Theil übergehen und nur diejenigen Punkte herausgreifen, welche auf den Beckenbefund an der Lebenden und Todten Bezug baben. Dank der grossen Wichtigkeit, welche unser Thema für die operative Therapie besitzt, sind seit Wertheim's Vorgang systematische Untersuchungen der Beckendrüsen zur Zeit wohl an jeder Frauenklinik im Gange, sei es, dass das Material bei der Operation, sei es, dass es bei der Section gewonnen wurde. Ich erinnere nur an die Mittheilungen von Ries, Cullen, Wertheim, R. König, Funke, v. Franqué, Wuelfing, Broese, Kermauner und Laméris, Kroemer, Olshausen (Oehlecker), H. W. Freund, Gellhorn, Tiburtius, Kleinhans, Kundrat, Kroenig, Glockner, R. Meyer, Falkner und die Arbeiten der Belgier und Franzosen, sowie der Amerikaner.

Trotz der Verschiedenheit der Meinungen haben die Untersuchungen schon jetzt bemerkenswerthe Resultate gezeitigt, welche ich hervorheben möchte:

Zunächst erscheinen die Zahlen, welche von den pathologischen Anatomen über die Häufigkeit der regionären Drüsen - Metastasen aufgestellt worden sind, zum mindesten nicht einwandfrei. Blau fand $33 \frac{1}{3}$ pCt., Dybowski 28 pCt., Wagner 50 pCt., Dittrich 40 pCt., Russel 44 pCt., Williams 72 pCt., Cruveilbier sah nahezu in allen Fällen inficirte Drüsen bei Carcinoma uteri. Abgesehen von der Verschiedenheit des Materials fällt bei diesen so differirenden Resultaten das Fehlen der mikroskopischen Serienuntersuchung ins Gewicht. Wir wissen durch unsere eigenen Untersuchungen, dass die makroskopische Diagnose der krebsigen Drüsenschwellung ohne mikroskopische Bestätigung täuschen kann. Eine Beweisführung auf Grund obiger Statistiken ist also unmöglich. 
- Die Ergebnisse der Kliniker, welche nur die bei der Operation entfernten Drüsen berücksichtigen, sind auch nicht einwandsfrei, da die Operation keine absolute Garantie für die Entfernung alles Kranken giebt, vielmehr die Section der nach der Operation gestorbenen Frauen oft die palliative Natur des sogenannten Radicalverfahrens nachweisen lässt (Kroemer, Gellhorn, Oehlecker). Das Material des Klinikers ist fïr den anatomischen Standpunkt ohne Bedentung, soweit die Resultate nicht durch die Section erhärtet sind. Das Material des pathologischen Anatomen kann dem Kliniker nicht Anskunft geben, wann die Carcinominvasion erfolgt.

Immerhin bleibt bemerkenswerth, dass die neueren Untersucher unter den pathologischen Anatomen selbst bei vorgeschrittenen, inoperablen Carcinomen der Gebärmutter die Häufigkeit der Drüsenbetheiligung nicht über 35 pCt. annehmen. Riechelmann (1900) fand bei 86 Sectionen (darunter waren nur 14 operable Fälle von Carcinoma uteri) $30 \mathrm{Mal}$ die regionären Drüsen befallen $=35 \mathrm{pCt}$ ! Ja Cullen, dessen bekanntes Werk über den Cteruskrebs zur Zeit die umfassendste Monographie auf diesem Gebiete darstellt, steht nicht an, auf Grund sorgfältiger mikroskopischer Untersuchungen den Satz aufzustellen, dass der Krebs der Gebärmutter, in welchem Theile derselben er anch sitzen mag, erst sehr spät und nach dem Befallensein der Parametrien die regionären Drüsen inficire, so dass unter dem Einfluss seiner Resultate Clark und Kelly die Drüsensuche bereits anfgegeben haben. Es nähern sich die Zahlen, welche durch die Untersuchung der operativ entfernten Drüsen festgestellt werden, immer mehr den von der Mehrzahlder pathologischen Anatomen gefundenen Werthen, und es scheint das Verhältniss von $331 \% \mathrm{pCt}$. Drüseninfection anf alle Carcinomarten berechnet richtig zu sein. Daher forderte ich, angeregt durch ähnliche Bestrebungen der v. Rosthorn'schen Klinik, die genaue anatomische Untersuchung der einzelnen, mit Carcinominfection der regionären Drüsen einhergehenden Tumoren, um diejenigen Geschwulstarten kennen zu lernen, welche zur frühzeitigen Infection der Drüsen neigen.

Die bisher gewonnenen Resultate und Schlussfolgerungen gab ich in einem kurzen Aufsatz in der Monatsschrift, Bd. XVIII, H. 5 bekannt und habe ich die Genugthuung, dass schon jetzt von Schauta Vieles von meinen Erfahrungen bestätigt wird.

Kehren wir nun zum speciellen Thema zurück, so erübrigt es sich zunächst für mich, in der folgenden Betrachtung die Tumoren 
der Bindegewebsklasse (die Sarkome und Endotheliome) von den Epitheliomen (den Carcinomen) zu trennen. Die Verbreitung bindegewebiger, wie epithelialer Geschwülste geschieht in gleicher Weise auf dem Lymph- wie auf dem Blutwege. Nur ist beim Sarkom der Verlauf ein rascherer, der Eintritt der Tumorelemente ins Blut erfolgt meist direct obne den Umweg über das Lymphgefässsystem, so dass das klinische Bild mehr von den Blutmetastasen beherrscht wird. Jedenfalls machen die Sarkome (Endotheliome) ebenso wie die Carcinome Lymphdrüsenmetastasen - nach unserer Erfahrung sogar früher als die Carcinome - und der Krebs bricht andererseits auch in Blutgefässe ein. (Goldmann, v. Recklinghausen). Gleich anderen Untersuchern (v. Franqué) fand ich die Gefässarrosion beim Uteruscarcinom meist nur in Venen und local im Primärtumor. Die entfernten Thromben der Vena uterina im breiten Ligament (s. Fig. 18) sind meistens frei von Carcinom. Alle Tumoren des Uterus wachsen zunächst vom Orte ihres Entstehens aus continuirlich in den endothellosen Bindegewebs - Interstitien. Wird dabei ein präformirter Hohlraum eröffnet, so schiebt sich der Tumor in diesem nach dem Ort des geringsten Widerstandes vor. Geschwülste, welche nur in den Lymphbahnen vordringen, giebt es wahrscheinlich nicht. Man findet in allen, selbst vorgeschrittenen Tumoren jeder Art offene, secretgefüllte, vielleicht neugebildete Lympheapillaren meist im Zustande der Staung. Die Richtung der Lymphgefässe in utero richtet sich nach dem Gefüge der Muskelbündel. Das Vordringen der Tumoren hält sich nur ganz im Groben an diese Structur, insofern es in den lockeren, gefässreichen Regionen rascher sich vollzieht.

Die Vaginalkrebse der Portio, welche nahe dem Fornix ihren primären Sitz haben, dringen gern im äusseren Drittel der Muscularis cervicis nach oben. Portiocarcinome dagegen, welche nahe dem Muttermunde entstehen, wählen den Schleimbautweg aufwärts und zerstören die Collumwand in Form eines sich nach oben verjüngenden Trichters. Merkwürdiger Weise lassen echte Plattenepithelkrebse, welche auf der vollen Portiofläche auskeimen, häufig genug die Mucosa cervicis intact, sie infiltriren zuweilen die volle Dicke des. Gebärmutterbalses im ganzen Umkreis, bis auf die Submucosa, so dass beim Zerfall im Stadium der Kraterbildung das intacte Rohr der. Cervixschleimhaut wie ein starrer Cylinder in der gähnenden Krebshöhle stehen bleibt, 
Cervixkrebse dringen von vornherein seitlich nach den Parametrien vor, denn hier bahnt ihnen ja die Menge der austretenden Blut- und Lymphgefässe den Weg.

Der Krebs der Körperschleimhaut hat erst das dicke Netz der relativ engen, complicirt gebauten Corpus-Lymphspalten zu überwinden und neigt dann noch eher zur Infection der Serosalymphbahnen (s. Fig. 8). Die Lymphlakunen im äusseren Theil der Muscularis (Zona subserosa) sind in der That, we Seelig betont, weiter als die übrigen Parenchymbahnen, und so werden Krebse, welche diese Schicht erreicht haben, hier am raschesten vordringen. Collumkrebse z. B. erreichen hier ihren höchsten Stand (s. Fig. 17) bis hoch in's Corpus hinauf, und selbst Körperkrebse wandern hier abwärts in die Cervixwand hinein. Fügen wir noch hinzu, dass auch der innere Muttermund keine absolute Grenze für die Corpusund Cervix-Carcinome bildet, sondern dass diese Linie sowohl aufwie abwärts überschritten werden kann, so werden wir uns die bunten Variationen in den einzelnen Fällen vergegenwärtigen. Das Speculumbild der Portio, das Tastgefühl bei der bimanuellen Untersuchung, ja sogar die Excochleation kann uns in manchen Fällen im Unklaren lassen über die Ausbreitungsart und Grenzen des Tumors.

Im Wosentlichen waehsen also die Tumoren continuirlich, die Sarkome (Endotheliome) freilich mit unregelmässig ausstrahlenden, oft weit vorgeschobenen Ausläufern. Die Thatsache des continuirlichen Wachsthums hat für mich nichts Wunderbares; denn das Fortschreiten der Geschwulstzellen bedeutet kein loses Wandern, sondern ein beständiges Sichvermehren, ein Fortwachsen in dem Sinne, dass Zelle sich an Zelle reiht und mit den Nachbarn sowie mit dem Geschwulstboden festen Contact sucht. Je geringer der Widerstand in der Umgebung, um so üppiger wird der Tumor in dieser Richtung vorwuchem, natürlich am raschesten in den präformirten Lymphspalten. In ihnen finden die Krebszellen genügend Nahrung, vielleicht spielen bis zu einem gewissen Grade chemotaktische Reize eine Rolle, so dass die Lymphkanäle sich ebensosehr mit Carcinomzellen vollsaugen, als sie von den mechanisch vorgeschobenen Elementen infiltrirt werden. Auch in den Lymphbahnen wurzelt der Tumor zum mindesten an einer Wandpartie fest. Vergl. Fig. 16 ${ }^{1}$, welche das Vordringen von PlattenepithelKrebszapfen in einer Cervixschleimhaut darstellt. Die infiltrirten

1) Fig. 16 ist in meiner früheren Carcinomarbeit, dieses Archiv, Bd. 65, H. 3, enthalten. Siehe auch die Erklärung der Abbild. am Schlusse. 
Lakunen erscheinen bedeutend grösser als die bei der Injection dargestellten normalen Lymphspalten. Das Endothelhäutchen geht auch nie um den ganzen Umfang der Krebszapfen herum; es fehlt an derjenigen Wandseite, an welcher die Tumorzellen am Gewebe haften. Der Krebs hat gewissermaassen die Lymphbahnen zum Bersten gebracht.

Die grosse Zahl der Lymphanastomosen, welche wir in allen Schichten des Uterus annehmen können, wird uns ein zuweilen zu beobachtendes, atypisches Wachsthum des Krebses in einer einseitigen Richtung hin begreiflich machen. Ihr Vorhandensein bedeutet aber nicht, dass der Tumor den von ihnen gebotenen Weg. benutzen muss. Man kann nur sagen: Von den vielen Strassen, welche dem Krebs offenstehen, sind diese oder jene in besonderen Falle als besonders geeignet vom Tumor benutzt worden. Ein Vorhersagen der Hauptwachsthumsrichtung irgend welcher klinisch beobachteten Geschwulst ist direct unmöglich.

Trotzdem kann man gewisse Schlüsse aus dem Sitz und der Art des Tumors stellen. Die an der Grenze zweier Epithelarten, in utero also am äusseren oder am inneren Muttermund entstehenden Krebse werden rasche Verbreitung finden, weil ihnen gewissermaassen 2 Lymphsysteme offen stehen, deren Stromrichtung mit ihrer Wachsthumsrichtung correspondirt.

Die in einer einheitlichen Epithelregion entstehenden Carcinome erscheinen uns in ihren vorgeschrittenen Stadien entweder als lokalisirte, runde Knoten - oder als diffuse Erkrankung der ganzen Region. Die ersteren will ich als unicentrische Tumoren den multicentrischen mit diffuser Entstehung gegenüberstellen. Bei beiden grossen Gruppen kann das Wachsthum evertirend nach der freien Oberfläche, oder invertirend nach der Tiefe sich erstrecken. So entsteht aus einem unicentrischen Carcinom der Portio entweder der breitgestielte, polypöse Tumor einer Lippe oder der tiefe Collumknoten. Die charakteristischen Vertreter der 2. Gruppe wären der cauliflore Portiotumor einerseits und das verjauchte Höhlencarcinom andererseits, bei welchem Neubildung undZerfall gleichen Schritt halten.

Von den unicentrischen Tumoren werden die tiefgehenden Formen z. B. die sogenannten tiefen Collumknoten besonders bösartig sein, weil sie rascher als die evertirenden Formen das Parametrium erreichen; von den multicentrischen Carcinomen geben die sogenannten lymphatischen Formen die schlechteste Prognose, denn diese - auf einem weiten Gebiet zugleich entstehend - inficiren 
gewissermaassen in der ersten Bildung eine Unmenge von Lymphbahnen. Sie infiltriren die Wand der Gebärmutter, welche scheinbar in der Form erhalten bleibt, aber durch ihr wurmstichiges Aussehen und ihre Bröcklichkeit den Tumor verräth. Mag man solche Formen lymphatische Carcinome oder infiltrirende Höhlenkrebse nennen, jedenfalls verhalten sie sich genau so wie die in den Saftspalten und Lympheapillaren selbst entstehenden Endothelkrebse. Sie erreichen rasch die subseröse Schicht und damit die breite parametrane bezw. intraligamentäre Strasse.

Ganz allgemein scheint die Grösse der localen Neubildung zu contrastiren mit dem Grade der regionären Ausbreitung in der Peripherie. Mächtige Portiocancroide geben eine bessere Prognose als der unansehnliche Cervixkrebs, von welchem man am gesehlossenen äusseren Muttermund kaum ein kleines Zöttchen herausragen sieht.

Cullen und Lubarsch haben die Grösse der Zellen ausserdem in Betracht gezogen und glauben, je kleiner die einzelnen Geschwulstelemente sind, je mehr sie sich dem Lumen der Spalten anpassen können, um so eher werden sie zur raschen Verbreitung geeignet sein. Auch diese Eigenschaft kommt den infiltrirenden Cylinderzellkrebsen und den Endotheliomen in gleicher Weise zu.

Fig. 14 und $15^{1}$ ) demonstriren die Anpassungsfähigkeit der von den Cylinderepithelien des Uterus ausgehenden Geschwulstzellen für das Corpuscarcinom. Die Schnitte, welche den Abbildungen zu Grunde liegen, entstammen einem breitgestielten Șchleimhautpolypen des Corpus uteri. Das Carcinom beschränkt sich auf den Polypen und seine Basis. Trotz der Metaplasie des Oberfläebenepithels möchte ich annehmen, dass auch die Drüsen als Ausgangspunkt betheiligt sind. In der obersten Schleimhautschicht (s) erblickt man neben wenigen normalen Drüsen (d) mit erhaltenem Cylinderepithel in den meisten Hohlräumen (m) das Epithel in starker Proliferation begriffen. Ueberall kann man Metaplasie und Mehrschichtung verfolgen. (Aehnliche Bilder aus einem Uteruspolypen bildete jüngst Opitz ab.) Die Membrana propria der veränderten Drüsenschläuche wird durchbrochen nnd die activirten Epithelien dringen als feine Zellstränge in die Saftspalten und Lymphbahnen der tieferen Schleimhautschichten. Namentlich in der Nähe der Blutgefässe $(g-a-v)$ tritt der bizarre, schlangenartig gewundene Verlauf der inficirten Lymphbahnen zu Tage. In der tiefen Schicht (c) der Mucosa folgen

1) Yergl. die Erklärung der Abbild. am Schlusse der Arbeit. 
breite Zellzüge, welche sich etwas von der Wand abgelöst haben, so dass zwischen den grosszelligen Carcinomsäulen und der Endothelgrenze ein Spalt bleibt. Diese Räume entsprechen offenbar den weiten Lakunen in der Schleimhautbasis meiner Injectionspräparate (siehe Fig. $9 \mathrm{a}$ and 11). Thre Ausläufer in der verbreiterten submucösen Schicht (s m) bilden zierliche Netze, deren enge Capillaren um die Venen und Arterien eine Art Strickleitersystem bilden.

Die Figg. 14 a, b und c erläutern im Einzelnen bei stärkerer Vergrösserung das Verbältniss der infiltrirten Lymphbahnen zu den Bluträumen der Mucosa, der submucösen Schicht und der Museularis. Nirgend ist eine Spur von Einscheidung der Blutgefässe zu erkennen. Beide Gefässarten sind nur aneinander gelagert. Die Lymphgefässe erscheinen als perivasculäre Sicheln. Die von allen Seiten ${ }^{1}$ ) neuerdings hervorgehobene Polymorphie des Corpuscarcinoms hat somit in diesem Falle zu einer natürlichen Injection der Lymphbahnen geführt.

Analoge Bilder - nur entsprechend der schmalen Form der Cervix-Lymphbahnen etwas variirt — erhält man bei den infiltrirenden Cervixkrebsen. Vergl. Gebhard's Abbildung: "Fig. 67. Carcin. cervicis lymphaticum" auf S. 144 seiner pathol. Anatomie d. weibl. Sexualorgane.

Ein Vergleich dieser letztbeschriebenen Bilder mit Fig. 16, welche eine Partie aus einem infiltrirenden Portiokrebs darstellt, lässt den charakteristischen Unterschied der letzteren Krebsart von den Cylinderzelltumoren erkennen. Der Plattenepithelkrebs der Portio wächst langsam selbst in den präformirten Spalten, indem er sich gewissermaassen plump unter Zerstörung der Lymphbahnen vorwärts drängt.

Die in neuerer Zeit sich mehrenden Beobachtungen von beginnenden Carcinomen in der Mucosa oder in Polypen des Uterus (Keitler, R. Freund, Hofmeier, Winter, Florenzo d'Erchia, Katzenstein, Gessner, Kroemer, Opitz) lassen sich mit der

1) Die von Hofmeier, Fränkel-Wiener, Kroemer, Emanuel beschriebene polymorphe Natur der Cylinderzellcarcinome des Corpus uteri ist neuerdings von Hitschmann bestätigt worden. Das Cervixcarcinom kann unter Umständen das gleiche Verhalten zeigen, wie ich mich an eigenen Präparaten überzeugen konnte. Bilder, welche den von $\mathrm{E}$. Ka ufmannn wiedergegebenen Adenocarcinomschläuchen absolut gleichen, finden sich neben Plattenepithelsträngen mit und ohne Verhornung in ein und demselben Primärtumor. Ich behalte mir vor, diese Erfahrungen später mitzutheilen. 
Theorie der Cohnheim'schen Keimversprengung nicht vereinbaren. Es wehrt sich der Gedankengang des Klinikers immer und immer wieder gegen die Berechtigung der Lehre von den versprengten Keimen, welche wie die schlummernden Vegetationskeime der Pflanzen zu irgend einer Zeit auswachsen können, nachdem man jahrelang nichts von ihnen wahrnehmen konnte. Solche schlummernden Keime trägt ja wohl jeder Mensch mit sich herum, und sie sind ja auch eine sehr bequeme Erklärung für bösartige Geschwülste. Aber wie soll man sich denn, um pro domo zu reden, einen schlummernden Keim in einer Mucosa uteri vorstellen, die sich vielleicht $100 \mathrm{mal}$ postmenstruell verjüngt hat, die bei mehreren Schwangerschaften ganz zu Grunde ging, die vielleicht wiederholt ausgekratzt wurde und schliesslich doch den Boden für ein Oberflächencarcinom abgiebt?

Es giebt nun dank der Stückchendiagnose Fälle genug, in welchen das Carcinom in getrennten Herden, z. B. in 2 getrennten Buchten eines und desselben Polypen in seiner Entstehung beobachtet werden konnte. Für solche Formen müssten also bereits 2 verlagerte Keime angenommen werden. Diese Schleimhautkrebse des Uterus geben interessante Aufgaben für die Plattenmodellir. methode nach Born.

Die Frühstadien der Uteruskrebse, in denen man das multiple Auskeimen der Krebszapfen von dem Oberflächenepithel und von den Drüsen zugleich verfolgen kann, sprechen ebenso wie die Fälle mit multiplen Carcinomherden im Uteruskörper, falls letztere vom Oberflächenepitbel ausgehen, wie im Fall Kunze, gegen die Annahme, dass der Krebs in allen Fällen unicentrisch entsteht. Wenn man sich eine Neubildung von einem Centrum aus wachsend vorstellt, so wird daraus stets mehr oder weniger eine Kugel oder Halbkugel werden, deren Peripherie ja freilich so unregelmässig als möglich gestaltet sein könnte. Wenn man aber z. B. bei einem diffusen Drüsencarcinom der Cervix vom inneren Muttermund nach abwärts bis kurz vor Beginn der Plattenepitheldecke der Vagina in der Nachbarschaft jeder Drüse die beginnenden Carcinomherde gleich weit vorgeschritten sieht, so wird man zugeben müssen, dass die Carcinome auch multicentrisch entstehen können. Man hat dann unwillkürlich den Eindruck, dass in solchen Fällen ein gemeinsam wirkender Reiz, sei er chemisch oder mechanisch oder parasitär, von der ganzen Innenfläche aus wirkend, die Neubildung verursacht habe. 
Einen solchen Reiz, welcher unter Umständen Carcinombildung anregt, kennen wir schon in der Tuberculose, die ja ohnedies im Uterus stets mit Epithelproliferation einhergeht. Die aus den Instituten E. Kaufmann's und von Lubarsch bekannt gegebenen Fälle sind nicht die einzigen, wie man aus der interessanten Arbeit J. Wallart's ersieht. In unserer Klinik harrt zur Zeit ein Fall von Cervixkrebs der operativen Erledigung, in welchem auf allen Schnittbildern der Probeexcision die Vereinigung von tuberculösen und carcinomatösen Formationen eine so innige ist, dass man an die Lupuscarcinome erinnert wird.

Auch bei den Corpuskrebsen kann man die unicentrischen Tumoren, welche kaum den 10. Theil unter allen Corpustumoren ausmachen, von den diffusen multicentrischen Epitheliomen unterscheiden. Im ersten Falle findet man einen beetartigen oder knolligen Herd, im letzteren Falle eine Zerstörung der ganzen Corpuswand von innen nach aussen, so dass je nach dem Stadium ein Drittel oder die Hälfte der ganzen Muscularis von innen her eingeschmolzen ist, bis endlich nur noch die allein erhaltene Serosa die weiche Carcinommasse mit ihrem riesigen, centralen Krater einschliesst.

Die Peripherie aller Carcinomarten kann, wie oben bereits erwähnt, unregelmässig strahlige Ausläufer und Vorposten treiben, am ehesten findet man dies Verhalten noch bei den Endotheliomen und bei den Corpuscarcinomen. Zu jeder Zeit ihres Bestandes können Zellcomplexe, welche sich in den Lymphbahnen vorschieben, an entfernten Stellen - hier meist subserös - auskeimen (vergl. Fig. 8 meiner früheren Arbeit über den Gebärmutterkrebs). Die Körperkrebse machen in Folge dessen im rorgeschrittenen Stadium bei bimanueller Tastung einen vielknolligen Eindruck, so dass man differentialdiagnostisch an multiple Myome zu denken veranlasst wird. (Es sind dies meist relativ sehr grosse Tumoren, die bis zur Grösse eines Kindskopfes und darüber anwachsen können.) In einem solchen Stadium ist bereits das Serosa-Lymphnetz vom Carcinom befallen, und ich erinnere mich zweier eclatanter Fälle, in denen die Autopsie bei der Operation eine multiple Carcinomaussaat auf bezw. in dem gesammten Peritoneum erkennen liess.

Wenn wir uns noch ein Mal kurz die Verbreitungsweise der einzelnen Carcinomarten des Uterus vergegenwärtigen, so greift der Vaginalkrebs der Portio mit Vorliebe nach oben auf den Gebärmutterhals, nach unten auf die Vagina und das subvaginale Gewebe über. Das Cervixcarcinom wächst nach den Seiten in 
die Parametrien hinein, der Körperkrebs strebt radiär nach aussen.

Bei der Durehsicht der zahlreichen carcinomatösen Uteri in der Sammlung der Giessener Frauenklinik fand ich die Bestätigung unserer früheren Erfahrungen an dem Breslauer Material. „Die häufigsten Collumcarcinome entstehen als isolirter Tumor einer Portiolippe oder einer Commissur und infiltriren yom Ort ihres Entstehens aus die Wand der Cervix sowie die Vaginalwand, sodass schliesslich das ganze Scheidengewölbe rom Carcinom erfasst sein kann. Je mehr das Carcinom blumenkohlartig wächst, um so länger bleibt das Scheidengewölbe erhalten, und man kommt oft um unförmliche Tumoren noch herum an freien Fomix."

Seltener ist schon das trichterförmige Wachsthum mit Verjüngung des Kraters nach oben, so dass die Cervicalschleimhaut ganz zerstört ist, die Musculatur nur im unteren Bereich der Krebshöhle. Am seltensten sah ich die gesammte Schleimhaut der Gebärmutter vom äusseren Muttermund bis hinauf in den Fundus vom Carcinom befallen; es sind dies wohl stets Ringcarcinome, welche am inneren Muttermınd entstehen und von da nach aufwärts und abwärts steigen. Die metastatische Verbreitung des Carcinoma (colli) uteri durch isolirte. Herde in der Wand der Gebärmutter und ihrer Adnexe, der Tube und des Orariums ist so selten, dass solche Fälle als Ausnahme das Niehtrorhandensein solcher Metastasen als die Regel bestätigen.

Nach persönlicher Mittheilung Prof. Walther's beobachtete Löhlein an der Giessener Frauenklinik eine isolirte Corpuswandmetastase bei operablem Portiocarcinom. Auch Seelig behauptete, dass schon bei beginnenden Collumkrebsen das Corpus inficirt sein könne durch vorgeschobene Posten in den Lymphgefässen. v. Franqué und Puppel wiesen nach, dass Seelig an einem inoperablen Material seine Untersuchungen angestellt hatte, bestätigten jedoch im Uebrigen seine anatomischen Befunde. Nur betonte v. Franqué mit Recht, dass die isolirten Herde gewöhnlich in der grossen Seitenanastomose Poirier's (vergl. den anatomischen Abschnitt dieser Arbeit!) sich finden, welche an der Seitenkante der Gebärmutter nach oben steigt und die Lymphbahnen des Collum uteri mit denen des Corpus verbindet. Blau sah bei 87 Cervixcarcinomen $8 \mathrm{mal}$ isolirte Metastasen in der äusseren Schicht der Corpuswand; einige Knötchen sassen subserös. Auch ich machte die gelegentlichen Befunde von carcinomatösen Lymphthromben in der 
Corpuswand wie in der subvaginalen Anastomosenstrasse bei vorgeschrittenen Collumtumoren. Metastasen in der Tubenwand fand Florenzo d'Erehia bei Portiocarcinom, Sondheimer bei Corpuscarcinom, Cullen bei beiden Krebsarten; Callen's mikroskopische Befunde in der Tubenmucosa sind nach Maassgabe der beigegebenen Abbildungen, wie ich wenigstens meine, nicht beweisend.

Die Betheiligung der Ovarien bei Carcinoma uteri - meist handelt es sich um die Combination von Körperkrebs, seltener von Cervixkrebs mit Krebs eines oder beider Ovarien - erfordert stets eine scharfe, kritische Beurtheilung. Abgesehen von dem continuirlichen Fortschreiten eines Körperkrebses, dessen Ausläufer in den Lymphbahnen der Ala vespertilionis sich bis in den Hilus ovarii. vorschieben (Blau sah dies bei 93 Sectionen 25 mal), ist bei den übrigen Fällen mit freiem Ligament die Entscheidung schwer, ob der Primärtumor im Ovarium oder im Uterus sitzt. Nicht die Grösse des Tumors entscheidet, sondern nach Winter (Veit's Handbuch für Gynäkologie) die Art des Uterusherdes selbst. Handelt es sich um diffuse Tumorbildung der ganzen Mucosa. corporis oder cervicis uteri, so spricht alle Wahrscheinlichkeit für einen primären Uteruskrebs. Im anderen Falle wird eine localisirte Uteruserkrankung im Corpus oder Collum bei grossem Ovarialtumor als Netastase verdächtig sein. Tritt die Uterusaffection localisirt in Erscheinung nach operativer Beseitigung der Ovarialtumoren, wie in den beiden von mir beschriebenen Beispielen (No. 1: Corpus- und Cervixmetastase bei [nach] Cystadenocarcinoma ovarii und No. 2: Portiometastase bei [nach] Endothelioma ovarii), so ist die Diagnose klar, sobald beide zeitlich aufeinanderfolgenden Geschwülste mikroskopisch denselben Bau aufweisen. Schliesslich kann ein primäres Uteruscarcinom sich auch jeder Zeit mit einem primären Ovarialcarcinom vergesellschaften. ${ }^{\mathbf{1}}$ )

Bei allen isolirten Metastasen - mögen sie in der Wand der Adnexe oder subvaginal sitzen, wie z. B. die Knoten im Urethralwulst unter der intacten Schleimhaut - spricht die grösste Wahrscheinlichkeit für ein Verschleppen der Carcinomkeime in den Venen, wie dies neuerdings Hellendahl wieder hervorgehoben hat.

Mit v. Recklinghausen und Goldmann möchte ich annehmen, dass die Carcinomverbreitung in den Lymphbahnen diffuse Knötchen und Stränge zeitigt, weil die Geschwulstpartikelchen in

1) Glockner's Arbeit über secundäres Ovarialoarcinom konnte ich leider nicht mehr berücksichtigen. 
den Knotenpunkten des lymphnetzes festsitzen werden. Die retrograde Verschleppung in der Blutbahn, d. $h$. in den relativ geräumigen, gestauten Venen lässt einen Pfropf leichter an Theilungsstellen der Gefässbahn passiren, ehe er zur Verankerung kommt. Die diffusen retrograden Metastasen im Lymphsystem kann man zuweilen bei sehr weit vorgeschrittenen Collumkrebsen per vaginam als multiple Knötchen tasten.

In der Regel wächst also der Krebs der Gebärmutter continuirlich. Der locale Tumor wird grösser und grösser, er schiebt seine Ausläufer, sobald er das Parametrium bezw. Ligament. lat. erreicht hat, in den breiten, bequemen Lymphstrassen vorwärts in Gestalt eines nach der Beckenwand sich zuspitzenden Keiles (Winter), d. h. er entfaltet die Ligamente (mit Vorliebe auch die Ligamenta sacrouterina), die mehr durch dieses Moment, als durch die entzündliche Infiltration verkürzt werden, und es verändert sich dadurch die Topik der Ligamentgebilde. Die Art. uterina wird nach vorn oder hinten verdrängt, der Ureter wird in Schleifen verzerrt, und da die Lymphbahnen die Art. uterina und den Ureter von vorn und hinten umschlingen, so scheint der Harnleiter schon $z u$ einer Zeit im Carcinom eingemauert, in welcher seine Wand noch vollständig intact ist und er sich in den Carcinomsträngen leicht verschieben, ja sogar intact herauspräpariren lässt. Die carcinomatöse Wandinfiltration des Ureters erfolgt erst in einem Stadium, in welchem die inficirten, parametranen Lymphstränge die Beckenwand erreicht haben, und der locale Carcinomkrater nach der Blase und dem Rectum zu durchbricht, d. h. der Ureter wird von der infiltrirten Blase her befallen. Er steht ja nicht in directer Lymphverbindung mit dem Uterus, sondern mit der Blasenwand und den Iliacaldrüsen.

Zum Schluss kann über dem Carcinomkrater im Becken, der nur noch eine einzige grosse Kloake darstellt, das kleine Corpus mit seinen Adnexen wie eingemauert stehen, und doch kann die ganze Erkrankung streng local geblieben sein olne Betheiligung der regionären Lymphdrüsen. Cullen hat uns classische Beispiele davon mitgetheilt. Wir selbst verfügen über Fälle, wo mächtige Portiotumoren, welche von anderer Seite mehrfach ausgeloffelt worden waren, weder bei der Radicaloperation noch bei der Section mikroskopisch einen Krebskeim in den geschwollenen Drüsen nachweisen liessen. Aehnliche Fälle beschreiben Broese, Gellhorn (E. Kaufmann). Es scheint, als ob begleitende, schwere Infectionen in solchen Fällen die Lymphstrassen verlegen. 
Jedenfalls sind diese Fälle Extreme, obwohl ich mich nie des Eindrucks erwehren konnte, dass Portiokrebse, welche local mächtige Tumoren erzeugen, wenig Neigung zur metastatischen Verschleppung zeigen. Das evertirende Wachsthum begünstigt vielleicht die Drüseninfection weniger, als das infiltrirende.

Der Krebs wächst mit Vorliebe in den Lymphspalten, greift aber - zum mindesten im primären Tumor - auch Blutgefässe (Venen) an, ähnlich wie die Sarkome. Wenn also die Tumoren gewissermaassen mit ihren Vorposten in Lymph- und Blutgefässen stecken, und durch die nachgewiesene Hyperämie und Gefässneubildung ein gesteigerter Säftestrom zwischen der Geschwulst und dem übrigen Körper sich einstellt, so müsste man ja annehmen, dass täglich Geschwulstbestandtheile abbröckeln und in entfernte Bezirke verschleppt werden. Die Verschleppung in den Blutbahnen - stets sind es Venen, welche arrodirt werden - wird glücklicher Weise meist verhindert durch die gleichzeitig mit der Arrosion zu Stande kommende Thrombosirung. Dies Moment fehlt in den wenig widerstandsfähigen und an Zahl viel reicheren Lymphbahnen, welche Schritt für Schritt infiltrirt werden. Solange die wachsenden Zellen am Mutterboden haften und das Lumen des Lymphgefässes ganz erfüllen, ist keine Gefahr vorhanden. Beim weiteren Wachsthum aber muss doch früher oder später ein Zeitpunkt eintreten, wo ein Pfropf in ein grösseres Lumen eindringt, flott wird und zum Wandern kommt. In der. That steht der Krebs in Zell- und Säfteaustausch mit dem Körper. Frühzeitige Kachexie und Magensymptome treten zuweilen ein, bevor die nachfolgende Anämie das Bild erklären kann. Es werden - um mit Thiersch zu reden - täglich Stoffe und Zellen vom Krebs in die Gewebe und Säfte der Mutter eingeschwemmt. Aber die Zellen sind zunächst verbraucht, todt, oder sie sterben rasch ab. - Zu ihrem Auskeimen muss ein zweites Moment begünstigend hinzukommen: Sie müssen in einer gewissen Masse und Lebensfähigkeit eindringen und sie müssen einen Locus minoris resistentiae finden.

Während des Transportes der Carcinomzellen in den abführenden Lymphstämmen der Gebärmutter, d. h. in den freien Ligamenten, sind sie schwer nachzuweisen. Menge nimmt daher an, dass die intercurrenten Lymphstämme carcinomfrei sind und dass nur in den Drüsen die gefährlichen Carcinomnester sitzen. Aber man muss sich dabei das Beispiel der Injection vor Augen halten. Auch bei den gelingenden interstitiellen Organinjectionen sieht man erst die 
regionären Drüsen sich färben, ehe die zuleitende Bahn, durchs Peritoneum schimmernd, zu Tage tritt, der mikroskopische Nachweis der wandernden Zellen in den makroskopisch freien Ligamentbahnen und Parametrien ist eminent schwer. Man wird nicht erwarten dürfen, jeden kleinen Keim zu finden. Oft durchsucht man die Zellmassen in den Lymphgefässen and kann doch nicht zur Entscheidung kommen, ob die hellen grossen, oder die kleinen, dunkelgefärbten Zellgebilde im Rahmen des Gefässes die Tumorvorposten einschliessen. Bis zu einem gewissen Grade bleibt die Diagnose bei den von Seelig und Puppel beschriebenen in dem freien Lumen liegenden "Carcinom"massen stets subjectiv. Angenommen, dass es wirklich Krebszellen sind, woher wissen wir, ob es noch lebendes Material ist. Freilich giebt es unzweideutige Befunde, in welchen gleich wio in den randständigen, inficirten Venenthromben (Goldmann) der Tumor bereits die Endothelien verdrängt hat und in die Gefässwand selbst eindringt (Kundrat).

Unzweifelhaft sind wohl auch alle jene Fälle, in welchen man bereits makroskopisch die Infiltration der Lymphbahnen in den Ligamenten erkennen konnte. Blau, Cullen, Russel, H.W. Freund sahen die Carcinomausbreitung in den Lymphbahnen, welche rom Uterushorn aus entlang der Tube zum Plexus soubovaricus verlaufen, Cullen auch im Ligamentum rotundum. Ausserdem beschrieben Veit und Mackenrodt carcinomatöse Lymphthromben im Parametrium und in den Ljgamenten, Veit bezeichnete diesen Vorgang als "sprungweise Infiltration" der Ligamentbahnen. Kermauner und Laméris sowie Kundrat konnten gleichfalls unzweideutige Krebsherde dieser Art finden.

Nach meinen Erfahrungen sitzen solche Krebspfröpfe stets in der Nähe der inficirten Lymphdrüsen. Die natürliche Infiltration des peripheren Lymphsinus in der Drüse verstopft den Weg, und so stauen sich vor dem Hinderniss die Zellelemente im Lymphstrom. Die Krebszellen können sich daher leichter festsetzen und vermehren. Es ist nichts Seltenes, dass man neben einer Infiltration des Lymphsinus mit Krebselementen eine zweite Aussaat kurz vor der Drüsenetappe im periglandulären Gewebe und in der Drüsenkapsel selbst findet.

Die parametranen Drüsen sind zwweilen nur seitliche Anhänge eines grossen Lymphgefässes and keine echten Stromunterbrecher. Wie die Injectionsmasse an diesen Noduli lymphatici im Parametrium vorüberfliessen kann, ohne sie zu färben, so werden 
sie auch zuweilen vom Carcinom übergangen, und man findet häufiger die Drüsen an der Beckenwand inficirt als die parametranen Knoten. Bei 26 positiven Drüsenbefunden der Wertheim'schen Carcinomfälle fand Kundrat nur 11. Mal Careinomherde in den parametranen Knötchen. Die Zeichnungen Fig. 17 und Fig. 18 stammen von einem Cervix- bezw. einem Portiokrebs mit freien Drüsen.

Anders steht es mit den sogenannten regionären Lymphdrüsen im Verlauf der grossen Beckengefässe. Da sie gewissermaassen als Sieborgane in den Lymphstrom eingeschaltet sind, so werden sie auf jede Veränderung des Primärtumors reagiren müssen. 'Jn der That kennen wir bereits eine Reihe typischer Veränderungen dieser Organe.

Um die pathologischen Drüsenerscheinungen kurz charakterisiren zu können, erinnere ich an die typischen Componenten, aus welchen die Lymphdrüsen zusammengesetzt sind, mögen sie in ihrer äusseren Form auch noch so variabel sein. (Vergl. Fig. 19 bis 30.)

Jede Lymphdrüse (Fig. 24) ist von einer bindegewebigen Kapsel umgeben, von welcher zarte, verzweigte Septen - die sogenannten Trabekel -, ins Innere der Drüse einstrahlen. Dadurch wird das adenoïde Drüsenparenchym gegliedert in die runden, peripheren Zellknoten, d. h. die Randfollikel und die strangartig gewundenen, centralen Markstränge. Die letzteren hängen unter sich und mit den Randfollikeln zusammen. Zwischen den Parenchymbestandtheilen und den Trabekeln bezw. Kapselwänden fliesst die Lymphe im sogenannten Sinus, der am convexen Pol als peripherer Randsinus, am concaven Hilus als Toldt'scher Endsinus bezeichnet wird. In den Randsinus mündet das Vas afferens, aus dem Endsinus entstehen die Vasa efferentia. Functionirt die Drüse noch im Körperhaushalt, so enthalten die Randfollikel helle Bezirke (Brutstätten für Leukocyten), die sogenannten Flemming'schen Keimcentren. Das bindegewebige Stützgerüst: „Kapsel und Trabekel" bekommen platte Nerven und Ernährungsgefässe vom convexen Pol, das Parenchym vom concaven Hilus her.

In einjgen Drüsen konnte ich im Parenchym einen directen Zusammenhang kleiner Lymphräume mit den Blutgefässen (Venen oder Capillaren) erkennen.

Fig. 20 erläutert die Verhältnisse des Lymphsinus, welcher überall von reticulären Fasern mit weiten Maschen durchsetzt ist. Die Trabekel sind bei menschlichen Drüsen junger Individuen oft sehr zart, so auch hier. Um so besser erkennt man Markstränge 
und Randfollikel, in den letzteren die Keimcentren und in diesen (angedeutet) zahlreiche Blutcapillaren. Die seröse Ueberfüllung der Drüse war hier durch Gravidität verursacht (combinirt mit Carcinoma cervicis). In ähnlicher Weise findet man bei ulcerirten Carcinomen des Corpus wie des Collum uteri den Lymphsinus erweitert, aber dabei sind die Maschen des Reticulums im Sinus erfüllt mit zahlreichen todten und lebenden Zellen und Zellfragmenten. Anders das Bild bei einer acuten Infection durch irgend welche Infectionserreger, welche in den ulcerirten Primärtumor eindringen können (s. Fig. 21). Sofort steht das ganze Parenchym unter dem Zeichen der activen und passiven Hyperämie, besonders sind die Venen strotzend gefüllt. Das Markgewebe schwillt, es erscheint vollgepfropft mit Lymphocyten und erdrückt die Keimcentren, welche allmählig versebwinden. Die Function der Drüse erlahmt. Endlich erseheinen im Parenchym diffuse Blutextravasate. Ist die Einfuhr des Infectionsstoffes bedeutend, so kann es zur Abscessbildung und Vereiterung der Drüse kommen. Die Herde machen dann kurz vor dem Einschmelzen den Eindruck todter Sequester wie bei Infarctbildung. Auch offenbare Folgezustände der stattgehabten, überwundenen Infection kommen bei der systematischen Untersuchung aller Drüsen ab und zu zu Gesicht. Die Drüse fühlt sich dann schon im frischen Zustande hart, wie lederartig an. Im gefärbten Schnitt fallen helle, strahlige Inseln auf, während die sonstigen Drüsen tief dunkel tingirte Bilder liefern. Das Mikroskop löst diese weissen Felder im Herde von sklerosirtem Bindegewebe auf. Wean der Vorgang ganz allgemein in der ganzen Drüse sich abspielt, so erhalten wir Bilder, wie in Fig. 27. Das Kapsel- und Trabekelwerk, überhaupt der ganze Gefässbindegewebsapparat, tritt gewissermaassen nackt und verdickt hervor, während die Parenchymbestandtheile verkümmern. Die Zeichnung der Randfollikel und Markstränge ist verwischt. Keimcentren fehlen ganz. Die Drüse ist blutleer, der Lymphsinus verödet. Die Gefässwände sind verdickt, das Bindegewebe ist sklerosirt und theilweise im Zustande der hyalinen Entartung.

Auch beim Ausbleiben der Infection kann es unter dem Einfluss von Anämien oder im Alter zur Degeneration von Lymphdrüsen kommen. Das Parenchymgewebe schmilzt dabei vom Drüsenhilus aus ein und wird ersetzt durch Fettgewebe (s. Fig. 23a u. b). Erst erscheinen einzelne Fettträubchen ganz isolirt in den Marksträngen (s. Fig. 36); dieselben wachsen und confluiren. Schliess- 
lich ist vom adenoiden Drüsengewebe nur noch eine convexe, dünne Platte übrig geblieben. Der ganze Hilusbezirk ist vom Fettgewebe ersetzt, und nur der erhaltene Gefässbindegewebsapparat der Drüse, namentlich die isolirten Sinus terminiferi, zeigen die ursprüngliche Grenze und Ausdehnung des Drüsengewebes an. Die Fettzellen erscheinen dabei auch in und zwischen den Randfollikeln, und der Rest des adenoiden Gewebes ist im Zustande der Degeneration. Die Zellen färben sich schwer und erscheinen daher blass. Colliquationsnekrosen sind allenthalben zu sehen, die Grenze der Keimcentren gegen ihren sonst zellreichen Parenchymbof ist verwaschen. Das Reticulum quillt und backt zusammen.

Zehnder und Petrick haben solche Bilder als Drüsenneubildung aus dem Fettgewebe gedeutet. Dagegen spricht aber der Zustand der allgemeinen Degeneration, das Vorhandensein eines Gefässbindegewebsapparates, der gewissermaassen wie ein zu weit gewordener Rock um das schrumpfende Parenchym herumliegt und schwerlich aus Fettgewebe entstehen kann, endlich eine von mir selbst gemachte Beobachtung, welche für die Möglichkeit des raschen Ueberganges von gesunden Drüsen zu diesen Degenerationsproducten zu sprechen scheint: "Bei einem zur Section kommenden Fall von Cervixcarcinom sind die bei der Operation enternten hypogastrischen Drüsen frisch und ausserordentlich typisch gebant. Die Operirte stirbt 12 Stunden nach der Operation. Die bei der am folgenden Tage stattfindenden Section entfernten Nachbardrüsen an der Art. iliaca ext. und communis, sowie an der Endausstrahlung der Art. hypogastrica befinden sich im Zustande ausgesprochener, fettiger Degeneration; and doch waren die einen Drüsen makroskopisch von den anderen nicht zu unterseheiden. Auf dem Durchsehnitt freilich sieht man sofort die gelbliche Verfärbung des Hilusbezirks. Das Fettgewebe quillt ausserdem vor."

Unter der wahren Drüsenneubildung möchte ich zweierlei verstehen: 1. das Auswachsen der kleinen Nebendrüsen, welche man so häufig in der Nähe grosser Lymphknoten findet, und 2. eine Erscheinung, welche speciell charakteristisch für Carcinominvasion zu sein scheint. Sobald der wachsende Krebsherd in der Drüse das Parenchymgewebe zusammendrückt, brechen an cinzelnen Kapselstellen Follikel heraus und gestalten die Oberfläche der Drüse zu einem welligen Niveau. Selbst in den grössten Lymphdrüsenmetastasen maligner Geschwülste findet man in dem Convolut zwischen den Geschwulsiherden und in ihrer Peripherie erhaltenes 
adenoides Gewebe, welches in das umgebende Gewebe gleichsam herausspritzt.

Die zahlreichen Rundzellenherde, welche man fast immer im periglandulären Fettgewebe findet - meist in der Peripherie eines Lymphgefässes, - möchte ich noch nicht als eine nengebildete Drüse ansehen. Es ist nur der Ausdruck dafür, dass die Lymphe leukotactische Stoffe führt, oder dass Zellen auch aus den grösseren Lymphstämmen ins Gewebe auswandern. Schliesslich könnte ja auch ein Lymphgefäss einen perivasculären Mantel von adenoidem Gewebe erhalten. Gleich Hammerschlag möchte ich entsprechend unseren Erfahrungen annehmen: "Die carcinomatösen Drüsen neigen eher zur gegenseitigen Verwachsung als zur Abspaltung neuer Drüsen. -

Interessanterweise haben die Forsehungen der letzten Jahre ergeben, dass das Carcinom des Uterus, und zwar gleichgültig, ob es ulcerirt ist, oder ob es eine intacte Oberfläche besitzt, in den Drüsen des Beckens, ja in extremen Fällen in allen abdominalen Drüsen eine Reaction auslöst, welche man am besten als weiche Hypertrophie bezeichnen könte. Durch eine rasche Vermehrung aller Bestandtheile der Drüse kommt es zu einer gleichmässigen, wahren Hypertrophie, so dass aus den kleinen Drüsen unförmliche Knollen werden, welche 3 und $31 / 2 \mathrm{~cm}$ lang und $1-11_{2} \mathrm{~cm}$ breit und diok werden können. Der Bau dieser vollsaftigen Organe ist absolut normal. Es handelt sich nicht um die sogen. grosszellige Hyperplasie, wie sie für skrophulöse Drüsen charakteristiseh ist; denn bei dieser erdrücken gewissermaassen die grossen Keimcentren, welche in Randfollikeln und Marksträngen zugleich auftreten, wachsend und confluirend den Mantel der dunkel gefärbten Lymphocyten, von denen nur schmale Stränge zwischen den hyperplastischen Zellfeldern stehen bleiben. Bei unserer weichen Hypertrophie bleibt das normale Verhältniss der Parenchymbestandtheile unter einander und zum Stroma gewahrt. Fig. 24 demonstrirt das gleichmässig grauröthliche Bild und die regelmässige Zeichnung; welehe solche Drüsen auf dem Querschnitt darbieten. Es ist eine Reaction, die schon bei intactem Primärtumor auftritt, und es liegt nahe, teleologisch diese Veränderung als Schutzmittel gegen die Krebsinvasion aufufassen. In der That giebt es Fälle (v. Franqué, Wertheim, Broese, Kroomer, Gellhorn), bei welchen lange Zeit, vielleicht dauernd, diese Drüsengiganten von Carcinom frei bleiben. Gewöhnlich aber kommt es beim Fortschreiten des Krebses 
auf das Parametrium früher oder später zur Drüseninfection trotz der Hypertrophie, und die Annahme Petersen's und Mackenrodt's, dass die Lymphdrüsen Carcinomkeime unschädlich machen können, ist durch nichts begründet. Fig. 26 stellt einen zweiten Längsschnitt durch die Drüse (Fig. 24) dar und zeigt demonstrativ den ersten Krebskeim als isolirten Herd im peripheren Sinus. Der extrem seltene Befund abgeschlossener Krebskeime in verkalkten Lymphdrüsen, der wohl nie allein — ohne freie Carcinomherde vorkommt, kann nicht als Gegenbeweis gelten, da wir doch von der Tuberculose her wissen, dass selbst die ältesten, ruhenden Herde wiederum Stoff zu neuer Infection geben können. Doch wird dies stets Ansichtssache bleiben, zu deren Klärung die $\mathrm{Zu}$ kunft mehr Material erbringen muss. Jedenfalls möchte ich den Standpunkt anderer Autoren (Vinay und Courtois-Suffit), welche diese Hypertrophie als Begleiterscheinung oder Vorläufer der Carcinominvasion auffassen, für berechtigt halten.

Vinay theilt die bei Carcinoma uteri gefundenen Drüsenveränderungen in 3 Gruppen:

1. Adénopathie inflammatoire précancerense, (d. i. unsere weiche Hypertrophie), ou Cirrhose précancereuse,

2. Adénopathie cancereuse proprement dite,

3. Adénopathie inflammatoire ulcérative.

No. 3 bedeutet unsere Secundärinfection vom ulcerirten Primärtumor aus mit irgend welehen pathogenen Mikroben.

Auch ich beobachtete neben der einfachen Hypertrophie Vereiterung durch Secundärinfection und Sklerosirung nach überstandener Secundärinfection neben wahren Krebsmetastasen.

$\mathrm{Ob}$ die weiche Schwellung, wie die Franzosen angeben, ein sicherer Vorbote der Krebsinvasion sei, möchte ich dahingestellt sein lassen, die Infection durch den Krebs kann eben in jedem Stadium der Hypertrophie, wic der Degeneration eintreten.

Auch die Drüse, Fig. 25, welche multiple, zerstreute Fettherde enthält, war bereits in einem kleinen Bezirk des peripheren Sinus vom Krebs inficirt.

Auch die histologischen Befunde sprechen dafür, dass. der Krebs in den Lymphdrüsen kein Hinderniss für sein schrankenloses Wuchern findet. Er erdrückt das Parenchym (Fig. 27 und 32), infiltrirt die Kapsel (Fig. 34), und dann die Umgebung (Fig. 28).

Alle Operateure kennen Fälle, in denen das Abpräpariren der krebsigen Drüsen von der Gefässwand unmöglich war. Selbst bei 
der Section bleibt zuweilen nach unseren Erfahrungen die Resection der Gefässdrüsenconvolute die einzige Möglichkeit die Drüsen zu entfernen.

Die Art der Krebsinvasion in die Lymphdrüsen ist für allc Körperregionen gleich und stimmt für den Gebärmutterkrebs mit den altbekannten Erfahrungen der pathologischen Anatomen und Chirurgen überein (Bozzolo, Gussenbauer, Goldmann, Zehnder, Petrick, Afanassiew u. a. m.). Die Krebszellen infitriren vom Vas afferens aus den Randsinus und den gesammten Lymphraum der Drüse, indem sie sich auf allen Stuitz-Trabekeln aufreihen. Vergl. Fig. 31, welche dieses Verhalten für den Plattenepithelkrebs, und Fig. 33, welche dieselbe Erscheinung an der Metastase eines Cylinderepithelcarcinoms demonstrirt. Erst nach der Anfüllung des complicirt gebauten Lymphsinus dringen die Krebszellen in das Lymphparenchym der Follikel und Markstränge und zuletzt in die im Parenchym verlaufenden Blutcapillaren. Meist wird das Parenchym schon vorher nekrotisch (s. Fig. 33!)

Der Gefahr der Krebsinfiltration sind alle Drüsen ausgesetzt, welche als Stromunterbrecher eingeschaltet sind. Ein Durchwandern von Krebszellen durch eine wahre Lymphdrüse, so dass letztere dabei gesund bleibt, ist eine mechanische Unmöglichkeit. Hochsitzende, isolirte Drüsenherde bei gesunderZwischenetappe(Tiburtius) entstehen durch primär vom Uterus aus höher aufsteigende Bahnen, oder bei verstopfter erster Leitung durch Communicationsbahnen im ableitenden System, welche schon vor dem Hinderniss abzweigen und zur nächsthöheren Gruppe ziehen. Die einmal inficirte Drüse setzt erst dawn wieder neue Metastasen, wemn die Krebszellen das ganze Drüsengewebe erdrückt und den Findsinus (Vas efferens) erreicht haben.

Ist die Aussaat in den Drüsen der I. Etappe erfolgt und der Strom hier verlegt, so sind zunächst nicht die höber gelegenen Drüsen gefährdet, sondern gerade die tieferen. Durch die Hindernisse im directen Stromverlauf kommt es zu einer Umkehr der Stromrichtung auf der befallenen Strecke. Das führt aber hier zur retrograden Infection der tieferen Etappen, d. i. der Gl. obturatoria, jschiadica und den Gl. iliacae externae. In den Operationsberichten Wertheims kann man dies häufig genug verfolgen. Auch Amann findet bei seinem transperitonealen Vorgehen die ersten infeirten Drüsen am Leistenring, d. h. an den Vasa iliac. ext. und 
von da einen Strang zur höheren Etappe an und hinter der Art. hypogastrica.

Die Infection der höheren Etappen (Gl. iliacae comm. und lumbales) bleibt nicht aus; sie ist entweder — um das Beispiel durchzuführen - eine indirecte, $d$. h. auf Umwegen über das Corpus uteri erzielte, indem bei verlegten Cervixbahnen der Lymphstrom über die grosse Seitenanastomose in die unteren Corpusbahnen geht, oder die Infection entsteht direct durch einen Collateralzweig im ableitenden System, der noch unterhalb der Gl. hypogastrica abgehend, sofort höher aufsteigt zu den Gl. lumbales. Diese collateralen Zweigbahnen sind offenbar wechselnd. Auch innerhalb derselben Etappe kann eine tiefer liegende Drüse von den höheren aus retrograd inficirt werden, weil gerade im Bereich derselben Gruppe das Vas efferens der einen Drüse zum Vas afferens der anderen wird.

Die directe, prograde Infection führt von den Vasa afferentia aus zur Infiltration des Randsinus (Fig. 26, 31, 36), die retrograde dringt mit dem $V$ as efferens in einen Endsinus am Drüsenhilus (Fig. 27, 30, 32). Die directen Metastasen infiltriren auch im weiteren Wachsthum vom convexen Pol aus die zunächst in der Form erhalten bleibende Drüse, die indirecten, retrograden Metastasen sitzen als centraler Keim im Herzen der Drüse und erdrücken wachsend wie ein Stempel das Parenchym (Fig. 32 und 41).

Die Metastasen nehmen dabei das möglichst einfache Bild des Muttertumors an, d. h. es findet eine Entdifferenzirung statt, nicht eine über die Differenzirung der Primärgeschwulst hinausgehende Evolution. Ich halte es z. B. für unwahrscheinlich, dass Metastasen eines echten Plattenepithelkrebses der Portio als vollendete Adenomschläuche mit und ohne Flimmern in den regionären Drüsen erscheinen können.

Solche einschichtige Cylinderepithelgänge finden sich in den Kapseltrabekeln, wie auch im Parenchym der Beckenlymphdrüsen (vorwiegend bei Portio-Carcinomen neben einfacher Hypertrophie, sowie auch neben echten Carcinommetastasen in den regionären Lymphdrüsen). Die Veröffentlichungen der letzten Jahre: Ries, Kermauner und Laméris, Wertheim, v. Franqué, Wuelfing, Borst, Kleinhans und meine eigene Arbeit (s. Fig. 35) $)^{\text {) }}$ haben zur Genüge darüber Mittheilung gemacht.

Während nun die anderen Beobachter (Ries, Borst vor allen)

1) Vergl. die Bemerkung bei der Erliärung der Abbildungen Fig. 35. 
Uebergänge zwischen diesen Epithelschläuchen und den echten Carcinomkeimen nicht beobachten konnten und infolgedessen diese Bildungen als Abkömmlinge des Wolff'sehen Körpers erklären wollten, stand Wertheim zunächst auf dem Standpunkt, dass es echte Krebsmetastasen seien. Seine Beweisgründe sind nicht mehr haltbar, nachdem $R$. Meyer in carcinomfreien Leichen diese Adenomschläuche in verschiedenen Drüsen des Beckens und des Schenkels gefunden hat und ihre Zellauskleidung als veränderte Lymph-Endothelien anspricht. Meyer's Vermuthung, dass chronische Reizzustände durch langdauernde eitrige Processe, Phlegmonen etc. die Ursache der epithelähnlichen Umwandlungen des Endothel's sind, scheint sich zu bestätigen, nachdem anch Wertheim (A. Fallkner) bei einem Falle von Beckenphlegmone diese Adenomschläuche in paravesicalen Drüsen nachgewiesen hat.

Die Nothwendigkeit, meine Abbildungen zu beschränken, hielt mich ab, einschlägige Bilder beizufügen.

Die Wahrscheinlichkeit der Meyer'schen Erklärung wird fast zur Gewissheit, nachdem Sick bei einem Lymphangiom der Nebennierenkapsel die gleiche epithelioide Schwellung der Endothelien in den Lymphgängen von Becken-Lymphdrüsen gesehen hat.

Dieselbe Erscheinung beschreibt Waelsch in den regionären Jymphdrüsen bei luetischer Elephantiasis vulvae und Proctitis.

Renaut weist darauf hin, dass in Folge von Wassereinwirkung die flachen Endothelien der Lymphcapillaren bis zur Höhe prismatischer Zellen anschwellen. An frischen Gefrierschnitten, welche ich im Wasser durchmusterte, konnte ich mich in der That davon überzeugen.

Anders steht es mit den Riesenzellen, welche ab und $z u$ in den Lymphdrüsen neben Krebsmetastasen gefunden werden. (S. Fig. 37!) Der Vergleich mit einfachen Tuberkeln, welche ich bei meinen rergleichenden Untersuchungen der Beckendrüsen einige Male antraf, lässt die Vermuthung aussprechen, dass diese unförmlichen Gebilde als eine Art von Fremdkörperriesenzellen um eingeschwemmte Bakterien oder Zellfragmente, vielleicht um todte Krebszellen entstehen.

In 2 Fällen sah ich in den Drüsen der höheren Etappe (Gl. lumbales) (bei Infection der tiefer liegenden Drüsen!) eine multiple Einwanderung von Tumorzellen in den ganzen Lymphsinus der betreffenden Drüsen. (S. Fig. 36.) Die grossen Zellkörper liegen in kleinen Verbänden, durch cinen Spaltraum vom Reticulum ge- 
trennt; in der Lymphbahn. Thre Färbung ist diffus, tief dunkel und undifferenzirt wie bei der Coagulationsnekrose, so dass die Annahme, es handle sich nicht um lebensfähiges Material, gerechtfertigt ist.

Im Gegensatz zu anderen Autoren kann ich ein sprungweises Wandern der Krebskeime in den Drüsen nicht anerkennen. Es waren in unseren Fällen stets ganze Drüsengruppen, niemals einzelne Drüsen befallen. S. Fig. 29, welche die Infection der hypogastrischen und sacralen Drüsen für ein Cervix-Carcinom schematisch darstellt. - Auch nach. v. Rosthorn (Kermauner) und Amann sind stets Drüsengruppen befallen, mit Vorliebe die Gl. hypogastricae und sacrales. Amann, Wertheim, Kleinhans fanden inficirte Drüsen an den Vasa iliaca externa nahe dem Schenkelring. Tiburtius wies nach, dass auch beim Cervix-Carcinom zuweilen die hypogastrische Gruppe übersprungen und die nächstfolgende Etappe inficirt wird. Williams endlich nimmt als Einziger bei Corpuscarcinom die Betheiligung der Inguinaldrüsen bis zu 25 pCt. an. So oft wir die geschwollenen Inguinaldrüsen bei Carc. uteri untersuchten, waren dieselben frei, oder sie erkrankten erst zur Zeit des Recidiv's.

Die Pathologischen Anatomen, welche auf dem Sectionstische die Endstadien des Gebärmutterkrebses sehen, haben auch die Fälle mit weitgehendster Betheiligung der Lymphdrüsen beschrieben: So berichtet Wagner über carcinomatöse Drüsen in der Beckentiefe an der Art. pudenda communis und am Plexus sacralis, Cruveilhier fand häufig die Gl. ischiadicae inficirt, Winkler beschreibt krebsige Drüsen am sacralen Nervengeflecht mit Infiltration der Nervenstämme (Ernst.). Williams erwähnt Fälle ron Cervixcarcinom, welche eine inficirte Lymphdrüsenkette an der Bauchwand aufwärts bis zu den Supraclaviculardrüsen aufwiesen, Petit, v. Ott, Beckmann desgleichen.

Winkler berichtet über die Collumkrebse (Fall Enzmann, Unger und 4 eigene Fälle), bei welchen die verschleppten Krebskeime die ganze Suite der retroperitonealen Drüsen vom Becken aufwärts bis zur Niere befallen hatten und sogar in den Ductus thoracicus eingedrungen waren.

Solehe Fälle haben mehr oder weniger anatomisches Interesse. Für die klinischen Verhältnisse bleiben sie Extreme. Bei allen diesen Befunden auf dem Sectionstisch - soweit sie nicht mikroskopisch erhärtet sind - muss man sich neuerdings die Frage 
vorlegen, ob denn auch wirklich alle geschwollenen Drüsen Krebseinschlüsse enthielten. Wenngleich es bis zu einem gewissen Grade wahr bleibt, dass bei Krebsinvasion die Drüsen verhärtet oder vergrössert erscheinen, so muss doch andererseits betont werden, dass man nicht im Stande ist, makroskopisch die Diagnose auf Krebs immer mit absoluter Sicherheit zu stellen. Grosse, geschwollene Drüsen können frei, kleine und unverdächtige vom Tumor befallen sein. Der Erfahrene wird im günstigen Falle, wenn der Probeschnitt durch die frische Drüse die richtige Fläche trifft, den wirklichen Krebskeim entdecken; auch wenn er klein ist. Der Krebs geht ja stets einher mit einer Zerstörung des Drüsenbaues (s. Fig. 26 und 27). Bei Sarkomen und Endotheliomen aber war ich zuweilen nicht im Stande, die Tumorinfiltration an den nicht vergrösserten Drüsen zu diagnosticiren, so bei der Drüse Fig. 30. Es kann daher die praktische Operationsmethode, welche sich mit der Entfernung der verbärteten und (oder) vergrösserten Drüsen begnügt, theoretisch nicht für rationell erklärt werden.

Wann kommt es nun zur Bildung der Drüsenmetastasen?

Wollte ich diese Frage im streng anatomischen Sinne beantworten, so müsste die Antwort negativ ausfallen. Wir wissen den Zeitpunkt nicht. Wir müssen zugeben, dass bcim Bestehen eines Krebses in jedem Moment die Metastasenbildung einsetzen kann, und dass es bei jugendlichen Personen Carcinome giebt, welche schon frühzeitig bei kleinem Primärtumor die Drüsen befallen. Der Kliniker aber braucht eine Richtschnur. Nicht die Ausnahme, sondern die Regel muss ihm als Wegweiser dienen - mit voller Berechtigung ganz besonders in dieser specifischen Frage; denn jene rasch verlaufenden, von vornherein metastasirenden Krebsformen sind durch kein auch noch so radicales Operationsverfahren heilbar. Die Fälle sind ausserdem so selten, dass sie in der grossen Masse der Gesammttumoren versehwinden.

Für die Gesammtmenge aber gilt gerade heute mehr wie je der Satz: „Das Carcinoma uteri wächst in der Regel continuirlich und setzterst im Spätstadinm uach dem Befallensein von Parametrien und Ligamenten regionäre Drüsenmetast a sen!" Diese von zahlreichen deutschen Klinikern(O I s h a u sen, Winter, Doederlein u. A. m.) vertretene Anschaung ist auch von der Pf annenstiel'schen Klinik seit Jahren verfochten worden. Ries, Wertheim, Irish waren dio wesentlichsten Gegner dieser Lebre. 
Wertheim begründete vor Jahren die Nothwendigkeit seiner Radicaloperation mit der Annahme, dass die Uteruskrebse frühzeitig und sprungweise bei noch freiem Parametrium die Drüsen inficiren. In jüngster Zeit hat er durch Kundrat das Resultat seiner mühsamen Forsehungen veröffentlichen lassen. Von 80 bisher untersuchten Fällen erwiesen sich die Parametrien inficirt in 44 Fällen $=55 \mathrm{pCt}$. Von diesen 44 Fällen waren $22 \mathrm{mal}$ die operativ entfernten Drüsen carcinomhaltig, $22 \mathrm{mal}$ carcinomfrei. Von den 36 Fällen mit freien Parametrien waren nur 4 mal die Drüsen befallen. Kundrat steht nicht an, auf Grund seiner verdienstvollen Untersuchungen den Satz aufzustellen, dass der Krebs in continuo wachsend und nicht sprungweise die Parametrien infiltrire. Wir können seinen Schluss ergänzen: Bei freien Parametrien sind nur in Ausnahmefällen die Drüsen inficirt, und selbst bei befallenen Parametrien sind noch in der Hälfte der Fälle die Drüsen frei.

Unsere eigenen Erfahrungen können sich zwar nicht auf ein so grosses Material stützen, sie scheinen uns aber nicht weniger gewichtig, da sie fast ausschliesslich an vorgeschrittenen Carcinomfällen gewonnen sind. Durch einen eigenthümlichen Zufall ist uns hier in Giessen (seit April 1902) ein Krebsmaterial zugegangen, welches fast ohne Ausnahme inoperabel war oder auf der Grenze dẹr Operabilität stand. Im Jahre 1903 fanden wir nur ein einziges Carcinom im Frühstadium mit freiem Parametrium, im Jahre 1902 nicht ein einziges.

Da die casuistische Veröffentlichung des klinischen Materials nicht in den Rabmen dieser Arbeit passt, behalte ich mir vor, darüber später zu berichten, nachdem auch die Untersuchung der in vielfacher Hinsicht interessirenden Primärtumoren einen gewissen Abschluss erreicht haben. Für unsere Feststellung genügt vorläuffig die Thatsache, dass die Betheiligung der regionären Drüsen - selbst bei unserem stets mit Infiltration der Parametrien complicirten Material - das Verhältniss von $45 \mathrm{pCt}$. nicht übersteigt.

Die zu den inficirten Drüsen gehörigen Primärtumoren waren fast durchweg Cervixtumoren, nur sahen wir in letzter Zeit einen Indothelkrebs des Corpus, der bereits auf die Cervix übergegriffen hatte, mit Infection der Gl. lumbales inferiores und superiores und der Noduli lymphat. parametranes.

Klinisch infiltrirte Parametrien scheinen uns nach wie vor ein wichtiges Zeichen fïr den Beginn des vorgeschrittenen Stadiums. 
Die infiltrirten Parametrien zeigen meiner Meinung nach dem Untersucbenden an, dass auf der Seite der Infiltration die Lymphbahnen verlegt sind und dass in Folge dessen der Strom über die andere gesunde Seite geht, weshalb man in solchen Fällen die carcinomatösen Drüsen auf der Seite des gesunden Parametriums findet. Sind beide Parametrien verlegt, so geht wahrscheinlich der Lymphstrom über die Sacralbahnen oder durch die Anastomosen zu den unteren Corpusbahnen. Wir scheiden bei der Untersuchnng nach Möglichkeit entzündliche Schwarten - welche prognostiseh nicht ungünstig sind - von krebsiger Infiltration, welch letztere stets durch die ganz unverhältnissmässig grosse Schrumpfung einseitige Verschiebungen der Beckenorgane, Verzerrung der Blase und des Ureters bedingt. Die Cystoskopie ist in solchen Fällen ein wesentliches Hilfsmittel zur Klärung des Falles. Ein Oedema bullosum; eine Verzerrung eines oder beider Ureteren macht die carcinomatöse Infiltration der Parametrien sicher. Wir rechnen dann von romherein mit der Nothwendigkeit der Ureteren-Resection, welche sich in den letzten 6 Fällen 2 mal als nothwendig erwies. Die resecirten Ureteren erwiesen sich trotzdem als krebsfrei.

Die Ablösung des Ureters von seiner Unterlage ist in den meisten Fällen unvermeidlich. Sie erfolgt, wenn sie bei der Abbindung der Art. uterina an deren Ursprung und bei der Drüsensuche glücklich vermieden wurde, fast mit Sicherheit beim Durchtremnen des Parakolpiums und beim Abschieben der Blase. Die secundäre Ureterfistel wird sich beim Radicaloperiren kaum ganz vermeiden lassen.

Die Drüsensuche, welche bis zu einem gewissen Grade stets unvollkommen bleibt, wird in unserer Klinik nie extrem betrieben, obwohl alle von mir erwähnten Pforten sorgfältig abgesucht werden. Insbesondere scheinen uns die Sacraldrüsen und die Gl: obturat. mehr Beachtung zu verdienen. Die Drüsen in der Beckentiefe (Lgl. ischiadicae und rectovaginales) sind auch bei dem jetzigen Radicalverfahren fast immer unzugänglich. Thre Entfernung gelingt selbst in der Leiche nur nach breiter Ablösung des Ureters, welcher mit dem Rectum weit nach der Gegenseite hinüber verdrängt werden muss, sowie nach Auslösung der Endausstrahlung der Art. hypogastrica.

Trotzdem muss man theoretisch die Möglichkeit zugeben, dass in gewissen glücklichen Fällen mit den verhärteten und (oder) vergrössérten Drüsen alle Carcinomherde - so weit sie in den Ijymph- 
drüsen sitzen - radical entfernt werden können. Meist aber zerstört eben gerade in den Fällen, in welchen die Drüsensuche nothwendig war, die eventuelle Section alle vorher gehegten Illusionen, radical vorgegangen zu sein. Die mikroskopischen Befunde in makroskopisch ganz unveränderten Drüsen (s. Fig. 36) auf weit vorgeschobenen Etappen sind geeignet, die Hoffnungen sehr herab zu schrauben.

Eine Betrachtung des Verlaufes der abführenden Lymphstämme im Parametrium und Ligament (s. Figg. 1 und 2), ]ässt uns nicht darüber im Zweifel, dass eine Entfernung der Lymphorgane in continuo mit dem Uterus ein frommer Wunsch bleiben muss. Der erste Schnitt im breiten Ligament und in jeglichem Haftband der Gebärmutter eröffnet zahlreiche Lymphbahnen. Man kann doch die Beckenorgane nicht wie bei der Section ausschälen.

In meinen früheren Arbeiten habe ich bereits auseinandergesetzt, wie schwierig es ist, ein richtiges Zahlenverhältniss für die Beurtheilung der Drüsensuche aufzustellen.

Meiner Meinung nach bleibt für die klinische Beweisführung der Berechtigung der Drüsensuche einzig und allein die Statistik, aber eine sehr gewissenhafte, gereinigte Statistik. Nur Fälle mit positiver Drüsensuche, in welchen das Mikroskop Krebskeime in den entfernten Drüsen nachgewiesen hat, dürfen als beweisend anerkannt werden.

Wenn die Zukunft lehrt, dass man mit dem modernen Radicalverfahren nur eine gewisse Anzahl vorgeschrittener Fälle mit Sicherheit retten kann, so wird man die Operation zwar anders als bisher, aber nicht geringer werthen.

Nur wird man dann, wie ich glaube, die Drüsensuche nicht als letzten Act der Totalexstirpation nachfolgen lassen, sondern man wird sich von vornherein über die Ausdehnung der Carcinomaussaat in den Drüsen orientiren und danach die Operabilitätsgrenzen ziehen. Die Drüsensuche muss der I. Act der Operation werden!

Die Thatsache aber, dass nur gewisse Formen von Tumoren zur Drüseninfection neigen, während bei anderen, selbst vorgeschrittenen Fällen nicht ein Mal verdächtige Drüsen gefunden werden können - eine Thatsache, die selbst durch die Section und mikroskopische Nachprüfung erwiesen ist - muss uns ein Ansporn sein, die malignen Fälle vor den gutartigen erkennen zu lernen, damit man nicht wahllos alle, auch die gutartigen Fälle, der erhöhten Lebensgefahr und der schweren Reconvalescenz (Urin- 
fistel!) aussetzt. Geht doch aus allen Statistiken hervor, dass die Häufigkeit der Drüseninfection bei wahlloser Berechnung auf alle operirten Fälle $331 / 3$ pOt. nicht überschreitet.

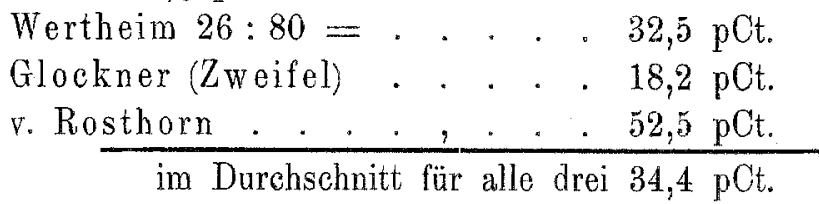

Unsere eigene Procentzahl von 45 pCt. bezieht sich nur auf die Fälle mit infiltrirten Parametrien und nicht auf die Gesammtzahl der z. Th. auch per vaginam entfernten Carcinome.

Wie bekannt ist es seit Jahren das Bestreben unserer Klinik, aus dem anatomischen Bilde der Gewebsstructur die Natur der betreffenden Tumoren erkennen zu lernen und wir glauben, die malignen Formen in den polymorphzelligen Cervixtumoren gefunden zu haben, die bald als weiche Geschwülste der Sarkomund Endotheliomklasse, bald als Adenocarcinome mit infiltrirendem Wachsthum sich darstellen. Mag man nun je nach den persönlichen, pathologisch-anatomischen Anschauungen sich bald mehr für die Diagnose: Endotheliom, bald mehr für die Diagnose: Carcinom entscheiden, die Hauptsache bleibt doch das Erkennen jener malignen Geschwulstformen, welche proteusartig unter den wunderlichsten, histologischen Bildern erscheinen und die Classifizirung erschweren. Ich meine dabei Geschwülste, welche eben in Folge ihrer dem Carcinom für gewöhnlich fehlenden Variationsfähigkeit im Aussehen ebenso sehr dem Sarkom wie dem Carcinom sich nähern, erfahrungsgemäss an den Geschwulstausläufern Uebergangs- oder Entstehungsbilder aus den Lymph- oder Blut- Endothelien erkennen lassen und in Folge einer gewissen Affinität zum Stroma schrankenlos wuchernd mit einer raschen Zerstörung des Mutterbodens einhergehen. Es fehlt die trennende Endothelhaut, welche beim Krebs die Zellpfröpfe rom umgebenden Stroma scheidet. Die Zellen dringen wie ausgestrent in unregelmässigen Grenzen vor; namentlich in den Lymphdrüsen-Metastasen kommt diese diffuse Infiltration und die zerissene, gewissermassen liederliche Zeichnung der Alveolengrenzen zum Vorschein.

Somit bleiben eben diese Tumoren eine wohlcharakterisirte, vom Carcinom za seheidende Gruppe und verdienen ihre Sonderstellung ebenso wie z. B. die sogenannten Peritheliome, die wohl besser als Angiosarkome zu bezeichnen sind; denn es handelt sich bei ihnen um eine Geschwulstproliferation der gesammten Gefäss- 
wandbestandtheile mit Ausnahme der erhalten bleibenden Endothelmembran und der Elastica interna. Gerade dass in den Endotheliomen sarkomatöse angiosarkomatöse Felder sich finden, bestärkt mich in der Annahme, sie eher den Tumoren der Bindegewebsklasse als den Epitheliomen zuzurechnen. In vorgeschrittenen Fällen mag es zuweilen schwierig, ja unmöglich sein (Gebhard), die Histogenese differentialdiagnostisch, zu klären. Aber wir müssen doch, meine ich, versuchen, durch Differenzirung in der Erkennung der Tumoren weiterzukommen, und dürfen nisht alle Geschwülste des Uterus einfach als Carcinome betrachten. Lehren uns doch die Arbeiten der besten Beobachter (Veit, v. Rosthorn, Pfannenstiel, E. Kaufmann, v. Franqué, Pick, Opitz), dass die malignen Tumoren des Uterus zahlreiche Besonderheiten aufweisen.

Für die klinische Berechnung ist es von grosser Wichtigkeit, alle oberflächlichen Plattenepithelkrebse der Vaginalportion als: "Vaginalcarcinome der Portio" von den Erosionscarcinomen, welche den Cervixkrebsen zuzurechnen sind, zu trennen. Freilich bilden auch die leizteren Plattenepithel- und Hornkrebsbilder. Aber daneben bleiben wohl immer polymorphe Formationen übrig, welche die Metaplasie aus dem CylinderEpithel diagnostiziren lassen. Die Zellen der echten Vaginalcarcinome bilden einförmige, in die Breite sich dehnende Elcmente mit flachem Kern, bei den Erosionscarcinomen sind selbst im geschichteten Plattenepithel häufg auf breite Strecken die Kerne nicht flach, sondern iängs neben- und übereinander gestellt, wie etwa im geschichteten, embryonalen Uebergangsepithel.

Die Differenzirung der Tumoren nach ihrem Sitz und histologisehen Bau erscheint mir um so unerlässlicher, je mehr aus allen detaillirten, klinischen Beobachtungen zahlenmässig ein verschiedenes Verhalten der einzelnen Gebärmutterabschnitte hinsichtJich der Schnelligkeit der Drüseninfection hervorgeht.

Dass die reinen Portio- und die Körperkrebse überhaupt erst sehr spät zur Drüseninfection neigen, ist wohl allgemein anerkannt. Für Cervixcareinome werden widerstreitende Angaben gemacht. Cullen behauptet: "auch die Cervixkrebse setzen erst in den Spätstadien Lymphdrüsenmetastasen." Belloeuf, Ries, Irish, v. Rosthorn, Doederlein, Oehlecker, Wertheim, ich selbst u. A. m. fanden gerade bei Cervixtumoren frühzeitiger als sonst inficirte Drüsen. Ich glaube, dass nach dem Studium der letzten 
Arbeiten auf diesem Gebiet (Kermauner und Laméris, Kroemer, Oehlecker, Tiburtius, Gellhorn), ein Zweifel über die relativ rasche Verbreitung der Cervixtumoren, in deren Rahmen sich ja auch die Endotheliome verbergen, gänzlich ausgeschlossen ist.

Freilich setzen auch die echten Portio (vaginal)-Carcinome Drüsenmetastasen, aber viel seltener und in der Regel im Spätstadium. Man ist erstaunt, in den verschiedenen Arbeiten bei Berichten über reichliche Carcinomaussaat in den Lymphdrüsen am Schlusse der Schilderung des Primärtumors so häufig die Diagmose: "Infiltrirender Cervixkrebs" zu lesen. Dieser Name schildert nur das charakteristische, periphere Fortschreiten der polymorphen Tumoren, die im Uebrigen local nach unseren Erfahrungen weiche, rasch zerfallende Adenocareinompartieen neben mehr soliden, alveolären. Feldern und infiltrircnden Zügen bilden können. Es ist der Ausdruck: infiltrirendes Cervixearcinom nicht absolut identiseh mit Seirrhus, obwohl auch bei dieser Krebsform nicht selten mächtige Xetastasen bei kleinen Tumoren sich finden.

Die klinischen Erfahrungen stimmen mit den obigen Anschaungen überein (v. Rosthorn: "Cervixcarcinome geben die schlechteste Prognose". Pfannenstiel: Cervixkrebse werden am raschesten inoperabel, weil sie am frühesten die Parametrien erreichen.").

Natürlich spielt bei der Frage der Metastasirung auch die allgemeine Constitution, die Weite der Lymphbahnen und die Lebhaftigkeit des Säftestromes eine Rolle. Zu Zeiten, wo die Genitalion in besonders reichem Säfteaustausch stehen, wird die Verschleppung eher erfolgen; so bei jugendlichen Krebskranken, vor allem bei denen in graviditate bezw. in puerperio entstehenden Tumoren, an welchem Abschnitt des Uterus sie auch sitzen mögev.

Die Indicationsstellung wnserer Klinik sucht diesen Erwägungen Rechnung zu tragen.

Die entscheidende Fragestellung lautet in jedem Falle:

1. ${ }_{n}$ Sind inficirte Drüsen mit Wahrscheinlichkeit zu erwarten?" und 2. "Bietet die Drüsenausräumung noch Aussicht auf Erfolg?" Practisch unterscheiden wir zwischen beginnenden und vorgeschrittenen Fällen und wenden das abdominale Radicalverfahren mit Drüsensuche an

a) bei beginnenden Fällen von

1. Sarkom oder Endotheliom, an welchem Theil des Uterus der Tumor auch sitzen mag, 
2. jugendlichen und Graviditäts-(Puerper.-) Carcinomen,

3. rasch zerfallendem Cervikrebs mit infiltrirendem Wachsthum;

b) bei vorgesehrittenen Krebsformen

1. der Portio uteri,

2. des Corpus uteri,

soweit sie nicht in a enthalten sind.

Die vaginale Totalextirpation genügt für die beginnenden, reinen Portio- und die Körperkrebse ohne Complication, natürlich stets mit Scheidendammincjsion und breiter Mitnahme der Parametrien.

Die vorgeschrittenen, weichen Geschwulstformen der Klasse a sind überhaupt nicht mehr operabel. Bei diesen wird selbst die radicalste Drüsensuche unvollkommen bleiben, was bisher noch alle Sectionsergebnisse demonstrirten.

Als nothwendige Folge meiner Ausführungen muss ich somit 3 Forderungen aufstellen:

1. Zur Indicationsstellung ist eine Probeexcision mit peinlich genauer, mikroskopischer Untersuchung unerlässlich,

2. In den Statistiken müssen die Radicaloperirten mit positiver (mikroskopisch als nothwendig erwiesener) Drüsensuche von den Uebrigen getrennt werden,

3. Das zur Section kommende Material muss für die mikroskopische Untersuchung ausgenutzt werden.

Die Section soll uns zeigen, was die Drüsensuche anatomiseh leistet, die klinische Beobachtung, welehe Erfolge für die Operirten daraus resultiren.

Das Material, welches der vorliegenden Arbeit zu Grunde liegt, ist mir von meinem hochverehrten Chef, Hern Professor Dr. P fannenstiel zur Verfügung gestellt worden. Dafür und für das Wohlwollen, mit welchem er diese meine Untersuchungen gefördert hat, sage ich ihm an dieser Stelle meinen wärmsten Dank. Auch Herm Geheimen Medicinalrath Professor Dr. Bostroem danke ich für die gütige Veberlassung des Sectionsmaterials. 


\section{Literatur-Verzeichniss.}

\section{A. Anatomischer rheil.}

1) Amann jz, Veber den Beginn und de Verbreitung der Lymphgelässe im Uterus. Vortrag in der Gesellschaft f. Morphologie u. Physiologie su München. 17. Februar 1891.

2) Aristoteles, Mr@i 'Adé $\omega \nu$ nach der Uebersetzung ron Mascagni s. unten.

3) Asellius, Caspar, De lactibus, sive de venis lacteis; Dissertatio. Mediolani. 1627.

4) Auspitz, Die Bubonen der Leistengegend. Arehiץ für Dermatologie a. Syphilis. 1873. Bd. V. S. 443.

5) Bartholinus, Thomas, De lacteis thoracieis in homine bratisque nuperrime observatis. Disputatio Hafniae. 1652.

6) Bonnet, Des kystes et abscès des glandes vulvo-vaginales. Gazette des bôpitaux. 1888. S. 637.

7) Bonnet, R., Grundriss der Entwicklungsgeschichte der Haussäugethiere. Berlin. 1891. (Ref. in Merkel-Bonnet's Jahresberichten. 1891. Bd. 1.) Confr. Polano.

8) Beaunis et Bouchard, Nouveaux eléments d'anatomie déscriptive. 3. éd. 1888.

9) Branne, Hinterlassene Schriften. Cit. von His, Die anatomische Nomenclatur. Arehiv f. Anat. u. Phys. Anatom. Abth. Jakrg. 1895. Supplementband.

10) Brubns, C., Ueber die Lymplgefässe der weiblichen Genitalien. Archiv f. Anat. u. Phys. Anat. Abth. 1898. S. 57.

11) Lncas-Championnière, Lymphatiques utérins et lymphangite utérine. Thè̀se. Paris. 1870.

12) Ohrobak und v. Rosthorn, Erkrankngen der weiblichen Geschlechtsorgane. I. Theil. Wien. 1900 .

13) Trzaska-Chrzonszezewsky in Kiew. Ueber meine Methode der physiologischen Injection der Blut- und Lymphgefässe. Virchow's Archir f. path. Anat. etc. Bd. 153 S. 110.

14) Cruikshank's, William und Paul Mascagni's Geschichte und Beschreibung der Saugadern des menschlichen Körpers. Uebersetzt von Ludwig. Leipzig. 1789 .

15) Cruveilhier, Anatomie déscriptive. T. III. Paris. 1834.

16) Derselbe, Anatomie pathologique du corps humain. Livre llI et XIII.

17) Debierre, Traité élémentaire d'anatomie de l'homme. 1890.

18) v. Ebner, V., A. Kölliker's Handbuch der Gewebelehre des Menschen. 6. Aufl. III. Band. Leipzig. 1902.

19) Encyclopaedie der mikroskopischen Technik mit besonderer Beräcksichtigung der Färbelehre von P. Ehrlich, R. Krause, M. Mosse, H. Rosin, C. Weigert. Wien. Urban u. Schwarzenberg. 1903. 
20) Fioupe, Lymphatiques utérins et parallèle entre la lymphangite et la phlébite utérines. Thèse de Paris. 1876. Confr. Bruhns.

21) Flemming, Zur Anatomie kleinerer Lymphgefässe. Archiv für miliroskopische Anatomie. Bd. 12.

22) Derselbe u. seine Schüler, Ueber die Zellvermehrung in den lymphoiden Drüsen. Archiv für mikroskop. Anat. Bd. 24.

23) Freund, W.A., Ueber die Methoden der tot. Exstirpation des Uterus etc. Beitr. zur Geb. u. Gyn. Vol. I.

24) Derselbe, Referat über Carcin. uteri zum IX. Congress der Deutschen Gesellschaft für Gynälologie. Giessen. 1901.

25) Frey, H., Untersuchungen über die Lymphdrüsen. Leipzig. 1861.

26) Fridolin, P., Des vaisseaux lymphatiques de l'utérus gravide. Russische Militärärztl. Zeitschr. Petersburg. 1872. Confr. Bruhns.

27) Gerota, D., Zur Technik der Lymphgefäss-Injection. - Eine neue Injectionsmasse etc. Anatomischer Anzeiger. 1896. Bd. XII. No. 8.

28) Derselbe, Ueber die Lymphgefässe und die Lymphdrüsen der Nabelgegend und der Harnblase. Anatom. Anzeiger. 1896. XII. S. 89.

29) Derselbe, Die Lymphgefässe des Rectums und des Anus. Archiv für Anat. u. Phys. Anatom. Abth. 1895. S. 240.

30) Gulland, Ueber die Entwickelung der Lymphknoten. The Journ. of Pathol. and Bacter. Edinbourgh. 1894. Vol. II.

31) Haase, J. G., De rasis cutis et intestinorum absorbentibus plexibusque lymphatieis pelvis humanae. Annotationes anatomicae cum iconibus. Lipsiae. 1786.

32) de Haller, Albert, Elementa Physiologiae. Lausanne. 1757. Vol. VII.

33) Hansen, Armaner, Beitr. zur normalen und pathologischen Anatomie der Lymphdrüsen. Virchow's Arch. Bd. 56.

34) Heidenhain, R., Vorlesungen über Physiologie. Breslau. 1893-1894.

35) Herasistratus, De Aministr. Anat. Lib. VII.

36) Herophilus, De usu partium. Liber IV, c. 19.

37) His, Ueber die perivascul. Lymphr. Zeitschr. für wissenschaftl. Zoologie. Bd. XV. S. 127.

38) His, Die anatomische Nomenclatur. Arch. für Anat. u. Phys. Anat. Abth. 1895. Suppl.-Bd.

39) His, W., Beobachtungen über den Bau des Säugethier-Eierstocks. Arch. für mikrosk. Anat. Bd. I. 1865.

40) Hoggan, G. u. F., Comparative anatomy of the lymphatics of the uterus. Journ. of anatom. and Physiol. 1882. XVI. S. 50.

41) Hagier, Mémoire sur les appareils sécrétoires des organes génitaux externes chez la femme et chez les animaux. Annales des sciences natur. III. Se. T. XIII.

42) Hoffmann, Carl, Lehrbuch der Anatomie des Menschen. 1877. 1, u. II.

43) Jolivius (Georges Jolyff), Nihil scriptum reliquit, cfr. Mascagni's Atlas, pag. 3.

44) Kölliker, A., Mikroskop. Anatomie. II. 2.

45) Derselbe, Handbuch der Gewebelehre. 6. Aufl. Bd. III.

46) Kraus, E., Ueber das Zustandelommen der Krebsmetastasen im Ovarium etc. Monatsschr. f. Geb. u. Gyn. XIV. H. 1. 
47) Leopold, Die Lymphgefässe des normalen, nicht schwangeren Uterus, Dieses Archiv. Bd. VI. S. 1.

48) Lindgren, Studier öfrer lifmodrenș byggnad hos nenniskan. Stockholm 1867, efr. Leopold. Med. Arch. III. Bd. Ill. No. 13.

49) Luschka, Die Anatomie des menschl. Bauches. Tübingen 1863.

50) Mascagni, Vasorum lymphaticorum corporis hamani Historia et Ichnographia auctore Paulo Mascagno, publico Anatomes professore, Senis, ex Typ. Pazzini Carli. 1787.

51) Martin, E., Handatlas der Gynäk. und Geburtsh. Berlin. 1878.

52) Martin u. Léger, cit. nach Bruhns. No. 10. S. 66.

53) Miercejewski, Recherches sur les lymphatiques de la conche sousséreuse de l'utérus. Journal de l'Anat. et de la Physiol. 1879. p. 201.

54) Moran, Remarques sur les vaisseaux lymphatiques des organes génitaux de la femme ot leurs anastomoses aveo ceux du rectum. Comptes rendus de la Société de biologie 1894. No. 33. p. 812 .

55) Nuck, Antonii, Adenographia curiosa nteri feminei anatome nova. Lugd. Bat. 1691 .

56) Peiser, E., Anatom. u. Kinische Untersuchungen über den Lymphapparat des Uterus mit besonderer Berücksichtigung der Tot. exst. des Uterus. Inaugural-Dissertation. Breslan 1898. Zeitscbr. f, Geb. und Gyn. Bd. 43. S. 259.

57) Poirier: P’., Lymphatiques des organes génitaux de la femme. Progress médical. 1889. Il. p. $491 \mathrm{ff}$.

58) Derselbe, Du rôle des lymphatiques dans les inflammations de l'atérus, des annexes et du péritoine pelyien. Progrès. méd. 1890. I. p. $41 \mathrm{ft}$.

59) Derselbe, Quinze leçons d'anatomie pratique. Paris. 1892.

60) Polano, 0., Zur Technili der Darstellung von Lymphbahnen. Deutsche med. Wochenschr. 1902. No. 27.

61) Derselbe, Beitrag zur Anatomie der Lymphb. im menschlichen Eierstock. Monatsschr. f. Geburtsh. u. Gynäk. 1903. Bd. 17. H. 引ُ u. 4.

62) Quénu, Vaisseaux lymphatiques de l'Anus. Bulletins de la Soc. anatom. de Paris. 1893. Juin. Fasc. No. 16.

63) Quain's, Anatomy. 8 éd. 1876.

64) Ranvier, Ueber die Entwicklung der Lymphspalten. Archir d'anatom. microskop. T. 1.

65) Derselbe, Comptes rendus de l'Acad. des Sciences. T. 123. p. 1038.

66) Derselbe, Du système lymphatique. Leçons - Progr. méd, 1873.

67) Raubor, Lehrbuch der Anatomie. 1893. 4. Aufl. Bd. II. S. 223.

68) Reclilinghausen, Zur Fettresorption. Virehow's Archir. Bd. XXVI.

69) Derselbe, Die Lymphgef. u. ihre Beziehungzum Bindegewebe. Berlin. 1862.

70) Derselbe, Das Lymphgefässsystem in Stricker's Handbuch der Lehre von den Geweben. Leipzig. 1871.

71) Richet, Anatomie médico-chirurgicale. 4 éd. 1874.

72) Rille, J. H., Bartholinitis a. Leistendrüsen. Arch, f. Dermatol. u. Syphilid. 1896. Bd. XXXVI. S. 381.

73) Rudbekius (A. Rudbeck), De sero eiusque vasis. Upsal. 1661 denue in Selectis Halleri Tom. VII edita; nova cxercitatio anatomica exhibens ductus hepatis aquosos et rasa glandularum serosa. Arrosiae 1653. 
74) Sa ck, Ein Fall von aligemeiner Lymphstauung (Stauungsödem) der Haut nach Vereiterung des grössten Theils d. region. Lymphdr. München. med. Woch. 1903. No. 3.

75) Sappey, Ph. C., Traité d'Anatomie déscriptive. Ed. 4. Paris, 1888.

76) Derselbe, Description et iconographie des vaisseaux lymphat. considérés chez l'homme et les vertébrés. Paris. 1885.

77) Saxer, Ueber die Entwicklnng der Lymphknoten. Anatom. Hefte. Bd. 6.

78) Schwarz, A., Ueber die Lymphg. des Ovarinm. Ref. bei Mier cejews si 47.

79) Stahr, In dem Atlas der topograph. Anatomie des Menschen von K. v. Bardeleben u. H. Häckel. 2. Aufl. Jena. 1901. Fig. 118.

80) Tarnier, Cit. pach Bruhns (10). S. 66. Note 4.

81) Teichmann, Das Sangadersystem. Leipzig. 1861.

82) Testut, Traité d'Anatomie humaine. 1893.

83) Tillaux, Traité d'Anatomie topographipue. 1887. p. 918.

84) Waldeyer, W., Das Becken. Bonn. 1899.

85) Derselbe, Eierstock und Ei. Leipzig. 1870.

86) Wallich, Recherches sur les vaisseaux lymphat. sous-séreux de l'utérus gravide et non gravide. Thèse de Paris. 1891.

87) Wessling (Veslingius), Epistolae post. Cit. nach Mascagni (44).

B. Pathologisch-Anatomischer Theil.

1) Abel und Landau, Beitr. zur normalen u. patholog. Anatomie des Gebärmutterhalses. Dieses Archiv. XXXXIII. S. 199.

2) Afanassiew, Centralbl. f. d. medic. Wissensch. 1876.

3) Amann, J. A., Jr., Zur Technik der transperiton. Exstirpation etc. Monatsschr. für Geburtsh. u. Gynäk. Bd. XVI. S. 290.

4) Baier, K., Ueber die Regeneration u. Neubildung der Lymphdrüsen. Prager Zeitschr. f. Heilkunde. Bd. 6. S. 105 und Bd. 7. S. 423

5) Be okmann, W., Einige klinische Beobacht. über Uteruscarcinom. Zeitschr. f. Geburtsh. u. Gynäk. Bd. 45. S. 492.

6) Belloeuf, Thèse de Paris. 1900.

7) Blau, Einiges Pathologisch-Anatom. über den Gebärmuttorkrebs. In. Dissertation. Berlin. 1870.

8) Borst, Die Lehre von den Gesebwïlsten. Wiesbaden. 1903.

9) Bourgéry et Jacob, Traité complet de l'Anatomie de l'homme. Paris. 1851.

10) Bozzolo, Verbreit. der Krebsnenbild. in den Juymphdrüsen. Centralblatt f. d. medic. Wissensch. 1876 .

11) Broese, Demonstrat. in der Berliner geburtsh. Gesellsch. 9. VI. 1899. Zeitschr. f. Geburtsh. u. Gynäk. Bd. 41.

12) Chrobak, R., Wiener klin. Wochenschr. 1900. No. 40.

13) Clark, J. G., A more radical method of performing hysterectomy for cancer of the uterus. Jobns Hopkins Hosp. Bull. 1895. Vol. VI.

14) Derselbe, Ten cases of cancer of the uterus operated upon by a more radical method of perform. hysterectomy. J. Hopk. Hosp. Bull. 1896. Vol. VII.

15) Courtois - Snffit, Journal des Praticiens, 1901, No. 21 über Lymphdrüsenveränderungen bei Cteruslirebs. 
16) Cruveilhier, Anatomie pathologique du corps humain. Paris. 1832 bis 1842 .

17) Cullen, T. S., The cancer of the uterus. 1900.

18) Derselbe, Med. Record. Dec. 9. 1899.

19) Cushing, J. of Am. med. Ass. July 26. 1902.

20) Dittrich, Pathologisch-Anatom. Bericht. Vierteljahrschr. f. pract. Heilkunde. Prag. 1845. 46.

21) Doederlein, A, Ceber abdomin. Fixstirp. d. carcin. Uterus nach Wertheim. Centralbl, f. Gynäk. 1903. No. 26. S. 681 .

22) Dybowski, Zur Statistik des Gebärmutterkrebses u. seine Metastasen, In. Dissert. Berlin. 1880.

23) Florenzo d'Erohia, Beitr. zum Studium d. prim. Uteruskr. Zeitschr. f. Geburtsh. v. Gynäk. Bd. 38. H. 3.

24) Ernst, Verbr. des Carein. in den Lymphb. der Nerven. Verhandl. der Dentsch. pathol. Ges., 4. Tag. Hamburg. 1902. Ref. Centralbl. f. Gynäk. 1902. No. 38 .

25) Kimanuel, Hornkrebs d. Corpus uteri. Zeitschr. f. Geburts. u. Gynäk. Bd, 32. S. 477.

26) Derselbe, Uaber gleichzeit. Vorkommen v. Drüsenkrebs und Hornkrebs im Uteruskörper etc. Zeitschr. f. Geburtsh. u. Gynäk. Bd. 46. S. 434.

27) Falkner, A., Zur Frage der epithelialen Einschlüsse in Lymphdrüsen. Centralbl. f. Gynäk. 1903. No. 50.

28) Fränkel E. u. G. Wiener, Drüsenkrehse d. Uterus. Hegar's Beitr. \%. Geb. u. Gyn. Bd. Il. H. 3.

29) v. Franqué, O., Das beginnende Portiocancroid u. d. Ausbreitungswege d. Gebärmutterkrebses. Zeitschr. f. Geburtsh. u. Gynälr. Bd. 44. H. 2.

30) Freund, A. W., Ueber die Methoden d. Tot.-Exstirp. d. Uterus ete. Beitr. zur Geb. u. Gyn. Bd. I. S. 343.

31) Derselbe, Carcinoma nteri. Referat für den IX. Congress d. Deatsch. Ges. für Gynäk. Giessen. 1901. (Referat und Verhandlungen.)

32) Freund, H. W., Zur erweiterten Freund'schen Oper. bei Krebs d. Gebärmutter. Zeitschr. f. Geburtsh. u. Gynäl. Bd. 46. S. 206.

33) Freund, R., Unteres Uterinsegment u. beginnendes Cervixcarcinom bei einem Fall von fibrösen Polypen des Cervix. Hegar's Beitr. z. Geburtsh. a. Gyn. 1900. Bd. 3. H. 2.

34) Funke, A., Beitr. zur abdomin. Tot.-Exstirp. etc. München. medicin. Woch. 1901. S. 309 und Zeitschr. f. Geb. u. Gynäk. Bd, 36. 1897 und Bd. 39. 1898.

35) Gebhard, C., Patholog. Anatomie d. weibl. Sexualorgane. Leipzig. 1899.

36) Derselbe, Eine Mischgeschwulst d. Uterus. Zeitschr, f. Geburtsh. u. Gynäk. Bd. 48. S. 111.

37) Gell horn, G., The Lymph Glands in Uterine Cancer. Repr. from American Gynecology. Nobr. 1902.

38) Gessner, Carcinomatös degenerirter Drüsenpolyp d. Corpus. Verh. d. Berlin. Ges, f. Geb. u. Gyn. 8. Novbr. 1898.

39) Derselbe, Ueber den Werth u. die Technik d. Probecurettements. Zeitschr. f. Geburtsh. v. Gynäl. Bd. 34. S. 3. 
40) Derselbe, Münchener med. Wochenschr. 1902. S. 78.

41) Glockner, Verhandl. d. Deutsch. Ges. f. Gyn. 3.-6. Juni 1903. Würzburg.

42) Goldmann, Anatom. Untersuch. über die Verbreitungswege bösartiger Geschwülste. Bruns Beitr. z. Klin. Chirurgie. 1897. Bd. 18.

43) Gussenbauer, Ueber die Entwickelung der secundären Lymphdrüsengeschw. Prager Zeitsehr, f. Heilkunde. 1881. Bd. 2.

44) Hammerschlag-Schlan, Ueber Vermehrung erkrankter Lymphdrüsen. Verhandl. d. Deutsch. Patholog. Ges. 22.-26. Septbr. 1902. 5. Tag. Karlsbad. 1902.

45) II ellendahI, H., Ueber Impfcarcinome am Genital-Tractus. Beitr. z. Geburtsh. u. Gynäk. Bd. VI. S. 422.

46) v. Herff, 0., Zur Drüsenausräumung bei Carcin. uteri. Hegar's Beitr. zur Geburtsh. a. Gynäk. Bd. 6. S. 1.

47) Herzfeld, Wiener klin. Wochenschr. 1900. No. 48.

48) Hitschmann, Ein Beitr. zur Kenntniss des Corpuscarc. Dieses Archir. Bd. 69. H. 3.

49) Hofmeier, Zur Anatomie u. Therapie des carc. corp. ut. Zeitschr. f. Geburtsh. u. Gynäk. Bd. XXXII. 2. S. 171.

50) Derselbe, Zeitschr. f. Geburtsh. u. Gynäk. 1866 und 1894. — Verhandl. d. Deutsch. Ges. f. Gynäk. 1901. Giessen. 9. Tagung.

51) Joerss, Cit. nach Goldmann (No. 42).

52) Irish, J. C., Abdominal Hysterectomy for Cancer of the Cervix. Boston Med. and Surg. Journ. 1899 p. 251.

53) Jordan, Die chirurgische Behandlung der Uteruscarcinome Zeitschr. f. Geburtsh. und Gynaek. Bd. 45. S. 300.

54) Katzenstein, Demonstr. eines seit 16 Jahren bestehenden Carcinoma corporis uteri. Zeitschr. f. Geburtsh. n. Gynaek. Bd. 42 . S. 176.

55) Kaufmann, E., Lehrbuch der patholog. Anatomie. II. Aufl.

56) Derselbe, Eine eigenartige Form carcinom. Entartung des Endometr. corporis uteri. Verhandl. d. Schles. Ges. f. vaterländ. Kultur. 5. Mai 1894.

5i) Derselbe, Untersuchungen über das sogenannte Adenoma malignum, speciell dasjenige der Cervix uteri nebst Bemerkungen über Impfmetastasen in der Vagina. Virchow's Archiv 1. path. Anat. Bd. 154. 1.

58) Keitler, H., Zur klinischen Dignität der Cervicalpolypen. Hegar's Beitr. z. Geburtsh. u. Gynäk. Bd. III. H. 2. S. 309.

59) Kelly, H. A.; Notes on an Improved Method of Removing the Canreronus Uterus by the Vagina. Bull. J. Hopkins Hosp. March. 1900.

60) Derselbe, The Present Status of Operations for Cancerous Uteri. Journ. Americ. Med. Ass. 19. May 1900.

61) Kermauner u. Laméris, Zur Frage der erweiterten Radicaloperation des Gebärmutterkrebses. Beitr. z. Geburtsh. und Gyn. Bd. V. No. 1.

62) Kermauner, Diskussionsbericht über 52 Fälle von abdomin. Radicaloperationen aus der Grazer Frauenklinik ref. Monatschr. f. Geburtsh. u. Gynäk. Bd. XVlII. H. 4. S. 614,

63) Klein, G., Die. operative Behandlung des Gebärmutterkr. Münchener medic. Wochenschr. 1903. No. 11 und 12. S. 472 und 513. 
64) Derselbe, Die chirurgische Behandlung der Ut. carc. 4. internat. Congr. zu Rom. Ref. Centralbl. f. Gynäk. 1902. S. 1353.

65) Derselbe, Carcinoma uteri. Naturforsch..-Vers. zu Karlsbad. Centralbi. f. Gynäk. 1902. S. 1146.

66) Kleinhans, F., Erfahrungen über die abdominale Radic.-Op. des Uteruscarc. Prag. med. Wochenschr. No. 48, 49, 50 u. 51.

67) Koenig, R., Hbdominale Radical-0p. bei Uteruscarcinom. Hegar's Beitr. z. Geburtsh. u. Gynäk. Bd. II. H. 2. S. 402.

68) Krans, E., Siehe in Literatur-Verz. Theil A.

69) Kroemer, Klinische und anatomische Untersuchungen über den Gebärmutterkrebs. Dieses Archiv. Bd. 65, No. 3.

70) Derselbe, Ueber die Lymphorgane der weibl. Genitalien und ihre Veränderungen bei Carcinoma uteri. "Monatsschr. f. Geburtsh. und Gynäk. Bd. XVIII. H. 5. S. 673 .

71) Derselbe, Ceber Drüsenbefunde bei Carein. uteri. Verhandlungen d. d. Deutschen Gesellschaft für Gynäk. Bd. X.

72) Kroenig, B., Zur Technik der abdom. Totalexstirp. des carcinomat. Uterus. Monatsschr. f. Geburtsh. n. Gynär. Bd. XV. S. 879.

73) Derselbe, Gleichzeit. Vork. von Uterus- u. Magencarc. Monatsschr. f. Geburtsh. u. Gynäk, Bd. XV. S. 896.

74) Derselbe, Die doppels. Unterb. der Aa. bypogastr. u. oraricae. Zur palliat. Beh. des Ut. carc. Centralbl. f. Gynäk. 1902. S. 1073.

75) Derselbe, Diskussionsvortrag über d. Wertbeim'sche Oper. Ref. Centraibl. f. Gynäl. 1902. No. 26.

76) Küttner, H., Die perforirenden Lymphg. des Zwerchfells n. ihre pathologische Bedentung. Beitr. z. klin. Chirurgie. Bd. 40. 1903. S. 136.

77) Kuestner, 0 ., Veber die Frend'sche Operation bei Gebärmutterkrebs Samml. klin. Vortr. No. 204.

78) Derselbe, Verbandl. d. Deutsch. Ges. f. Gynäk. Bd. IX. 1901. S. 100.

79) Lubarsch, Geschwülste, Ergebnisse der allgem. Pathologie u. pathelogischen Anatomie. 1895, Jahrg. I. Abth. 2.

80) Kundrat, Ueber die Ausbr. d. Carcinoms im parametr. Gewebe bei Krebs des Collum uteri. Dieses Archiv. Bd. 69. S. 355.

81) Kunze, Ein Fall von zahlreichen Impf-Metastasen eines primär. Plattenepithellr. der Cervix auf d. Mucosa des Cavum ut. Hegar's Beitr. z. Geburtsh. u. Gynäk. Bd. 4. S. 31.

82) Makenrodt, A., Beitr, z. Verbesserung der Danerresultate der Totalexstirp. bei Carc. ut. Zeitschr. f. Geburtsh. u. Gynäk. Bd. 29. 1894.

83) Derselbe, Verbandl. d. Dentsch. Gesellsch. f. Gynälx. 1901. IX. S. 139.

84) Derselbe, Verhandl. der Deutsch. Gesellsch. f. Gynäli. 1903. X. and ebenda 1902. S. 1207.

85) Derselbe, Centraibl, f. Gynäk. 1901.

86) Derselbe, Zeitschr. f. Geburtsh. a. Gynäk. Bd, 47. S. 126 und 152, ebenda Bd, 48. S. 188.

87) Nartin, A, Verhandl. d. Dentsch. Gesellsch. f. Chirurgie. XIIf. Berlin. 12. April 1901.

88) Menge, Diskussionsvortrag zur Frage der Radical-Operat. bei Carc. ut. Centralbl. f. Gynäk. 1902. No. 26. S. 701. 
89) Meyer, R., Ueber epitheliale Hohlräume in Lymphdrüsen. Verhandl. d. Gesellsch. f. Geburtsh. u. Gynäk. zu Berlin. Zeitschr. f. Geburtsh. und Gynäk. Bd. 49. S. 554 .

90) Odebrecht, I Fall ron lange best. Uteruscarcinom ohne Metastasen Zeitschr. f. Geburtsh. u. Gynäk. Bd. 42. S. 177.

91) Oehlecker, Drüsenuntersuchungen bei 7 Füllen von Uteruscarcinom. Zeitschr. f. Geburtsh. u. Gynälk. Bd. 48. H. 2.

92) Olshausen, R., Zur Statistik u. Operat. des Gebärmutterlirebses. Verhandl. d. Doutsch. Gesellsch. f. Gynäk. IX. S. 156.

93) Derselbe, Ueber Impfmetastasen und Spätrecidive nach Carcinomoperationen. Zeitschr. f. Geburtsh. u. Gynäk. Bd. 48. H. 2.

94) Dersèlbe, Zum Vergleich der vaginalen u. abdominalen OperationsMethode bei Carcinoma uteri. Zeitschr. f. Geburtsh. a. Gynäk. Bd. 50. H. 1. S. 1.

95) Opitz, Zwei ungewöhnliche Uterus-Carcinome nebst Bemerkungen zur Theorie der tösartigen Geschwülste. Bd. 49. S. 169.

96) v. Ott, Dimitri, Ueher die operat. Behandlung des Gebärmutterkrebses. Monatsschr. f. Geburtsh. u. Gynäk. Bd. 12. S. 261.

97) Peiser, E., Anatom. u. Klin. Untersuchungen über den Lymphapparat des Uterus etc. Zeitschrift f. Geburtshülfe und Gynälologie. Bd. 43. S. 259 .

98) Petersen, Verbandl. des 13. Congresses der Deutsch. Gesellsch. für Chirurgie. Berlin 1902.

99) Petit, A., Ganglion sus-claviculaire gauche cancéreuse dans un cas de cancer de l'utérus. Bull. et Mém. Soc. Mód. d'Hôp. Paris. 1888. 26.

100) Petrik, Ueber die Verbreitung des Carcinoms in den Lymphdrüsen. Deutsche Zeitschr. f. Chirurgie. Bd. 32. 1891.

101) Pfannenstiel, J., Ueber die Heilerfolge bei Krebs der Gebärmutter. Centralbl. f. Gyn. 1901. S. 361.

102) Derselbe, Ueber das gleichzeitige Auftreten von Carcinom am Collum und am Körper des Uterus. Ebenda. 1892. S. 841.

103) Derselbe, Beitr. zur pathol. Anat. u. Histogenese des Uteruskrebses ete. Ebenda. 1893. No. 78.

104) Puppel, E., Ueber die Ansbreitung des Gekärmutterkrebses in prälormirten Lymphbahnen. Monatsschr. f. Geburtsh. u. Gynäk. Bd. 13. S. 76 und Beitr. zum Studium der Ausbreitung des Gebärmutterkrebses eto. Inaug.-Dissert. Königsberg. 1900. (Virchow's Archiv. Bd. 140.)

105) v. Recklinghausen, Ueber die venöse Embolie und den retrograden Transport in den Venen und in den Lymphgefässen. Virchow's Archiv

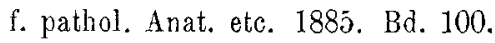

106) Ribbert, Ueber Regeneration und Entzündung der Lymphdrüsen in Ziegler's Beitr. zur path. Anat. etc. Bd. 6 S. 187.

107) Riechelmann, W., Eine Krebsstatistik yom pathologisch-anatomischen Standpunkt. Berl. klin. Wochenschr. 1902. No. 31-32.

108) Ries, E., Eine neue Operationsmethode des Uteruscareinoms. Zeitschr. f. Geburtsh. u. Gynäk. 1895. Bd. 32.

109) Derselbe, Eine neue Operationsmethode des Uteruscarcinoms. Ebenda. 1897. Bd. 37. 
110) Ries, E., Results of the Extended Operations for sarcinoma of the Uterus. Americ. Gyn, and Obst. Journ. Vol. 13 p. 570.

111) Derselbe, Recent Developments in Our Knowledge of Cancer of the uterus. Americ. Journ. of Obstetr. Vol. 44 p. 29.

112) v. Rosthorn, A., Erfahrungen über die momentanen Heilerfolge etc. Centralbl. f. Gynäk. 1901. S. 588.

113) Derselbe in Chrobak und Rosthorn, Die Erkrankungen der weiblichen Geschlechtsorgane.

114) Derselbe, Verhandlungen der Deutschen Gesellschaft für Gynäkologie. 29.-31. Mai. 1901. Giessen. IX.

115) Derselbe, Ueber Schleimhautverhornung der Gebärmutter. Festschr. der Deutschen Gesellschaft für Gynäkologie. Wien, A. Hölder.

116) Derselbe, Demonstration zum Chorionepitheliom, Verhandlungen der Deutschen Gesellschaft für Gynälkologie. 3.-6. Juni 1903 zu Würzburg.

117) Ruge, $C$., Ueber Adenoma uteri malign. und die verschiedenen Formen desselbon. Zeitschr. f. Geburtsh. und Gynäk. und Verhandlungen der Dentsohen Gesellschaft für Gynälkologie. Berlin. S. auch Winter's Lehrbuoh der Diagnostik.

118) Rumpf, Zur Radiealoperation. Demonstration eines Carc. ut. Zeitschr. f. Geburtsh. u. Gynäk. 1895. Bd. 33. S. 212.

119) Russel, W. W., The Operative Significance of Metastases and Postoperative Recurrences in Carcinoma of the Uterus. Americ. Journ. of Obstetr. Bd. 34 . p. 851 .

120) Schauta, Ueber Krebsoperation. Demonstr. in der geburth.-gynäk. Gesellsch. in Wien. R. Centralbl. f. Gynäk, 1902. S. 209.

121) Derselbe, Die Operation des Gebärmutterkrobses mittelst des Schachardt'sehen Paravaginalschnittes. Monatssohr. f. Geburtsh. a. Gynäk. Bd. XV. S. 133.

122) Seelig, A., Path.-anat. Untersuchungen über die Ausbreitungswege des Gebärmuttetkrebses. Inaug.- Dissert. Strassburg. 1894.

123) Staude, C., Verhandlungen der Deutschen Gesellschaft für Gynäkologie. IX. 1901. S. 177.

124) Derselbe, Ueber Totalexstirpation des carcinomatösen Uterus etc. Monatsschr. f. Geburtsh. u. Gynäk. Juni 1902.

125) Sick, Ueber Lymphangiome und Flimmerepitheloysten in der Aebennierenkapsel und in einer Beckenlymphdrüse. (Aus dem pathol. Institut in Bern.) Virch. Arch. f. pathol. Anat. Bd. 172. H. 3.

126) Sondheimer, Primäres Corpuscarcinom mit Haematom und Haematocolpos bei Atresia rag. senilis. Monatsschr. f. Geburtsh. u. Gynäk. Bd. I. S. 348 .

127) Stein, Beiträge zur Kenntniss der Entstebung des Gebärmutterkrebses. Monatsschr. f. Geburtsh. u. Gynäk. Bd. XVII. S. 209.

128) Terrier, Gaz. des Hôp. July 22. 1900.

129) Thiersch, Der Epithelialkrebs namentlich der äusseren Haut. Leipzig. 1865 .

130) Tiburtius, Collumcarcinom von kurzer Dauer und geringer Ausbreitung bei hochgradigen Lymphdrüsen-Metastasen. Hegar's Beitr, zur Geburtsh. 1. Gynäli, Bd. VII. H. 1. 
131) Veit, J., Ueber Operationen bei vorgeschrittenem Uteruscarcinom. Berl. klin. Wochenschr. 1899. No. 5 .

132) Derselbe, Verhandlungen der Deutsch. Gesellsch. f. Gynäk. 1901. IX.

133) Derselbe, Zur Anatomie des Carcinoma uteri. Verhandiungen d. Berl. Gesellsch. f. Geburtsh. u. Gyn. 26. A pril 1895. Zeitschr. f. Geburtsh. 1. Gynäk. 1895. Bd. 32 .

134) Vinay, C., Ueber Carcinom in den Lymphdrüsen. Lyon. Méd. 1901. No. 38 .

135) Waelsch, L., Ueber die Beziehungen zwischen Rectumstrictur, Elephantiasis Vulvae und Syphilis. Arch. f. Dermatol. u. Syphilis. Bd.LIX. H.3.

136) Wagner, Gebärmutterkrebs. Fine patholog.-anatom. Monographie. Leipzig. 1858.

137) Waldeyer, Das Becken. Bonn. 1899.

138) Werder, X. 0., A New Operation for the Radical Treatment of Cancer of the Cervix. Americ. Journ. of Obst. 1898. Bd. 37. S. 289.

139) Wertheim, E., Zur Frage der Radicaloperation beim Uteruskrehs. Dieses Archiv. Bd. 61. H. 3.

140) Derselbe, Ein neuer Beitrag zur Frage der Radicaloperation etc. Dieses Archiv. Bd. 65. H, 1.

141) Derselbe, Kurzer Bericht über eine 3. Serie ron 30 Uteruskrebsoperationen. Centralbl. f. Gynäk. 1902. S. 249.

149) Derselbe, Vergl. auch die Verhandlungen der Deutschen Gesellschaft für Gynäkologie in Giessen. IX. und X. in Würzburg. Desgl.

143) Derselbe, Die chirurgische Behandlung des Uteruscarcinoms. Monatsschr. f. Geburtsh. a. Gynäk. Bd. XVI. S. 576 und IV. internat. Gynäkologen-Congress in Rom.

144) Derselbe, Zur Frage der Radicaloperation bei Uteruscarcinom. Centralbl. f. Gynäk. 1902. S. 693.

145) Wertheim, E., Demonstr. (Wien. Ges. f. Geburtsh. u. Gynäk.) Centralbl. f. Gynäk. 1902. S. 1251.

146) Derselbe, Zum Aufsatz Winter's über die Principien der CarcinomStatistik. Centralbl. f. Gynäk. 1902. No. 4. S. 225.

147) Derselbe, Zur Frage der Carcinomstatistik. Centralbl. f. Gynäk. 1902. S. 633 .

148) Derselbe, Zur Kenntniss der regionären Lymphdrüsen beim Uteruscarcinom. Centralbl. f. Gynäk. 1903. No. 4. S. 105.

149) Williams, W. R., Ueber den Krebs der Gebärmutter, übers. von Abel u. Landau. Berlin 1890.

150) Derselbe, The Clinical Features of Uterine Cancer. Lancet 1896. II. S. 1074 .

151) Derselbe, The Surgical Treatment of Uterine Cancer. Lancet 1899. Bd. II. S. 1086.

152) Winter, Ueber die Revidive des Uteruscarcinoms ete. Zeitschr. f. Geburtsh. u. Gynäk. Bd. XXVII. S. 101.

153) Derselbe, Carc. corpolis ut. mit Metastasen im Orarium. Zeitschr. f. Geburtsh. u. Gynäk. Bd. XXX. 1. S. 285.

154) Derselbe, Zur Frage der Carcinomstatistil: Centralbl. f. Gynäk. 1902. S. 81 u. S. 545 . 
154 P. Kroemer, Dio Lymphorgane der weiblicben Genitalien.

155) Derselbe, Verhandl. der Deutsch. Gesellsch. f. Gynäk. IX u. X.

156) Derselbe, Anatomie des Carc. uteri in Veit's Handbueh d. Gynäk.

157) Derselbe, Ueber die Radicaloper. bei Carc. ut. Referat f. d.Verhandl. d. Deutsch. Ges. f. Gynäk. Giessen 1901.

158) Winkler, Ueber die Betheiligung des Lymphgetässsystems an der Ver* schleppung bösartiger Geschwülste. Virchow's.Arch. Bd. 151. 1898.

159) Wuelfing, H., Zur Pathologieder Geschwulstbild ung im weibl.Gesehlechtsapparat. Zeitschr. f. Geburtsh. u. Gynäk. Bd. 44. S. 1.

160) Zehnder, Ueber Krebsentw, in den Lymphdrüsen. Virchow's Arch. Bd. 119. 1890. S. 261.

161) Derselbe, Ueber regenerative Neubildnng dar Lymphdrüsen. Virchow's Arch. Bd. 120. 1890. S. 294.

162) Z weifel, P., Die chirurg. Behandl. des Uteruscarc. 4. internationaler Gynäk.॰Congress zu Rom. Centralbl. f. Gynäk. 1902. S. 1212.

163) Derselbe, Discussion za Wertheim's Vortrag. Centralbl. f: Gynäk. 1902. No. 26. 696.

164) J. Wallart, Ueber die Combinat, von Carc. u. Tuberculose des Uterus. Zeitschr. f. Geburtsh. u. Gynäk. Bd. 50. S. 243.

\section{Erklärung der Abbildungen auf Tafel I-VI.}

Figur 1. Verlauf der Lymphbahnen des Uterus (von vorn betrachtet) im breiten Ligament. Der Uterus ist nach der linken Scite dislocirt und die r. T'ube emporgezerrt zur Entfaltung des br. Ligaments.

1. Die tiefen, zu den Iliacalgefässen ziehenden Collum- und Corpusbahnen.

2. Die hohen Corpusbahnen verlaufen zum Ligam. ovariopelv, und in diesem zur Aortengegend. Ihr Verlauf im br. Ligam. entspricht dem Hilas ovarii. Blase and Tube sind von dem einen einzigen Einstich aus (in die Portio) mit injicirt.

Figur 2. Verlanf der Lymphbahnen des Uterus und des Ovarium. Der Uterus ist stark anteflectirt über die Symphyse gelegt und nach vorn geklappt.

A. Vasa lymphatica colli:

1) zu den Lymphoglandulae sacrales laterales durchs Ligam. sacrouterinum und

2) zu den Lymphoglandulae hypogastric, et iliacae extern. ziehend.

B. Vasa Jymphatica corporis uteri:

3) die Bahnen des unteren Corpusabschnittes verlanfen wie die Collumbahnen 2;

4) die Bahnen des oberen Corpusabschnittes verlaufen mit den Ovarial-Lymphbahnen zusammen zu den Lymphoglandulae lumbales.

5) Die Ovarialbahnen. 
Figur 3. Die Lymphbahnen der Tuba Fallopii (ron der Vorderseite des br. Ligaments aus betrachtet). Die Arterienanastomose zwischen Art. uterina und Art. spermat. ist mit rother Masse injicirt. (Lymphb.blan).

1. Sammelgefäss der Fimbria ovarica tubae.

2. Die zwei Sammelgefässe der Pars ampullaris $u$. isthmica tubae (No. 1 u, 2) tauchen ins Ligam. ovariopelric. Die Lymphe der Pars keratina tubae fliesst zum Corpus uteri.

Figur 4. Das Lageverhältniss der Lymphoglandulae bypogastricae, iliac., ischiadic. und rectovaginales zu den grossen Beckengefässen am herausgeschnittenen Präparat.

Figur 5. Die Drüsen vor und hinter den Gefässen stehen in Lymphcommunication.

Figur 6. Durchschnitt durch die Vasa iliaca haemat. Die Drüsen liegen au der Hinterseite der Arterien und umgeben die Vene von rorn und von hinten. Der Ureter-Querschnitt macht die Vorderseite kenntlich.

Figur 7. Interstitielle Injection der Lymphbahnen im Myometrium des Corpus uteri. (Dicker Rasirmesserschnitt in Xylol aufgehellt) bei sebwacher Vergrösserung $(80 \mathrm{f.})$. Die dunkel umrandeten hellen Stellen maikiren Blatgefässe.

Fig. 8. Interstitielle Injection der Lymphbahnen des Corpus uteri (dicker Rasirmesserschnitt in Xylol bei $80 \mathrm{f}$. Vergrösserung gezeichnet). Das Bild zeigt die äusserste Muskelschicht mit der Serosa, welche ihr eigenes Jymphgefässsystem hat. 'Die feinen Lymphröhren der Serosa communiciren in der Tiefe mit den sternförmigen Jakinen der Muslielschicht. An der Oberfläche mehrere freie Oeffnungen.

Fig. 9. Interstitielle Injection der Lymphbahnen in der Mucosa uteri (Rasirmesserschnitt in Xylol aufgehellt).

9a. J.ängsschnitt. Die Schleimhautdrüsen sind nicht eingezeichnet. 1. Das System der senkrecht aufsteigenden Bahnen mit. zahlreichen Queranastomosen mündet in die Längslakunen (2) der Grenzschicht. Mit diesen communiciren die diffus sternförmig anastomosirenden Lymphräume des angrenzenden Myometrium.

9 b. Flachschnitt. Die Schleimhautdrüsen undeutlich ketntlich - entsprechend der Schnittdicke - werden von den Lymphkanälen umsponnen.

Fig. 10. Interstitielle Injection der Lymphbahnen der Cervix uteri. (Rasirmesserschnitt.) Die Lymphbahnen der Schleimhaut bilden feine Netze: LK, welche bis unter das Lipithel der Oberfläche [Ob. Ep.] und der Drüsen (Dr.) beranreichen; in der submucösen Grenzschicht veriaufen die Lymphbahuen horizontal (t. S. Lb.) und erreichen ein grösseres Lumen, um dann senkreclt die Muscularis int. zu durchbrechen (p. im. Lb.). Die Blutgefässe [Bl. g.] sind leer.

Fig. 11. Interstitielle Injection der Lymphbahnen in der inneren Muskelschicht des Uteruskörpers. (Gefriersehnitt $15 \mu$, Vergrösserung 240f.) Zwischen den groben Sammelröhren, welche zu den Venen streben, breitet sich ein reiches Netz feinster Capillaren aus, welche im In- 
156 P. Kroemer, Die Lymphorgane der weiblichen Genitalien.

neren der grossen Muskelfelder die einzelnen Bündelchen unspinnen. An der submucösen Grenzschicht fallen 3 weite Lakunen auf, künstlich durch Injectionsdruek dilatirt. In der angrenzenden Schleim. haut ebenfalls präformirte Bahnen, welche die Drüsen umgeben.

Fig. 12. Querschnitt einer Tube mit interstitieller Injection der Lyruphbahnen bei Iupenbetrachtung.

Fig. 13. Lymphstaung der Tubenschleimbaut bej Gravidität. Die Lymphbahnen L sind blaw injicirt und umgeben Arterien und Venen sichel. förmig, so dass die Blutgefässe sich an einigen Stellen in die Lymphbahnen vorbuchten. Die Muskelbahren sind eng und lassen kein Endathel erkennen.

Fig. 14. (S. Fig. 5 Taf. XVII dieses Archiv. Bd. 65. H. 3 aus meiner früheren Arbeit über den Gebärmutterikrebs!). Natürliche Injection der Jymphbahnen durch Krebszellen bei einem Corpuscarcinom: a) in der mucösen, b) in der submucösen, c) in der musculären Schicht.

Fig. 15. (S. Fig. 4 Taf. XVI dieses Archiv: Bd. 65. H. 3 aus meiner Arbeit über den Gebärmutterkrebs!) Natürliche Injection der Lymphbahnen in der Mucosa uteri und in der submucösen Grenzschicht. (Sm.) durch ein Caroinoma corporis uteri. Die Lymphbahnen umstricken die Blotgefässe.

Tig. 15. (S. Fig. 6 Thaf. XVIL dieses Arcbiv. Bd. 65. H. 3 meiner früheren Krebsarbeic!) Vordringen eines Carcinoma portionis uteri in den Lymphspalten der Mucosa cervicis. Ueberall hebt sich von den Carcinommassen die Endothelschicht $a b$; bei L. Einbruch in ein grösseres Sammelgefäss.

Fig. 17. Horizontalschnitt durch einen wegen Carcinoma cervicis entfernten Uterus. Der Krebs ist in der mittleren Zone der Muscularis am höchsten gedrungen unơ hat hier die Höhe des inneren Muttermundes überschritten. Das Cavum ateri ist dicht über dem inneren Muttermund getroffen. Die gefässreiche Zone Seelig's findet sich aussen am Ligamentursprung; in dem Verlauf der beiden Parametrien rechts und links je eine Lymphdrüse mit Andeutung von Randfollikeln; beide Drüsen sowie das Carum uteri im Körper sind frei von Carcinom.

Fig. 18. Schrägsehnitt dureh das linke Paranetrium. 3 kleine Lymphlnoten (L. Kn.) ragon pilzförmig in das Lumen der certicalen Lymphbalınen, welche mit den Vasa haemat. uterina verlaufen. Art. ut. = Arteria uterina; $V$, ut, thr. $=$ thrombosirte Vena uterina: $G=$ Ganglion sympath. mit Nervenstamm.

Fig. 19. Lymphoglandula (halbschematisch nach einer pararectalen Drüse gezeichnet).

Von der Kapsel K gehen spärliche zarte Trabekel Tr. in's Drüsengewebe. K. G. = Kapselblutgefässe; V. aff. = Vas afferens; V. efferens; R. F. $=$ Randfollikel; $K$. O. $=$ Keimcentrum im Follikel; R. S. = Rand-Sinus; die hellen Ränder um die Randfollikel und zwischen den inneren Marksträngen (M. Str.) stellen den Lymphsinus der Drüse dar. 
Fig. 20. Randschnitt aus einer Beckenlymphdrüse bei Gravidität (complicirt durch Carc. cervicis). Der Lymphsinus ist durch den Reichthum an seröser Flüssiglkeit maximal erweitert. K. = Kapsel; L. S. =Lymphsinus; R. F. = Randfollikel: K. C. = Keim-Centrum. Tr. = Trabekel; M. Str. = Markstränge. Die Drüse ist frei von Carcinom.

Fig. 21. Acute Entzündung einer Beckenlymphdrüse. Activ-passive Hyperämie, Degeneration der Keimcentren; Parenchym und Lymphsinus sind überschwemmt von Wanderzellen.

Fig. 22. Ausgang einer acuten Adenitis in Sclerose: Verödung des Lymphsinus, Verdickung der Kapsel, der Trabekel und des gesammten gefässführenden Reticulums. Die Drüse ist blutleer, die Zeichnung der Follikel, Keimcentren und Markstränge ist verschwunden oder verwischt.

Fig. 23. a beginnende, b rorgeschrittene Degeneration einer Beckenlymphdrüse. Das ausfallende Parenchym wird vom Hilus her durch Fettgewebe ersetzt. Das Gefässgerüst bleibt stehen. Fg. = Fettgewebe. N. Dr. = Nebendrüschen.

Fig. 24. Gutartige Hyperplasie einer Beckenlymphdrüse bei Carcinoma uteri. (Adénopathie précancereuse).

Fig. 25. Fettige Degeneration einer geschwollenen Lymphdrüse. Bemerlsenswerth sind die reichen Gefässe am Hilus und die kleine Nebendrüse.

Fig. 26. Beginnende Krebsinvasion in den Randsinus einer geschwollenen Beckendrüse vom Vas afferens aus.

Fig. 27. Vorgeschrittene Krebsinvasion vom Hilus (Vas efferens) aus. Der Carcinomknoten hat die Lymphdrüse L. Dr. zersprengt.

Fig. 28. Verwachsung der lrrebsigen Lymphdrüsen mit ihrer Umgebung bei 1; und mit der Vena iliaca communis; bei 2 bricht das Carcinom ins periglanduläre Gewebe. Lupenzeichnung (4fache Vergrösserung). art. = Arterie.

Fig. 29. Schematische Darstellung der mit einem Carcinoma cervicis operativ entfernten Drüsen. Links sind die Lgl. parametranes, hypogastricae, iliacae communes und sacrales entfernt, rechts die Lglandulae hypogastricae. Die Lymphdrüsen enthalten alle Carcinomherde.

Fig. 30. Sarcommetastase im Centrum (Vas efferens) einer erbsengrossen, n i c h t verhärteten Lymphdrüse.

Fig. 31. Beginnende Krebsinvasion in den Randsinus einer Beckenlymphdrüse. K. = Kapsel; R. S. = Randsinus; R.F. = Randfollikel; K. C. = Keimcentrum.

Fig. 32. Krebsinvasion vom Hilus (Vas efferens) aus, also retrograd. Das Carcinom $C$. in continuo wachsend erdrückt das Lymphdrüsenparenchym $L . D r$. K. $=$ Kapsel.

Fig. 33. Infiltration einer Lymphdrüse durch einen Cylinderzellenkrebs der Cervix. Die Zellen reihen sich auf allen Fasern des sklerosirten Reticulum und der Trabekel auf. Das eigentliche Parenchym $P$. liegt als nekrotische Masse abgelöst in den krebsigen Hohlräunen. 
158 P. Kroemer, Die Lymphorgane der weiblichen Genitalien.

Fig. 34. Hornkrebs in einer Leistendrüse bei Cancroid der Vulva beobachtet. R. F. = Randfollikel; K. C. = Keimcentrum; K. = infiltrirte Kappe. Das Bild $K_{2}$ stammt von derselben Drüse. Die Krebszapfen enthalten schollige Einschlüsse (Riesenzellen?).

Fig. 35. (S. Fig. 20 Taf. XIX dieses Archiv. Bd. 65. H. 3 aus meiner Arbeit über den Gebärmatterkrebs!) Flimmerepithelschlauch in der Kapsel einer Lymphdrüse aus dem Gefässdreieck zwisehen den Vasa iliaca ext. und int.

Fig. 36. Schnitt durch eine tiefe Beckendrüse (Gland, obturatoria) zeigt das erste Einschwemmen von noch nicht ausgelieimten Krebszellen.

Fig. 37. Riesenzellen in einer Lgl. iliaca bei Care. cervicis (Fremdlörperriesenzellen und Carcinomzellen?). 


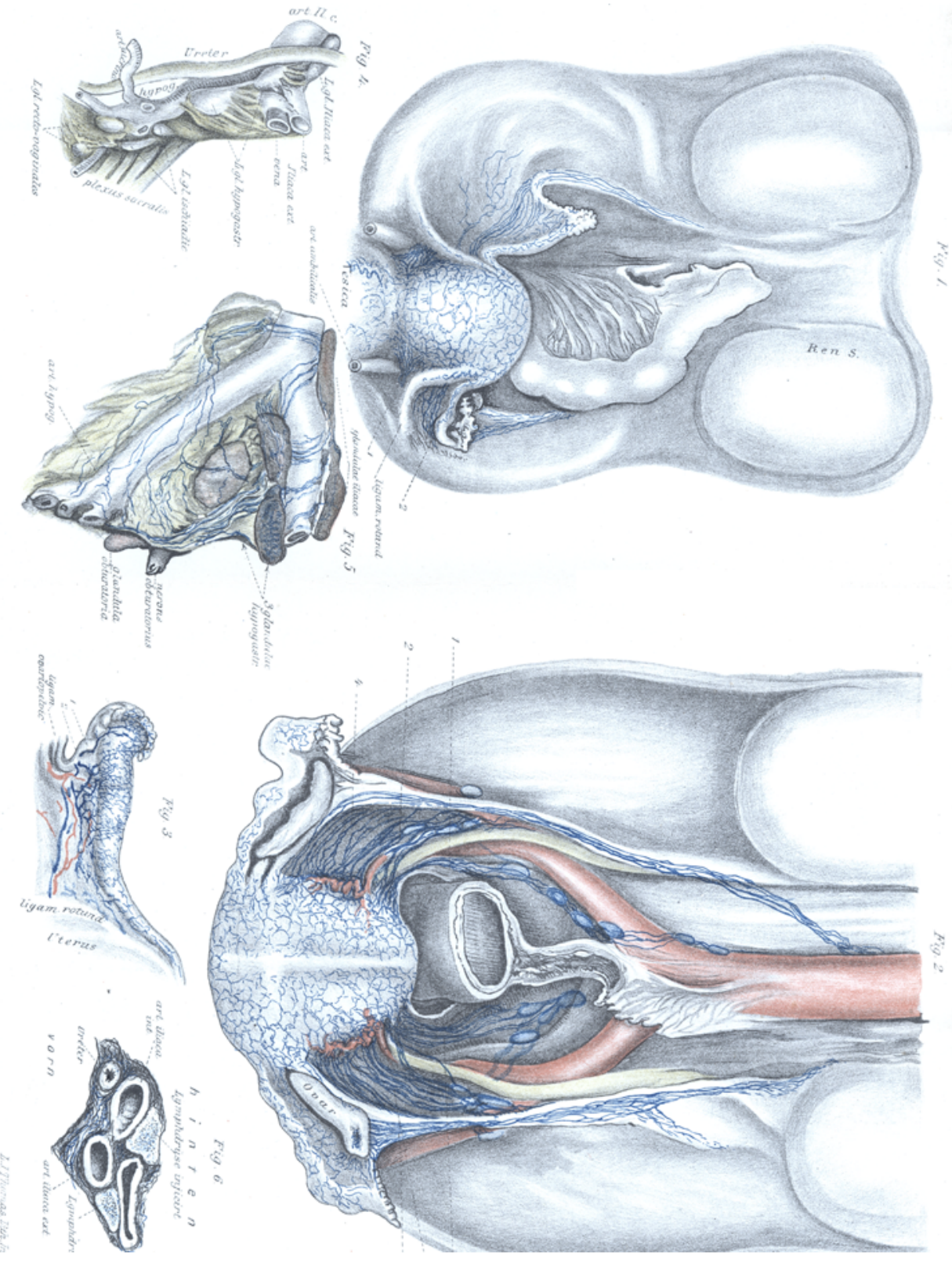




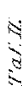
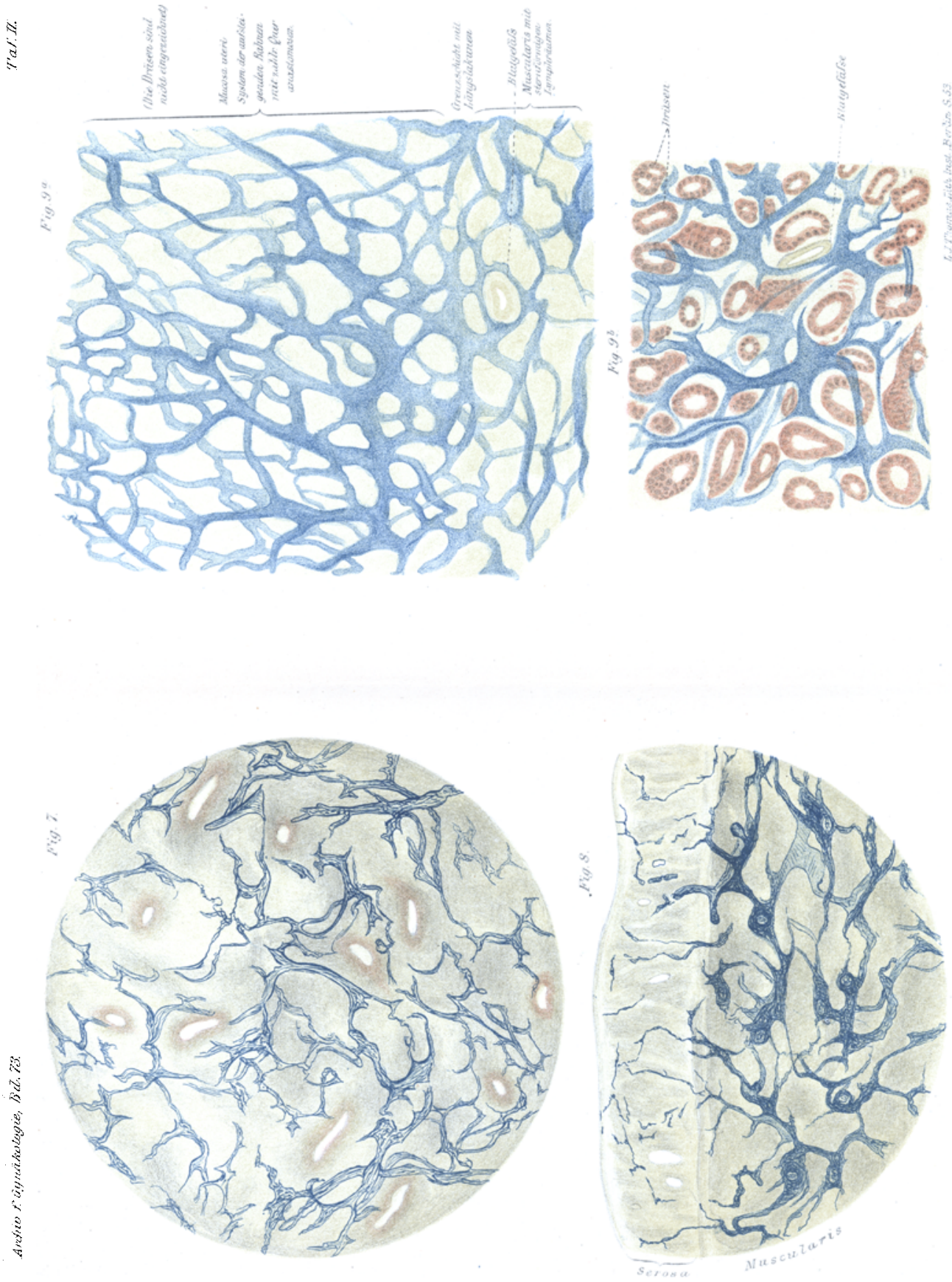


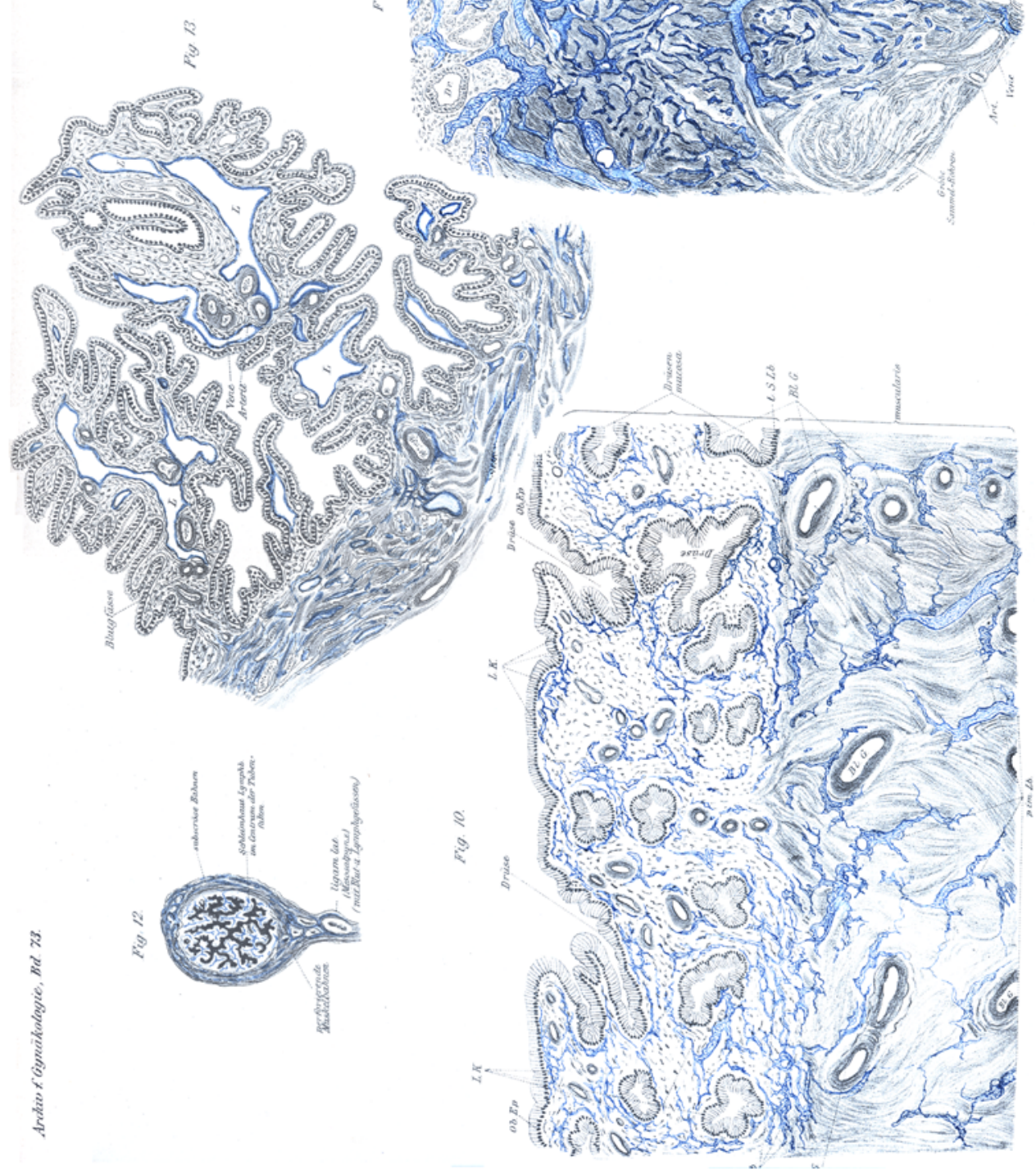




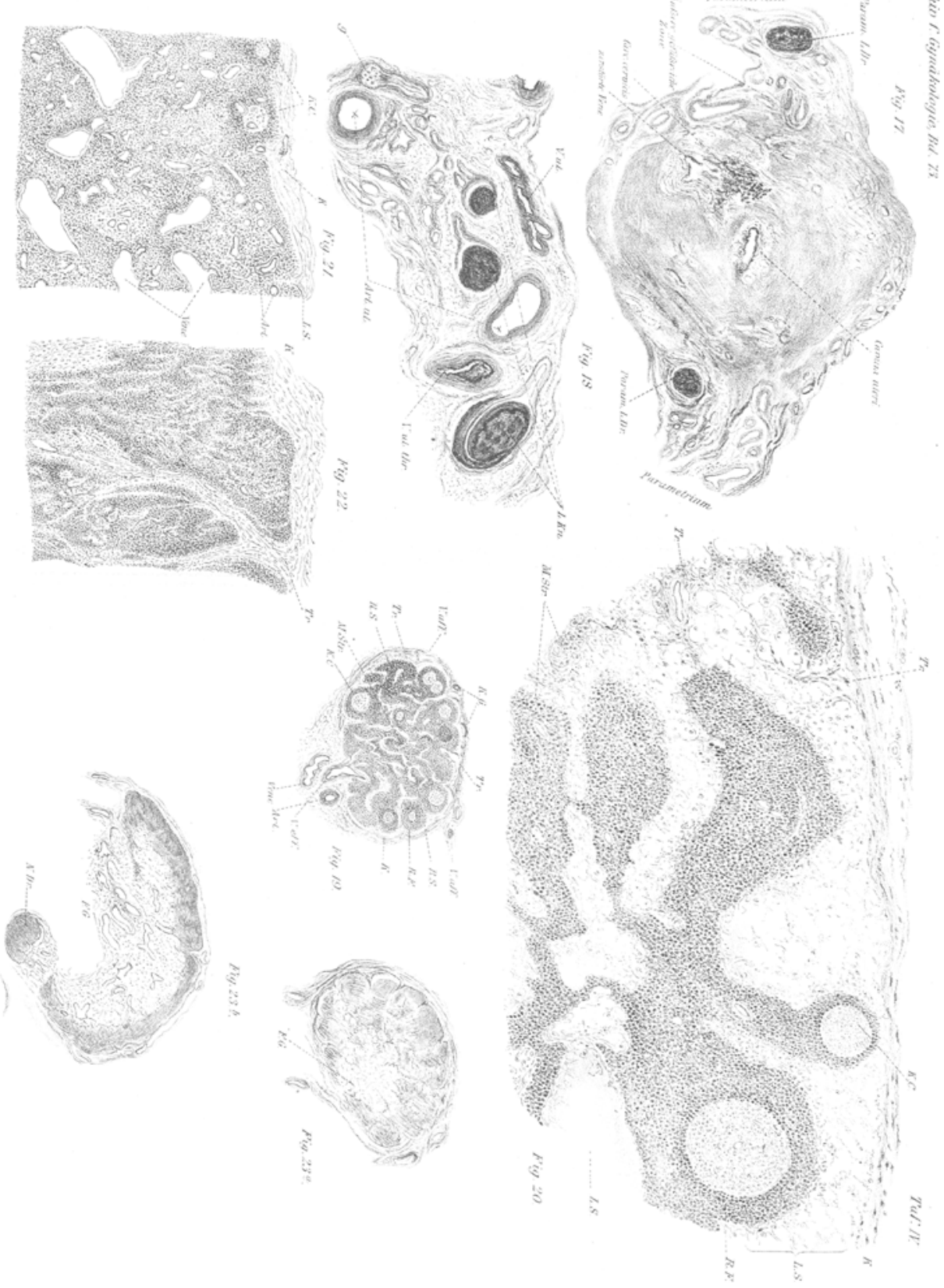


$\stackrel{5}{a}$
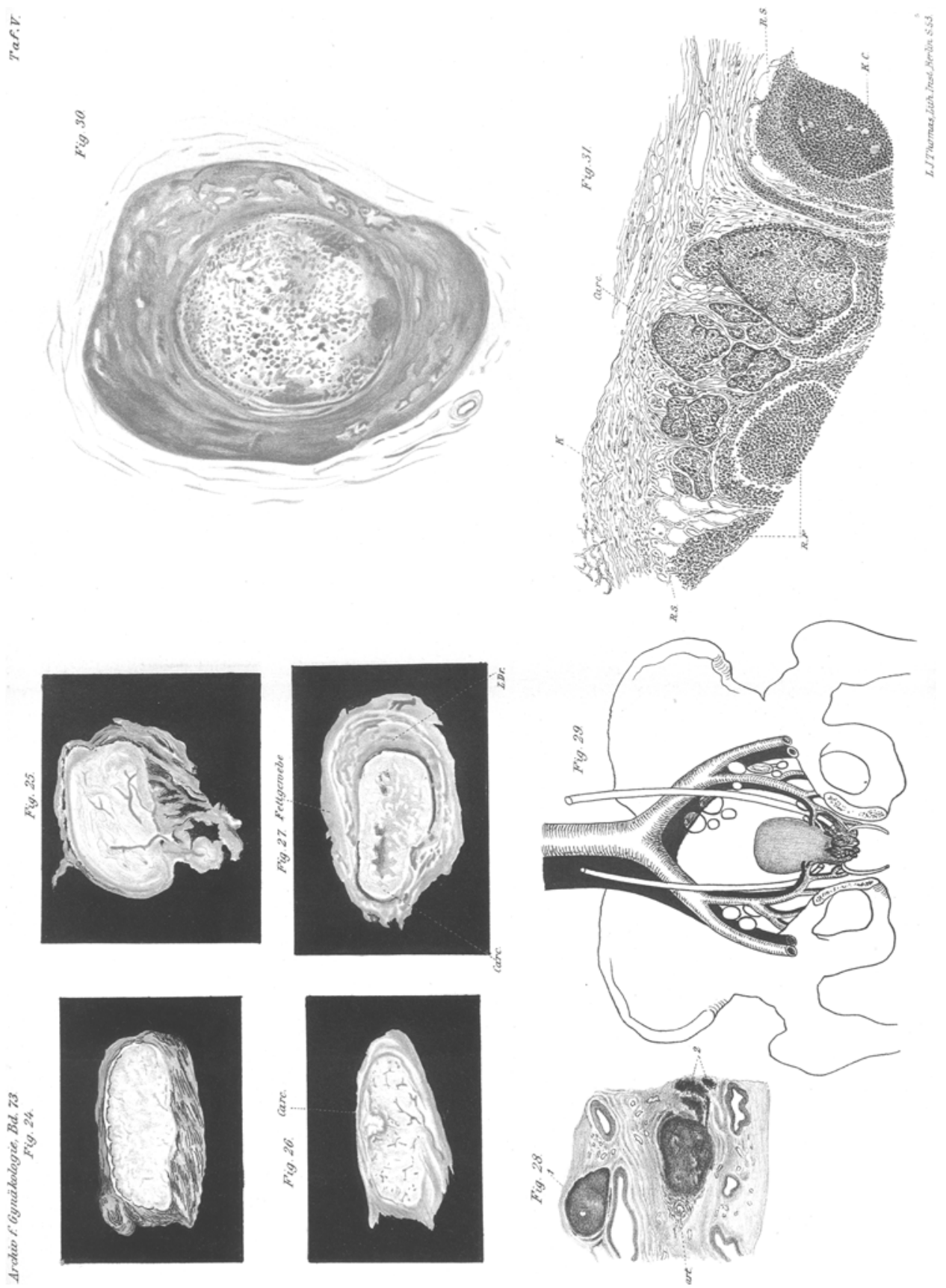


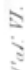
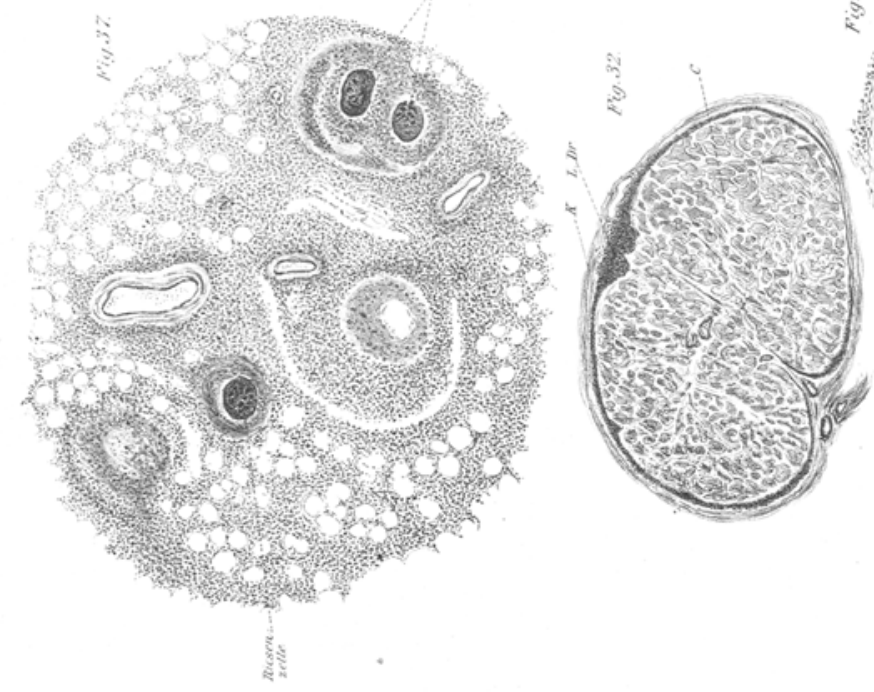

ฺุ

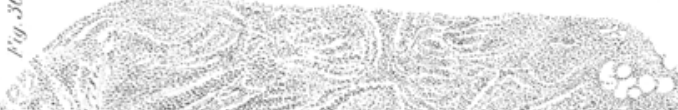

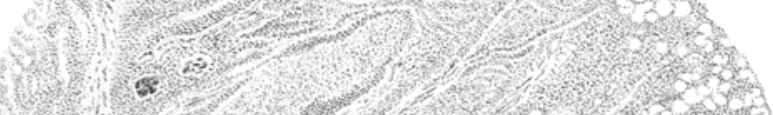

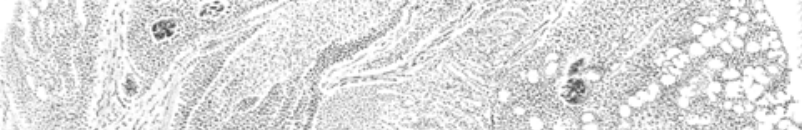

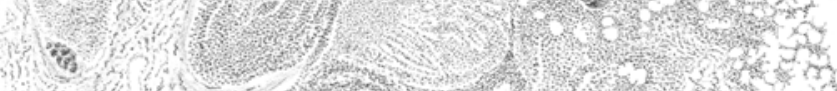

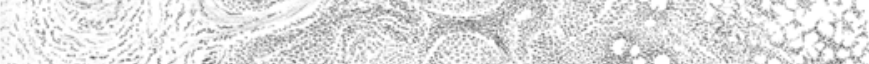
(1)

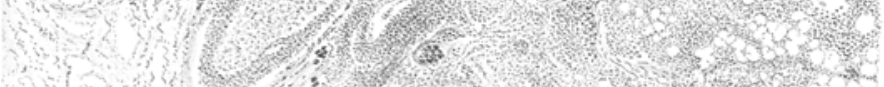
4 la

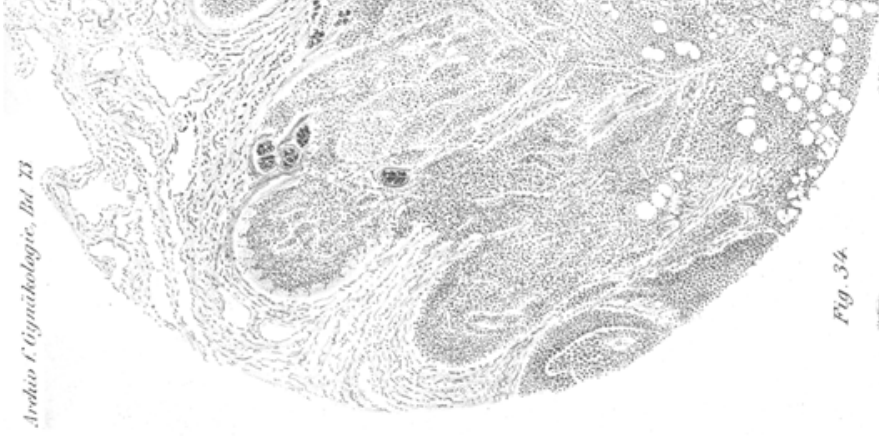

के

3

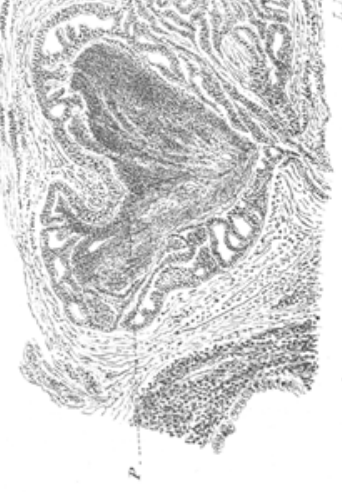

1.

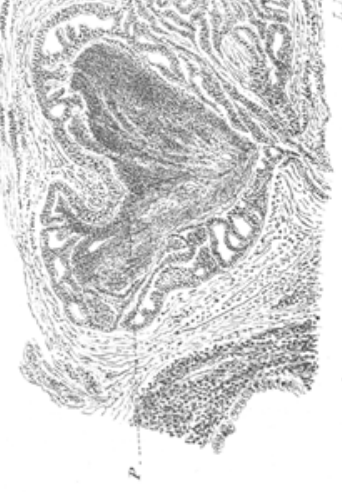

Bis

8
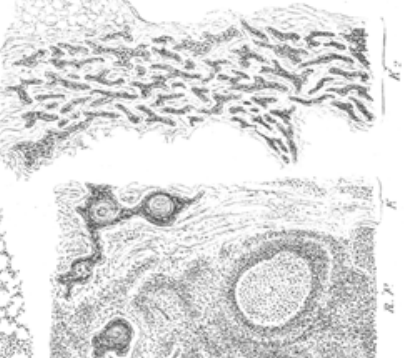

요

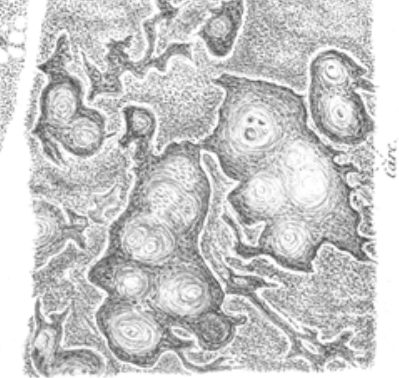

